\title{
Edaphic, structural and physiological contrasts across Amazon Basin forest-savanna ecotones suggest a role for potassium as a key modulator of tropical woody vegetation structure and function
}

J. Lloyd ${ }^{1,2}$, T. F. Domingues ${ }^{3}$, F. Schrodt ${ }^{4,5}$, F. Y. Ishida ${ }^{2}$, T. R. Feldpausch ${ }^{6}$, G. Saiz ${ }^{7}$, C. A. Quesada ${ }^{8}$, M. Schwarz ${ }^{9}$, M. Torello-Raventos ${ }^{10}$, M. Gilpin ${ }^{11}$, B. S. Marimon ${ }^{12}$, B. H. Marimon-Junior ${ }^{12}$, J. A. Ratter ${ }^{13}$, J. Grace ${ }^{14}$, G. B. Nardoto $^{15}$, E. Veenendaal ${ }^{16}$, L. Arroyo ${ }^{17}$, D. Villarroel $^{18}$, T. J. Killeen ${ }^{19}$, M. Steininger ${ }^{\text {a }}$ and O. L. Phillips $^{11}$

${ }^{1}$ Department of Life Sciences, Imperial College London, Silwood Park Campus, Buckhurst Road, Ascot, Berkshire SL5 7PY, UK

${ }^{2}$ Centre for Tropical Environment and Sustainability Sciences (TESS) and College of Marine and Environmental Sciences, James Cook University, Cairns, 4870, Qld, Australia

${ }^{3}$ Universidade de São Paulo, Faculdade de Filosofia Ciências e Letras de Ribeirão Preto, Av Bandeirantes, 3900, CEP 14040-901, Bairro Monte Alegre, Ribeirão Preto, São Paulo, Brazil

${ }^{4}$ Max Planck Institute for Biogeochemistry, Postfach 10 0164, 07701 Jena, Germany

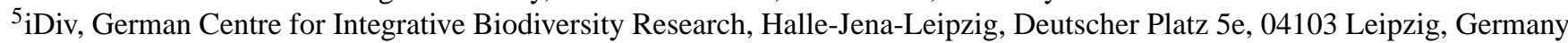

${ }^{6}$ Geography, College of Life and Environmental Sciences, University of Exeter, Exeter, EX4 4RJ, UK

${ }^{7}$ Karlsruhe Institute of Technology, Institute of Meteorology and Climate Research, 82467,

Garmisch-Partenkirchen, Germany

${ }^{8}$ Instituto Nacional de Pesquisas da Amazonia, Manaus, Cx Postal 2223 - CEP 69080-971, Brazil

${ }^{9}$ Fieldwork Assistance, PSF 101022, 07710, Jena, Germany

${ }^{10}$ Centre for Tropical Environment and Sustainability Sciences (TESS) and College of Science

Technology and Engineering, James Cook University, Cairns, Qld, Australia

${ }^{11}$ School of Geography, University of Leeds, LS2 9JT, Leeds, UK

${ }^{12}$ Universidade do Estado de Mato Grosso, Br 158, Km 655, Antiga FAB, Nova Xavantina, MT. CEP 78690-00, Brazil

${ }^{13}$ Royal Botanic Garden, Edinburgh, EH3 5NZ, Scotland, UK

${ }^{14}$ School of Geosciences, University of Edinburgh, EH8 9XP, Scotland, UK

${ }^{15}$ Campus Darcy Ribeiro - Prédio da FACE Brasília, Distrito Federal, 70910-900, Brazil

${ }^{16}$ Centre for Ecosystem Studies, University of Wageningen, P.O. Box 47, 6700AA, Wageningen, the Netherlands

${ }^{17}$ Universidad Autonoma Gabriel Rene Moreno, Avenidas Centenario, Venezuela y Av. 26 de Febrero 56

Santa Cruz de la Sierra, Bolivia

${ }^{18}$ Museo Noel Kempff Mercado, Av. Irala no 565 - casilla 2489, Santa Cruz, Bolivia

${ }^{19}$ Agrotecnologica Amazonica, Santa Cruz, Bolivia

aformerly at: Conservation International, Washington D.C., USA

Correspondence to: J. Lloyd (jonathan.lloyd@imperial.ac.uk)

Received: 25 March 2015 - Published in Biogeosciences Discuss.: 26 May 2015

Revised: 6 October 2015 - Accepted: 11 October 2015 - Published: 18 November 2015 
Abstract. Sampling along a precipitation gradient in tropical South America extending from ca. 0.8 to $2.0 \mathrm{~m} \mathrm{a}^{-1}$, savanna soils had consistently lower exchangeable cation concentrations and higher $\mathrm{C} / \mathrm{N}$ ratios than nearby forest plots. These soil differences were also reflected in canopy averaged leaf traits with savanna trees typically having higher leaf mass per unit area but lower mass-based nitrogen $\left(\mathrm{N}_{\mathrm{m}}\right)$ and potassium $\left(\mathrm{K}_{\mathrm{m}}\right)$. Both $\mathrm{N}_{\mathrm{m}}$ and $\mathrm{K}_{\mathrm{m}}$ also increased with declining mean annual precipitation $\left(P_{\mathrm{A}}\right)$, but most area-based leaf traits such as leaf photosynthetic capacity showed no systematic variation with $P_{\mathrm{A}}$ or vegetation type. Despite this invariance, when taken in conjunction with other measures such as mean canopy height, area-based soil exchangeable potassium content, $[\mathrm{K}]_{\mathrm{sa}}$, proved to be an excellent predictor of several photosynthetic properties (including ${ }^{13} \mathrm{C}$ isotope discrimination). Moreover, when considered in a multivariate context with $P_{\mathrm{A}}$ and soil plant available water storage capacity $\left(\theta_{\mathrm{P}}\right)$ as covariates, $[\mathrm{K}]_{\mathrm{sa}}$ also proved to be an excellent predictor of stand-level canopy area, providing drastically improved fits as compared to models considering just $P_{\mathrm{A}}$ and/or $\theta_{\mathrm{P}}$. Neither calcium, nor magnesium, nor soil $\mathrm{pH}$ could substitute for potassium when tested as alternative model predictors $(\triangle \mathrm{AIC}>10)$. Nor for any model could simple soil texture metrics such as sand or clay content substitute for either $[\mathrm{K}]_{\mathrm{sa}}$ or $\theta_{\mathrm{P}}$. Taken in conjunction with recent work in Africa and the forests of the Amazon Basin, this suggests in combination with some newly conceptualised interacting effects of $P_{\mathrm{A}}$ and $\theta_{\mathrm{P}}$ also presented here - a critical role for potassium as a modulator of tropical vegetation structure and function.

\section{Introduction}

Forests and savannas dominate the tropical vegetated regions of the Earth covering around 0.2 of the Earth's surface (Torello-Raventos et al., 2013). At a broad scale, it has been long recognised that the distribution of these two biomes, each with its own structural characteristics and species composition, is to a large degree governed by precipitation and its seasonality (Schmimper, 1903), but with soil chemical characteristics also important (Lloyd et al., 2008; Lehmann et al., 2011; Veenendaal et al., 2015). Edaphic conditions are especially influential in regions where the two biomes intersect - often referred to as "ecotones" or zones of (ecological) transition (ZOT) - both forest and savanna existing as discrete "patches" under similar climatic conditions (Murdoch et al., 1976; Furley and Ratter, 1988; Cochrane, 1989; Ratter, 1992; Thompson et al., 1992; Lehmann et al., 2011; Saiz et al., 2012; Schrodt et al., 2014; Veenendaal et al., 2015).

The role of soils in influencing vegetation distribution patterns within ZOT is, however, still equivocal with some authors arguing that fire-mediated feedbacks determine the nature of alternative vegetation types within this region through a mechanism related to the maintenance of alternative stable states (Warman and Moles, 2009; Hirota et al., 2011; Staver et al., 2011; Hoffmann et al., 2012; Murphy and Bowman, 2012). It has also been argued that large-scale differences in fire-mediated feedbacks are required to account for apparent inter-continental differences in savanna-precipitation relationships (Lehmann et al., 2014).

One key argument of the fire-mediated feedback/alternative stable state community has been that in many cases woody vegetation formation types can be found where they would not be expected on the basis of climate and/or soils alone (Staver et al., 2011; Murphy and Bowman, 2012; Lehmann et al., 2014). Yet - other concerns aside (Hanan et al., 2013; Veenendaal et al., 2015) - we perhaps should ask ourselves if at present we really do know exactly what climatic and/or edaphic factors are likely to be important. Here, of particular note is the importance of physical as well as chemical soil properties in influencing tropical vegetation structure, with a range of physical factors such as soil texture, depth to water table and the presence/absence of impermeable layers all being potentially important (Cole, 1960; Avenard and Tricart, 1972; Ratter, 1992; Thompson et al., 1992; Williams et al., 1996; Mills et al., 2006; Lloyd et al., 2008, 2009).

Tropical South America provides a particularly interesting "living laboratory" for an investigation into the importance of climate-soil interactions as drivers of variations in tropical vegetation structure and function, with "Seasonally Dry Tropical Forest" extending into rainfall areas with mean annual precipitation rates $\left(P_{\mathrm{A}}\right)$ of less than $0.9 \mathrm{ma}^{-1}$ (Prado and Gibbs, 1993; Killeen et al., 2006; Pennington et al., 2006) and, most importantly, often occurring in close proximity to a structurally and floristically distinct savanna-like cerrado formations (Daly and Mitchell, 2000). This occurs not only at relatively low precipitations of $<1.0 \mathrm{~m} \mathrm{a}^{-1}$ (Villarroel et al., 2010) but also - with both vegetation types found more or less in a continuum - across a range of differing precipitation regimes extending to the southern Amazon forest boundary for which $P_{\mathrm{A}}$ is typically around $1.6 \mathrm{ma}^{-1}$ (Ratter, 1992; Killeen et al., 1998; Durigan and Ratter, 2006; Marimon et al., 2006; Mews et al., 2012; Torello-Raventos et al., 2013; Veenendaal et al., 2015). Moreover, within the Amazon Basin itself savanna "inliers" are sometimes found growing in close proximity to the dominant forest vegetation at rainfall up to $2.0 \mathrm{~m} \mathrm{a}^{-1}$ and sometimes beyond (Cole, 1960; Eiten, 1978; Thompson et al., 1992; Cochrane and Cochrane, 2010; Torello-Raventos et al., 2013; Rossatto, 2014). It is thus possible to find paired savanna and forest sites across a precipitation gradient extending from less than 1.0 to more than $2.0 \mathrm{~m} \mathrm{a}^{-1}$. This provides a ready means for quantifying the relative importance of soils vs. climate as modulators of forest/savanna structure and function.

In terms of measurement and modelling strategies appropriate to quantify the relative importance of soils vs. climate as modulators of tropical vegetation structure and function, 
some guidance can be obtained from the production orientated forestry literature for which there are many examples of empirical models integrating both edaphic and climatic factors with the overall aim of predicting site-to-site differences in stand productivity. For example, Grigal (2009) found a soil site index measure incorporating water availability (depth to water and drainage), nutrients (base saturation and organic matter) and site physical properties (bulk density and stone volume) to provide good predictions of the growth of aspen trees in Minnesota. Male (1981) found soil depth (to rock) to be a good predictor for a range of coniferous species in subtropical Queensland (Australia). Turner et al. (1990) found a wide range of attributes such as parent rock type, texture profile, depth to and nature of any impeding layer and condition of the uppermost $0.1 \mathrm{~m}$ soil combining together as factors contributing to variations in the productivity of $\mathrm{Pi}$ nus radiata forest in Australia. Briggs (1994) used soil rooting depth and drainage class to delineate forest productivity classes in Maine, and Ritchie and Hamann (2008) found that water capacity of the soil (depth, texture and type of bedrock) was effective at characterising the productivity of Douglas fir saplings (Weiskittel et al., 2011).

Most of the above studies have not focussed on specific soil chemical parameters - and indeed deliberately so: the reason being to facilitate the ready scaling up of these productivity measurements on the basis of limited spatial soils information. But with, at least in some cases, soil chemical status indirectly included as a predictor variable through the inclusion of a parent material term. Soil physical and chemical properties are inevitably correlated to at least some degree due to their mutual associations during pedogenesis (Quesada et al., 2010). Thus, some "hidden soil fertility effects" are probably present in many of the above metrics despite these being based solely on soil physical properties.

It is reasonable to anticipate that soil nutrient status should affect tropical vegetation structure and dynamics as there are numerous studies both correlative (Askew et al., 1970; Goodland and Pollard, 1973; Lopes and Cox, 1977; Furley and Ratter, 1988; Oliveira-Filho and Ratter, 2002; Quesada et al., 2012; Schrodt et al., 2014) and experimental (Wright et al., 2011; Santiago et al., 2012; Sayer et al., 2012; Alvarez-Clare et al., 2013) showing specific nutrient effects on a range of ecosystem properties. Conceptually at least three mechanisms by which nutrients could affect vegetation structure and function can be envisioned. First, as may be especially relevant to high biomass vegetation types, there may simply not be enough nutrients available to sustain a higher biomass. This is implicitly assumed by Bond (2010) and Silva et al. (2013) in their analyses of savanna and nutrient stocks. Second, a shortage of photosynthetically relevant nutrients such as nitrogen could potentially be associated with reduced rates of carbon acquisition as is implicitly assumed in many process-based models of forest productivity in the temperate zone (Weiskittel et al., 2011) - for example Comins and McMurtrie (1993) - and has also been suggested for soil phosphorus and Amazon forest wood production rates (Mercado et al., 2011). Third, given the many roles played by both macro- and micro-nutrients in plants (Hänsch and Mendel, 2009; Maathuis, 2009), it is quite conceivable that processes not directly related to photosynthetic carbon acquisition or structural biomass accumulation might be affected. As an illustration, there are clear and important roles for both potassium and calcium in wood cambial growth (Fromm, 2010), with the many reports of positive effects of potassium fertilisation on crop productivity mostly accounted for via improved plant water relations rather than photosynthetic carbon acquisition per se (Römheld and Kirkby, 2010; Wang et al., 2013; Ahmad and Maathuis, 2014; Anschütz et al., 2014; Hafsi et al., 2014; Shabala and Pottosin, 2014; Zörb et al., 2014). This is thought to be due to the role of potassium as a key osmoticum in plants, as well as with important roles in long-distance water transport (El-Mesbahi et al., 2012; Wang et al., 2013; Anschütz et al., 2014).

Indeed, these observations, taken along with the many positive reports of woody plant growth responses to improved soil potassium status (Tripler et al., 2006), numerous demonstrations that potassium can - at least to some extent - ameliorate adverse effects of soil water, deficits on plant growth (Egilla et al., 2005; Umar, 2006) and the clear tendency for savanna species to have a lower potassium requirement than forest species (Rossatto et al., 2013; Schrodt et al., 2014; Viani et al., 2014), all suggest that potassium availability could potentially be important in accounting for any edaphic effects across the wide precipitation range for which forests and savanna both occur.

It is also possible that other cations could be involved in any other observed soil-associated modulations of tropical vegetation physiognomy. For example, Cochrane (1989) found very low $\mathrm{Ca} / \mathrm{Mg}$ ratios in Brazilian savanna sub-soils and hypothesised that these might be limiting for new root growth. High concentrations of toxic ions might also be important with Priess et al. (1999), for example, attributing very high fine-root turnover rates in Venezuelan sub-montane forests to high exchangeable aluminium concentrations in the soil.

Especially as many (but by no means all) tropical soils are old and highly weathered, it is also possible that trace element deficiencies may account for some differences in vegetation structure observed across the tropics. For example, working in the Cerrado Region of Brazil, Marques et al. (2004) found the acid pH soils there to be depleted in both divalent or monovalent trace element cations $\left(\mathrm{Rb}^{+} \mathrm{Mn}^{2+}\right.$, $\mathrm{Co}^{2+}, \mathrm{Ni}^{2+}, \mathrm{Cu}^{2+}, \mathrm{Zn}^{2+}, \mathrm{Sr}^{2+}, \mathrm{Ba}^{2+}$ and $\mathrm{Pb}^{2+}$ ) compared to temperate zone soils. Nevertheless, whatever the hypothesis for the underlying cause of variations in woody plant cover in the tropics, as grasses are also present in most open woody vegetation formation types, tree-grass competition also needs to be considered. For example, according to Walter's "two-layer" hypothesis of tree-grass coexistence as ap- 
plied to arid and semi-arid savannas (Ward et al., 2013), there may be a stratification of below-ground resources with - at least in the area not directly under the tree crown - grasses typically utilising water from the uppermost layer and trees from a slightly lower depth. Thus even if one were to take the view that the presence of grasses in arid or semi-arid savannas is simply a passive consequence of an inability of trees to occupy all the available canopy space - though with subsurface lateral root spread extending far beyond the canopy crown areas themselves (Schenk and Jackson, 2002) - then the presence in open non-shaded areas must also serve to reduce woody plant water use and hence productivity.

Nevertheless, under certain conditions it is clear that herbaceous life forms (axylales) are directly favoured over their woody competitors, for example where soils are frequently waterlogged and/or very shallow (Lloyd et al., 2008; Torello-Raventos et al., 2013), and it has even been suggested that soil nutrient status may directly affect the relative viability of woody versus herbaceous life forms. Here, according to the theory of maximum energy intensity, the latter should tend to dominate at both the lowest and highest levels of soil nutrient availability, with trees and shrubs only successful at intermediate soil fertilities (Milewski and Mills, 2010).

But in any case, as already noted, some authors have suggested that tropical vegetation structure and function across the 1.0 to $2.0 \mathrm{~m} \mathrm{a}^{-1}$ precipitation range are mostly determined by fire-mediated feedbacks and the existence of alternative stable states (Warman and Moles, 2009; Hirota et al., 2011; Staver et al., 2011; Hoffmann et al., 2012). In which case it would be reasonably expected that no systematic pattern of vegetation structure in relation to climate and/or soils should emerge (Sankaran et al., 2005; Hoffmann et al., 2012; Murphy and Bowman, 2012; Lehmann et al., 2014). Soilclimate-vegetation interactions along "long" ecological gradients are, however, likely to be complex with significant multiple interactions. For example, a number of studies have shown that the optimum vegetation rooting depth should (and does) increase with precipitation as long as potential evaporation continues to exceed rainfall (as a rule of thumb this is for $P_{\mathrm{A}}<2.2 \mathrm{~m} \mathrm{a}^{-1}$; Schenk and Jackson, 2002; Collins and Bras, 2007; Guswa, 2010). This means that any adverse effect of a restricted root zone on annual rates of plant water uptake is likely to be considerably less at lower compared to higher $P_{\mathrm{A}}$.

Moreover, impermeable layers, such as laterite, which are common in all but the most severely weathered soils groups typically found across tropical lands (Thomas, 1974), could potentially even have a positive effect on soil water balances, and hence vegetation structure at low $P_{\mathrm{A}}$ if reductions in drainage losses associated with such layers were not to be fully offset by increased runoff rates during large precipitation events. This has been suggested, for example by Dye and Walker (1980), as one potential causative factor for the existence of very high biomass Colophospermum mopane stands often found at $P_{\mathrm{A}}<0.7 \mathrm{ma}^{-1}$ in southern Africa (Mapaure, 1994).

In addition to measurements of soil and climate, leaf trait characterisations can also help disentangle causes for regional-scale variations in canopy structure. For example, where a nutrient is limiting it might reasonably be expected that foliar concentrations would be more closely correlated with the appropriate measures of soil availability than when a nutrient is available in excess (Quesada and Lloyd, 2015). Likewise, measurements of photosynthetic capacity in relation to foliar nitrogen and/or phosphorus concentrations can also yield information as to the extent to which these elements may be influencing rates of carbon acquisition (Domingues et al., 2010, 2015; Bloomfield et al., 2014). Leaf-level measurements on their own do, however, only tell part of the story. For example, in high-light and water-limited environments theory suggests that optimal whole-plant photosynthetic carbon gain should be attained through the construction of relatively few leaves but with higher photosynthetic capacities as compared to moister lower-insolation climates (Buckley et al., 2002; Farquhar et al., 2002). This photosynthetic capacity-leaf area trade-off means that any sensible interpretation of variations in leaf-level photosynthetic rates in terms of whole-plant carbon gain also requires some knowledge of concurrent changes in canopy leaf areas (Cernusak et al., 2011).

Analysis of the $\delta^{13} \mathrm{C}$ of leaf dry matter further provides a convenient method for investigating leaf physiology because it relates to the ratio of intercellular to ambient $\mathrm{CO}_{2}$ mole fractions $\left(\mathrm{C}_{\mathrm{i}} / \mathrm{C}_{\mathrm{a}}\right)$ during photosynthesis (Farquhar et al., 1989). Thus, foliar $\delta^{13} \mathrm{C}$ provides a time-integrated proxy measurement of important leaf gas exchange characteristics, especially in terms of changes in photosynthetic capacity relative to those of stomatal conductance, hence providing some indication of the extent to which leaf-level carbon acquisition might be "compromised" as a consequence of stomatal closure in relation to high soil and/or atmospheric water deficits (Lloyd and Farquhar, 1994; Schulze et al., 1998; Miller et al., 2001). In term of cations, a role for potassium in the adjustment of savanna trees to more severe soil water deficits has already been suggested by Schrodt et al. (2014), as an explanation for high foliar concentrations in the leaves of African savanna species at lower $P_{\mathrm{A}}$.

The current study reports on the climate, soil, leaf and canopy structural characteristics of 9 forest and 11 savanna stands of the Amazon Basin sampled along a precipitation gradient extending from 0.82 to $2.12 \mathrm{ma}^{-1}$. The following specific questions are addressed:

1. Are there consistent differences in the physical and/or chemical properties of forest vs. savanna soils across a range of sites differing in precipitation?

2. If so, how are these differences reflected in differences in leaf-level measures of foliar nutrient content, $\delta^{13} \mathrm{C}$ and photosynthetic capacity? 

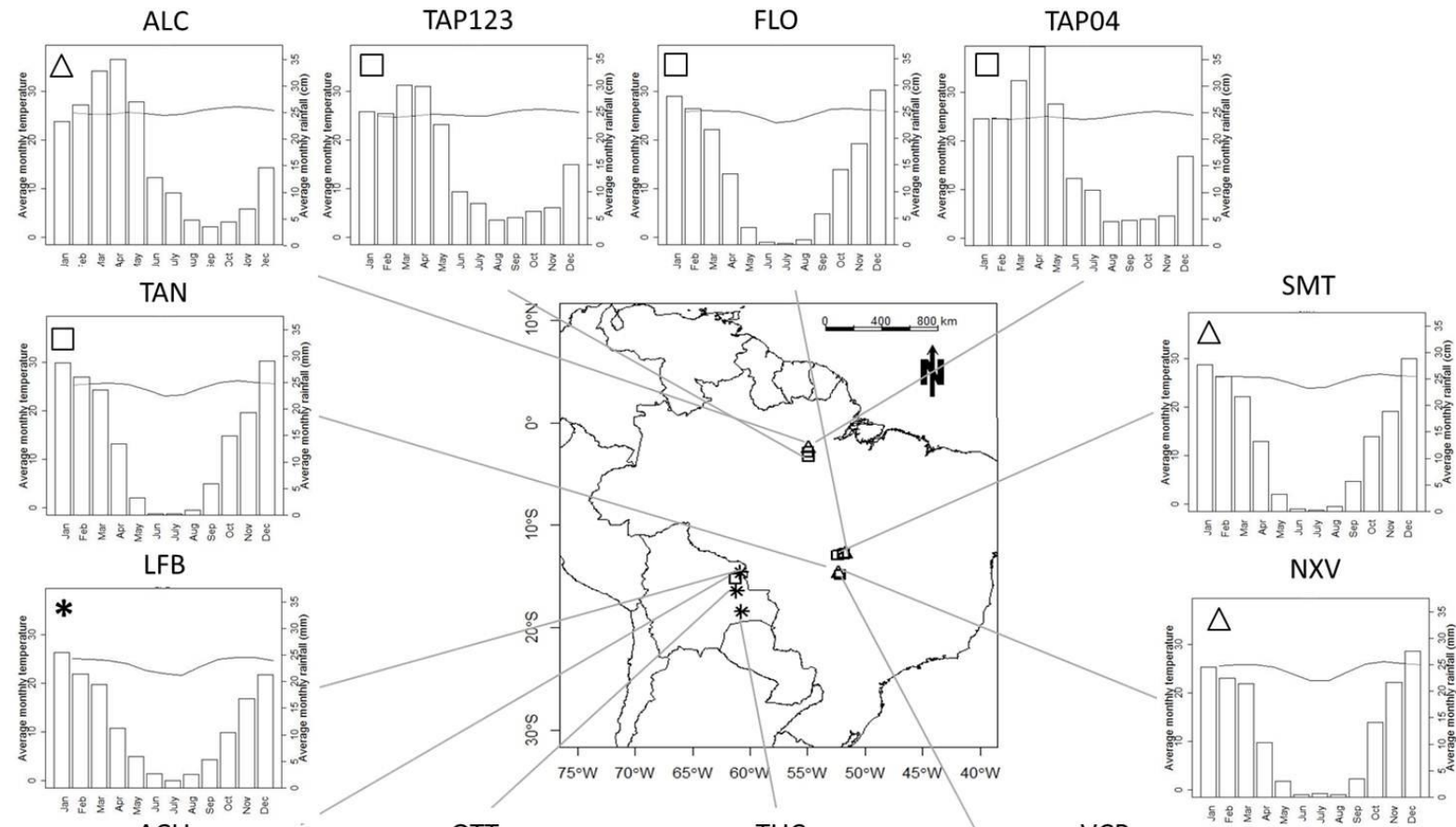

$\mathrm{ACU}$
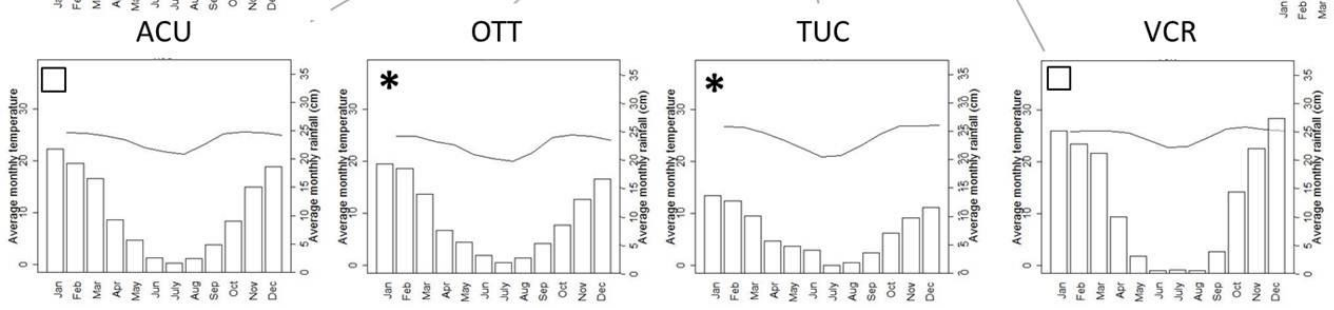

NXV

Figure 1. Map showing sampling sites and their temperature $\left({ }^{\circ} \mathrm{C}\right)$ and precipitation climatologies.

3. How do associated canopy structural characteristics such as leaf area, average and upper canopy tree heights and stand-level biomass vary with precipitation for forest vs. savanna vegetation formation types?

4. And once variations in soil physical and chemical properties have been taken into account - noting the likely importance of interactions with precipitation regimes can we then account for variations in tropical forest and savanna structure using simple statistical models such as those applied in the forestry production literature? Or do variations in canopy structure in relation to climate remain so enigmatic that an invocation of "alternative stable states" becomes necessary?

\section{Materials and methods}

\subsection{Study area}

Data presented here come from 20 plots sampled in the southern and eastern areas of the Amazon Basin, and located in regions where both forest and savanna vegetation formation types were known to occur (Figs. 1 and 2). Most of these plots were specifically sampled as part of the Tropical Biomes in Transition (TROBIT) project (Torello-Raventos et al., 2013), though with both plant and soil data for two forest plots (viz. TAP-123 and TAP-04) coming from previous measurements made through the Amazon Rainforest Inventory Network (RAINFOR) (Fyllas et al., 2009; Quesada et al., 2010, 2011). Additional photosynthesis and foliar $\mathrm{N}$ and $\mathrm{P}$ data for the forest plot TAP-04 come from Domingues et al. (2005). A list of all plots sampled along with selected climate and soil properties can be found in Supplement Table S1.

Measurements from the TROBIT program were made in two field campaigns, each over a period of ca. 2 months. First, sampling in Bolivia from February to April 2007 of nine plots across a rainfall gradient from $0.82 \mathrm{~m} \mathrm{a}^{-1}$ at TUC01 to $1.45 \mathrm{~m} \mathrm{a}^{-1}$ at LFB-01 (Noel Kempff Mercado National Park). Second, a sampling of 10 plots in Brazil from April to June 2008 with a range of $P_{\mathrm{A}}$ from $1.51 \mathrm{~m} \mathrm{a}^{-1}$ at NXV-01 to $2.02 \mathrm{~m} \mathrm{a}^{-1}$ at ALC-02. All sampling campaigns had been timed to coincide with the end of the wet season and the timing of expected maximum plant physiological activity and standing herbaceous biomass. 

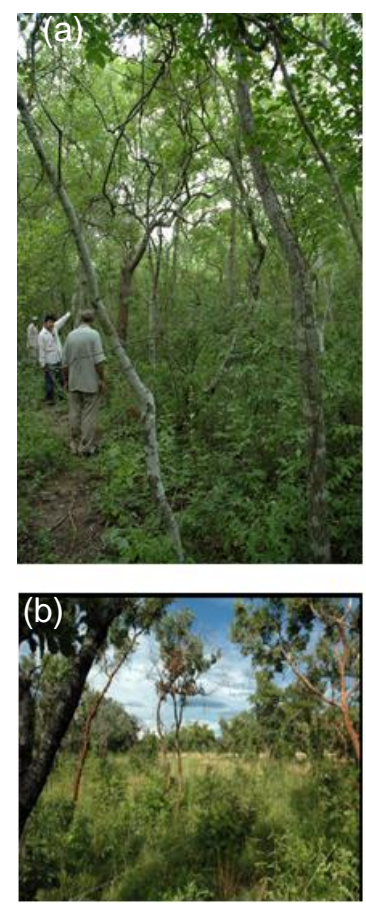
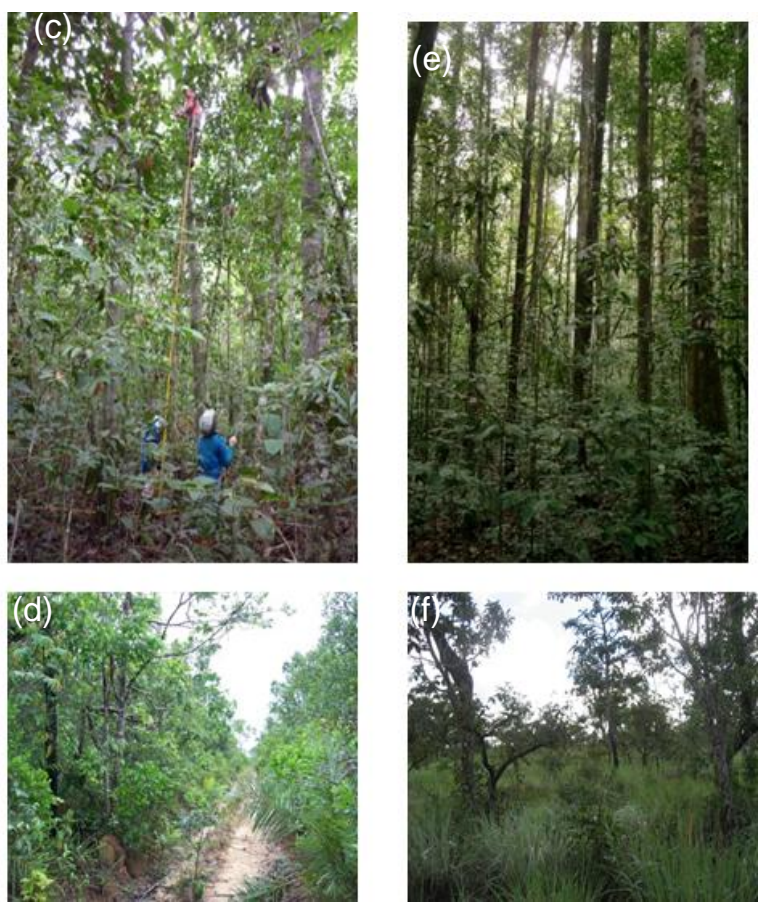

Figure 2. Examples of forest (top row) and savanna (bottom row) vegetation formation types found along the precipitation gradient. (a) TUC01 forest, (b) TUC-03 savanna (both towards the drier end of the transect); (c) FLO-01 forest, (d) SMT-02 savanna (both in the middle of the Transect); (e) TAP-123 forest (f) ALC-02 savanna (both at the moister end of the transect). Specific details of site locations, climatology and soils are given in Fig. 1 and Table S1 of the Supplement.

\subsection{Stand structure and species identification}

Full details of canopy cover, tree height $(H)$ and stand biomass estimates are provided in Torello-Raventos et al. (2013) and Veenendaal et al. (2015), and are thus only summarised briefly here. In short, we inventoried all trees and shrubs with a diameter $(D)$ - at breast height $(1.3 \mathrm{~m})-$ of greater than $0.1 \mathrm{~m}$ with transect measurements being used for the estimation of size and abundance of smaller saplings, shrubs and seedlings ( $D>25 \mathrm{~mm}$ and $H>1.5 \mathrm{~m}$ ). Selected trees and shrubs in each plot were then used for determination of site-specific allometric equations relating either $H$ or estimated projected canopy areas $\left(C_{\mathrm{A}}\right)$ to $D$. These equations were then used to estimate mean and 0.95 quantile heights (hereafter denoted as $\left\langle H_{\mathrm{U}}\right\rangle$, and $H^{*}$, respectively) as well as stand-level crown area index, $C_{\mathrm{W}}$ - defined as the sum of all woody individual canopy-projected area (including the skylight transmitted component) divided by the ground area. Allometric equations employing some combination of $D$ and/or $H$ and/or $C_{\mathrm{A}}$ taken from a range of previously published sources or specifically developed as part of the TROBIT project were then used to estimate stand-level biomass (Veenendaal et al., 2015). Height and biomass estimates for the non-TROBIT forest plot TAP-123 comes from Feldpausch et al. (2011) with $C_{\mathrm{W}}$ for TAP-123 and the nearby TAP-4 calculated from leaf area index measurements of these stands (Fyllas et al., 2014) using relationships given in Veenendaal et al. (2015). Woody and herbaceous species were usually identified in the field by local botanists, but where necessary specimens were collected and verified against herbarium collections.

\subsection{Soil physical and chemical properties}

Soil sampling methods are described in detail in Quesada et al. $(2010,2011)$ and are thus only briefly summarised here. In brief, for each 1 hectare plot, five soil cores were collected and soil retained over the depths $0-0.05,0.05-0.10$, $0.10-0.20,0.20-0.30,0.30-0.50,0.50-1.00,1.00-1.50$ and $1.50-2.00 \mathrm{~m}$ using an undisturbed soil sampler (Eijkelkamp Agrisearch Equipment BV, Giesbeek, the Netherlands). In addition, each plot usually had one soil pit dug to a depth of $2.0 \mathrm{~m}$ with samples collected from the pit walls at the same depths as above. Where possible, coring from the bottom of the soil pit for a further $2.0 \mathrm{~m}$ was also undertaken, giving a total maximum depth sampled of $4.0 \mathrm{~m}$. All sampling was done following a standard protocol of RAINFOR network (http://www.geog.leeds.ac.uk/projects/rainfor/ pages/manualstodownload.html) in such a way to best account for spatial variability within the plot.

Soil samples were air dried, usually in the field, and then once back in the laboratory had roots, detritus, small rocks and particles over $2 \mathrm{~mm}$ removed. 


\subsubsection{Soil bulk density}

Samples for bulk density determinations were taken from pit wall samples using specially designed container rings of known volume (Eijkelkamp Agrisearch Equipment BV, Giesbeek, the Netherlands) and subsequently oven dried at $105^{\circ} \mathrm{C}$ until constant weight, cooled to room temperature in a sealed desiccant before final weight determinations were made. Three bulk density samples were collected at each sampling depth.

\subsubsection{Soil texture and plant available soil water}

Particle size analysis was performed using the pipette method (Gee and Bauder, 1986) with plant available soil water $\left(\theta_{\mathrm{P}}\right)$ obtained through an estimation of soil water retention characteristics based on the particle size pedotransfer functions for tropical soils given by Hodnett and Tomasella (2002) for each sampled layer. Individual layer values $(-0.01$ to $-1.5 \mathrm{MPa}$ ) were then integrated to the maximum rooting depth for each profile or integrated to $4 \mathrm{~m}$ for the case of roots not having been observed to be constrained in any way.

\subsubsection{Soil chemical properties}

As described in detail by Quesada et al. $(2010,2011)$ samples were analysed for $\mathrm{pH}$ in water at $1: 2.5$, with exchangeable cations determined by the silver-thiourea method (Pleysier and Juo, 1980). Phosphorus pools were obtained from standard fractionation procedures as modified from Hedley et al. (1982). Soil carbon and nitrogen was determined using an automated analyser (Pella, 1990; Nelson and Sommers, 1996). Samples from Bolivia were analysed in the School of Geography, University of Leeds, with those from Brazil at Instituto Nacional de Pesquisas da Amazonia in Manaus.

\subsubsection{Plant available nutrients}

As in Quesada and Lloyd (2015), the amount of nutrient available per unit ground area $\left([\Theta]_{\mathrm{S}, \mathrm{a}}\right)$ was estimated according to

$[\Theta]_{\mathrm{S}, \mathrm{a}}=\int_{z=0}^{z=d} \rho_{\mathrm{b}}[\Theta]_{\mathrm{ex}, \mathrm{m}} \mathrm{d} z$

where $[\Theta]_{\mathrm{S}, \mathrm{a}}$ is the soil nutrient content (expressed as $\mathrm{g} \mathrm{m}^{-2}$ or mol $\mathrm{m}^{-2}$ ), $\rho_{\mathrm{b}}$ is the soil bulk density (typically in $\mathrm{kg} \mathrm{m}^{-3}$ ), $[\Theta]_{\text {ex,m }}$ is the plant available soil nutrient on mass basis (typically $\mathrm{gg}^{-1}$ or mmolg ${ }^{-1}$ ), $z$ is the soil depth (below the soil surface) and $d$ is the depth of soil nutrient availability considered, here - so as to be consistent with Quesada et al. (2012) - taken to be $0.3 \mathrm{~m}$.

\subsection{Leaf traits}

Traits were assessed on an individual basis for at least 10 individuals with a diameter at breast height $(1.3 \mathrm{~m})$ greater than $0.1 \mathrm{~m}$ within each 1 ha plot. Trees were further selected on the basis that climbing the tree or cutting the branch from the ground could retrieve sun-exposed top-canopy branches. For each tree, a branch was harvested from the top canopy as described in Lloyd et al. (2010). A list of the species sampled is given in Table S2 along with details of the species' assumed affinity (forest vs. savanna) and leaf habit - both these characteristics being mostly based on local botanical knowledge. In terms of leaf habit, trees were categorised as being deciduous (trees remain bare until leaf flush is induced by re-hydration), brevi-deciduous (short bare period in the dry season followed by leaf flush), semi-deciduous (trees losing old foliage as growth of new leaves starts) or evergreen (trees are never leafless but flush or shed leaves in regular periods or continuously throughout the year).

\subsubsection{Leaf mass per unit area $\left(M_{\mathrm{a}}\right)$}

The ratio of fresh, one-sided area of a leaf to its dry weight was obtained by separating at least 10 healthy adult leaves from the bulk leaf sampled from each branch. Each leaf was then scanned using a flatbed scanner attached to a laptop as soon as possible after harvesting in the field. Where scanning on the day of collection was impossible due to logistical reasons, leaves were stored in tightly sealed plastic bags under cool and dark conditions for a maximum of 2 days to avoid changes in the leaf area. The surface area of the leaf scans was subsequently analysed on an individual basis using WinFOLIA ${ }^{\mathrm{TM}}$ (Regent Instruments Inc., Ottawa, Canada). The scanned leaves were then oven dried to constant weight at $70^{\circ} \mathrm{C}$ for about $24 \mathrm{~h}$ to prevent enzymatic decomposition, and their dry-mass determined after cooling in a desiccator. Where this was not possible due to logistical constraints, leaves were air dried in the field and oven dried as soon as possible.

\subsubsection{Sample preparation}

Bolivian leaf sample preparation and analyses were undertaken at the University of Leeds (UoL) with Brazilian samples processed and analysed at the Instituto Nacional de Pesquisas da Amazonia (INPA) in Manaus, with the exception of carbon and nitrogen determinations, which were undertaken at the Centro de Energia Nuclear na Agricultura (CENA) in Piracicaba, Brazil. Leaf material not used for the determination of $M_{\mathrm{a}}$ was dried as described above. About $20 \mathrm{~g}$ dry weight subsamples were then taken for the determination of foliar nutrients and isotopes. To prepare the leaf samples for these analyses, the main vein and petiole of each leaf were removed and the dried subsample ground through a $1.0 \mathrm{~mm}$ (20 mesh) sieve. 


\subsubsection{Carbon and nitrogen determinations}

Foliar nitrogen $[\mathrm{N}]_{\mathrm{m}}$ and carbon $[\mathrm{C}]_{\mathrm{m}}$ in the bulk leaf samples were determined on 15-30 mg of the ground plant material using elemental analysis (EURO EA CHNSO Analyser, HEKAtech GbhB, Wegberg, Germany in UoL and a CARLO ERBA EA $1110 \mathrm{CHN}$, Thermo Fisher Scientific, GmbH, Germany at CENA).

\subsubsection{Cation and phosphorus determinations}

At UoL, foliar cations (calcium, potassium and magnesium) and phosphorus in the ground samples were determined by inductively coupled plasma optical emissions spectrometry (ICP-OES) (PerkinElmer Optima 5300DV, PerkinElmer, Shelton, CT, USA) following acid digestion (Lloyd et al., 2010). In the INPA laboratory, samples were digested using a nitric-perchloric acid mixture, with concentrations of $\mathrm{Ca}, \mathrm{Mg}$ and $\mathrm{K}$ determined using an Atomic Absorption Spectrophotometer (AAS) (Model 1100b, Perking Elmer, Norwalk, CT, USA) as described by Anderson and Ingram (1993) with phosphorus determined by Colorimetry (Olsen and Sommers, 1982) using a UV-visible spectrophotometer (model 1240, Shimadzu, Kyoto, Japan). Sample dilutions for AAS determinations were made with a $0.55 \%$ lanthanum suppressant solution for $\mathrm{Ca}$ and $\mathrm{Mg}$, with a $0.2 \%$ $\mathrm{CsCl}$ solution for $\mathrm{K}$. Details of solutions and standard series preparation can be obtained from Van Reeuwijk (2002).

\subsubsection{Leaf construction costs}

The cost of leaf construction (expressed as g glucose $\mathrm{g}^{-1}$ DW) was estimated as in Poorter and de Jong (1999), viz.

$K=\left(-1.041+5.077 \mathrm{C}_{\mathrm{m}}\right)\left(1-\phi_{\mathrm{m}}\right)+5.325 \mathrm{~N}_{\mathrm{org}}$,

where $K$ is the construction cost, $\mathrm{C}_{\mathrm{m}}$ is the leaf carbon concentration, $\phi_{\mathrm{m}}$ is the leaf mineral content and $\mathrm{N}_{\text {org }}$ is the leaf organic $\mathrm{N}$ concentration (all in $\mathrm{g} \mathrm{g}^{-1} \mathrm{DW}$ ). For the purposes of calculation we assumed that all $\mathrm{N}$ present in the leaves was in the organic form (i.e. free nitrate levels were minimal as seems to be the case at least for Amazon forest species; Bloomfield, 2012), with leaf mineral content being approximated as the sum of the measured major cations (Sect. 2.4.4).

\subsubsection{Estimation of canopy nutrient concentrations}

The total amount of each nutrient contained in the foliage $\Theta_{C}$ was estimated as (Quesada and Lloyd, 2015)

$\Theta_{\mathrm{C}}=L\left\langle\Theta_{\mathrm{m}}\right\rangle\left\langle M_{\mathrm{a}}\right\rangle$,

where $L$ is the stand leaf area index $(D>0.1 \mathrm{~m})$ taken from Veenendaal et al. (2015) $-\left\langle\Theta_{\mathrm{m}}\right\rangle$ and $\left\langle M_{\mathrm{a}}\right\rangle$ are the speciesabundance-weighted mass-based leaf nutrient estimates and leaf mass per unit area, respectively (see Sect. 2.6.2). Equation (3) is by necessity an approximation - ignoring within canopy gradients for example - also assuming a species' abundance is also a good indication of its relative leaf area. But especially for comparison of canopy and soil available nutrient stocks, it does have advantages as compared to more simplistic approaches, such as in Cleveland et al. (2011), where variations in leaf area or $M_{\mathrm{a}}$ are not even taken into account. Moreover, taken in conjunction with the "soil equivalent” (Eq. 1; Sect. 2.3.3), Eq. (3) allows both plant and soil nutrient stocks to be expressed on a per unit ground area basis (e.g. $\mathrm{mol} \mathrm{m}^{-2}$ ), therefore providing a ready means for quantitative comparisons.

\subsection{Climatological data}

Precipitation climatologies for all sites were obtained from the interpolated WorldClim data set (Hijmans et al., 2005).

\subsection{Statistical analyses}

\subsubsection{Variance partitioning}

As in Fyllas et al. (2009), the relative proportions of the total variance within the data set were apportioned to genetic, environmental and "residual" components for each trait $(\Theta)$. Taking into account that the majority of species sampled could be assigned as being affiliated with either the forest $(\mathbb{F})$ or savanna $(\mathbb{S})$ biomes, the model fitted here was

$\Theta=\mathbb{A} / S+p+\varepsilon$,

where $\mathbb{A}$ represents the affiliation of species $S$ (either forest or savanna) located within plot $p$, and $\varepsilon$ is the residual variance: the nesting of $S$ within $\mathbb{A}$ allows for a splitting of the total between species variance into an intra- and interbiome component. As noted by Fyllas et al. (2009), the residual variance component includes any intra-species variability as well as any measurement error. These calculations were done using the "Ime4" package (Bates et al., 2014) available within the "R" statistical platform (R-Development-CoreTeam, 2014), treating all terms as random effects.

\subsubsection{Variations in plot-level means in relation to vegetation type and precipitation}

For each leaf trait $\Theta$ (including the area-based light and $\mathrm{CO}_{2}$ saturated photosynthetic capacity, $A_{\max }$ ) plot-level community-weighted means $\langle\Theta\rangle$ and standard deviation (SD) were estimated using standard formulas (Bevington and Robinson, 1969) and weighting each observation according to the ratio $n_{\mathrm{s}} / n_{\mathrm{p}}$, where $n_{\mathrm{s}}$ is the number of individuals of that species sampled in the plot (Lopez-Gonzalez et al., 2011) and $n_{\mathrm{p}}$ the total number of that species in the plot as determined through floristic inventory (TorelloRaventos et al., 2013). These calculations were done using the "wt.mean" function within the "SDMTools" package (VanDerWal et al., 2014) available within the "R" statistical platform (R-Development-Core-Team, 2014). Estimates 
of $\langle\Theta\rangle$ and associated weights so obtained were then investigated in relation to variations in mean annual precipitation according to

$$
\langle\Theta\rangle=\mu+\alpha \mathbb{S}+s_{1}\left(P_{\mathrm{A}}\right)+\mathbb{S}_{s_{2}}\left(P_{\mathrm{A}}\right),
$$

where $\mu$ represents the data set mean for trees located within the forest $(\mathbb{F}$ ) vegetation type (i.e. $\mathbb{V}=\mathbb{F}$ ), $\mathbb{S}$ is an indicator variable taking a value of 1 for all trees located within savanna formations (for which by definition $\mathbb{V} \neq \mathbb{F}$ ) and zero otherwise, $s_{1}$ is a non-parametric smoother, fitted to the data set as a whole, $P_{\mathrm{A}}$ is the mean annual precipitation as estimated for the plot in question and $s_{2}$ is a non-parametric smoother defining the difference between forest and savanna vegetation formation types. Equation (5) thus allows for differences in overall average trait values as well as for differing interactions with precipitation for forest vs. savanna vegetation formation types: with these two aspects of variation tested through a simple $t$ test on the (fixed) $\alpha$ term with $s_{2}\left(P_{\mathrm{A}}\right)=0$ (i.e. an imposition of the same precipitation response on both $\mathbb{V}$ ), and a simple $F$ test evaluating the effect of inclusion of the $s_{2}\left(P_{\mathrm{A}}\right)$ term in Eq. (5; Zuur et al., 2009). For the fitting of Eq. (5), we used the "gam" function within the "mgcv" package (Wood, 2006, 2011) as available on the "R" statistical platform (R-Development-Core-Team, 2014).

Equation (5) was also used (without weights) in analyses of variations in bulked stand-level soil and canopy properties.

\subsubsection{Soil-climate-vegetation associations}

A variety of regression/correlation techniques were applied depending on the nature of the data and questions posed. These included ordinary least squares (OLS) regression, Kendall's distribution-free test for independence (Hollander and Wolfe, 1999) and non-parametric (robust) regression (McKean et al., 2009). All were undertaken using the "R" statistical platform (R-Development-Core-Team, 2014) using the "stats" or "Rfit" package (Kloke and McKean, 2013). For multivariate OLS regressions, variance inflation factors (VIF) were also calculated and are presented in the relevant tables along with the associated "tolerance" (i.e. $1 / \mathrm{VIF}$ ). OLS regression coefficients are presented in both original and standardised form. The latter are presented as standardised values, this giving the relative change in the dependent variable per unit SD of each independent variable. Though potentially open to misinterpretation (Grace and Bollen, 2005), this provides a simple measure of the relative importance of the various factors accounting for the variation in stand structure or physiological variables investigated, the standardising factor being the variability (after transformation where appropriate) of the various candidate independent variables along the precipitation transect as measured by our data set.

\section{Results}

\subsection{Soil properties}

Across the precipitation $\left(P_{\mathrm{A}}\right)$ gradient, forest soils had an exchangeable base cation content (usually referred to as the "sum of bases": $[\mathrm{Ca}]_{\mathrm{ex}}+[\mathrm{K}]_{\mathrm{ex}}+[\mathrm{Mg}]_{\mathrm{ex}}+[\mathrm{Na}]_{\mathrm{ex}}=\Sigma_{\mathrm{B}}$ ) greater than the savanna soils (Fig. 3a) as reflected by an estimated $\alpha=-9.1 \pm 3.1 \mathrm{mmol} \mathrm{kg}^{-1}$ for the model fit of Eq. (5) $(p=0.010)$. That analysis also showed a difference between the two $\mathbb{V}$ in their overall precipitation dependencies with the " $s_{2}$ " term in Eq. (5) being significant at $p=0.005$; i.e. the forest $(\mathbb{F})$ and savanna $(\mathbb{S})$ soils differed both in their overall average $\Sigma_{\mathrm{B}}$ and in the way that $\Sigma_{\mathrm{B}}$ varied with precipitation. For both $\mathbb{V}, \Sigma_{\mathrm{B}}$ were clearly higher at low $P_{\mathrm{A}}$. Across the precipitation gradient individual cation concentrations were typically $[\mathrm{Ca}]_{\mathrm{ex}} \geqslant[\mathrm{Mg}]_{\mathrm{ex}} \gg[\mathrm{K}]_{\mathrm{ex}}$ for any individual plot, with $[\mathrm{Ca}]_{\mathrm{ex}}$ and $[\mathrm{Mg}]_{\mathrm{ex}}$ increasing more markedly with declining $P_{\mathrm{A}}$ than was the case for $[\mathrm{K}]_{\mathrm{ex}}$ (see Table $\mathrm{S} 1$ for actual values).

Soil $\mathrm{C} / \mathrm{N}$ ratios $\left(\mathrm{CN}_{\mathrm{s}}\right)$ also varied with both $\mathbb{V}$ and $P_{\mathrm{A}}$ (Fig. 3b) with $\mathbb{S}$ soil being on average $2.3 \pm 0.6 \mathrm{~g} \mathrm{~g}^{-1}$ higher than for $\mathbb{F}$ soils $(p \leq 0.001)$. In both cases, $\mathrm{CN}_{\mathrm{s}}$ declined with decreasing $P_{\mathrm{A}}$ with (after accounting for intercept differences) no apparent difference between the two fitted curves $(p=0.155)$.

Extractable soil phosphorus concentrations, $[\mathrm{P}]_{\text {extr }}$, also showed a dependence upon both $\mathbb{V}$ and $P_{\mathrm{A}}$ (Fig. 3c) with markedly lower values in savanna sites as reflected in the fitted value of $\alpha$ in Eq. (5) being $-143 \pm 44 \mathrm{mg} \mathrm{kg}^{-1}$ ( $p=$ $0.005)$. There was also a clear difference between $\mathbb{F}$ and $\mathbb{S}$ in the way $[\mathrm{P}]_{\text {extr }}$ varied with precipitation $(p=0.023)$ with the lack of any clear savanna $P_{\mathrm{A}}$ dependency $(p=0.58)$ in marked contrast to the increasing forest $[\mathrm{P}]_{\text {extr }}$ as $P_{\mathrm{A}}$ declined (for which $p<0.001$ ). In all soils, the bulk of the $[\mathrm{P}]_{\text {extr }}$ pool was made up of the less accessible $\mathrm{NaOH}$ extractable organic and inorganic fractions ( $\mathrm{P}_{\mathrm{NaOH}(\mathrm{o})}$ and $\mathrm{P}_{\mathrm{NaOH}(\mathrm{i})}$, respectively). Small amounts of mineral $\mathrm{P}$ were also present in some of the lower $P_{\mathrm{A}}$ soils as indicated through the presence of an $\mathrm{HCl}$ extractable component.

Further site information (including other soil characteristics of the study plots) may be found in the Supplement (Table S1) from which we note both a tendency for the savanna plots to be sandier than their nearby forest counterparts though with no consistent difference between $\mathbb{F}$ and $\mathbb{S}$ in terms of their plant available water holding capacity $\left(\theta_{\mathrm{P}}\right)$, which was itself highly variable (ranging from 0.18 to $0.74 \mathrm{~m}$ ). Also of note is that - with the exception of the driest TUC-01 and TUC-03 plots, which were Cambisols - all soils were of the highly weathered Acrisol, Arenosol or Ferralsol World Reference Base great soil group. 


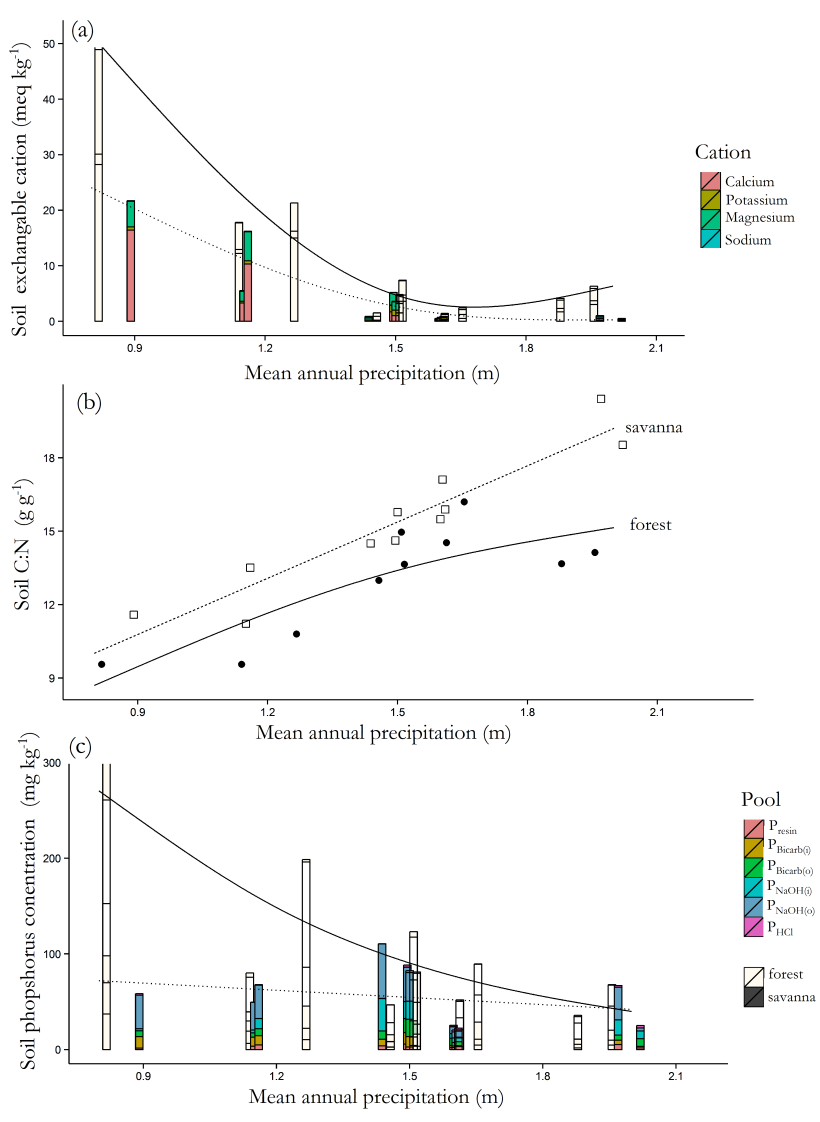

Figure 3. Variations in key soil chemical properties $(0.0-0.3 \mathrm{~m}$ depth) in relation to precipitation and vegetation formation type (a) soil exchangeable cations; (b) soil $\mathrm{C} / \mathrm{N}$ ratio; (c) soil phosphorus pools. For (a) and (b) forest plots are shaded more lightly than savanna with the fitted curves (solid for forest plots, dashed for savanna) representing generalised additive model fits representing for (a) total exchangeable cations (sum of bases) and for (c) total extractable phosphorus. In (c) the phosphorus pools are as per the Hedley fractionation procedure (see Sect. 2.3.3): $[\mathrm{P}]_{\text {resin }}$ - resin extractable $\mathrm{P}$; $[\mathrm{P}]_{\text {Bicarb(i) }}$ - bicarbonate extractable inorganic phosphorus; $[\mathrm{P}]_{\mathrm{Bicarb}(\mathrm{o})}$ bicarbonate extractable organic phosphorus; $[\mathrm{P}]_{\mathrm{NaOH}(\mathrm{i})}-\mathrm{NaOH}$ extractable inorganic phosphorus; $[\mathrm{P}]_{\mathrm{NaOH}(\mathrm{o})}$ bicarbonate extractable organic phosphorus; $[\mathrm{P}]_{\mathrm{HCl}}-$ $\mathrm{HCl}$ extractable phosphorus.

\subsection{Canopy characteristics}

All three canopy structural properties showed differences both in absolute values and precipitation dependencies for forest vs. savanna plots (Figs. 2 and 4). Specifically, there was a clear decline in forest canopy area index $\left(C_{\mathrm{W}}\right)$ with declining precipitation $(p<0.001)$, but with the best-fit line for savanna plots (which were on average of a lower $C_{\mathrm{W}}$ than their forest counterparts) only significant at $p=0.183$ (Fig. 4a).

Also observed was a tendency for the increase in 0.95 quantile canopy height with rainfall to approach its maximum at high $P_{\mathrm{A}}$ (overall response significant at $p<0.001$ ) but with no systematic dependency of $H^{*}$ on $P_{\mathrm{A}}$ for $\mathbb{S}(p=$ 0.106 ): the trees in savanna plots being on average $10.5 \mathrm{~m}$ shorter than their forest counterparts (Fig. 4b).

Above-ground biomass $\left(B_{\mathrm{U}}\right)$ estimates showed similar patterns for $C_{\mathrm{W}}$ and $H^{*}$ (Fig. $4 \mathrm{c}$ ), although in this case (interestingly) with the slight increase in savanna $B_{\mathrm{U}}$ as $P_{\mathrm{A}}$ declines, statistically significant at $p<0.001$.

Overall, we find a marked decline in stature and canopy area with precipitation for forest sites but not for savannas. Thus, savanna and forest are much more similar in their above-ground structural characteristics at lower $P_{\mathrm{A}}$.

\subsection{Leaf traits}

\subsubsection{Variance partitioning (mass-based traits)}

Through fitting the multilevel model of Eq. (4), a partitioning of the variance to genetic- and plot-level components was achieved with results presented for leaf mass per unit area $\left(M_{\mathrm{a}}\right)$, mass-based nutrient concentrations and estimated leaf construction costs (Eq. 2) shown in Fig. 5. Here, because each species could be assigned as primarily affiliated with either forest or savanna, it was further possible to partition the genetic component into that systematically associated with where a species typically grows (its "affiliation") as opposed to genetic variation within the forest and savanna grouping themselves. This analysis shows not only that relative contributions of the genetic-components vs. the plot-components vary from trait to trait, but also that the relative magnitude of the residual component (representing within-species variability and experimental error) is trait dependent.

The genetic component that is systematically associated with a species' affiliation was typically a small proportion of the overall variability, the one exception being for potassium $\left(\mathrm{K}_{\mathrm{m}}\right)$ where the relative contributions were approximately equal. With the exception of phosphorus $\left(\mathrm{P}_{\mathrm{m}}\right)$, the variance explained by the combined genetic components was of equal or greater magnitude than the plot-dependent (environmental) component with the latter being only a minor contributor to the overall variations in $\mathrm{C}_{\mathrm{m}}$ and the associated leaf construction costs $(K)$.

Whether or not one should attempt to assign error estimates and associated inferred level of significance to random effect estimates as used in deriving Fig. 5 is a point of contention (Wood, 2006); nevertheless, the "affiliation" of forest vs. savanna species is just as readily perceivable as a fixed effect allowing reasonable error estimates and associated significance levels to be obtained. When this is done, species affiliation (forest vs. savanna) is found to exert a significant influence on all trait values investigated in Fig. 5 at $p<0.05$ except $\mathrm{P}_{\mathrm{m}}$ (Table S3); i.e. even after accounting for differences in soil properties, intrinsic differences between forest and savanna in all traits except $\mathrm{P}_{\mathrm{m}}$ existed. From Table $\mathrm{S} 3$ it can be seen in some cases that these differences - although significant at $p<0.05-$ are relatively small (e.g. $M_{\mathrm{a}}, \mathrm{N}_{\mathrm{m}}$, 

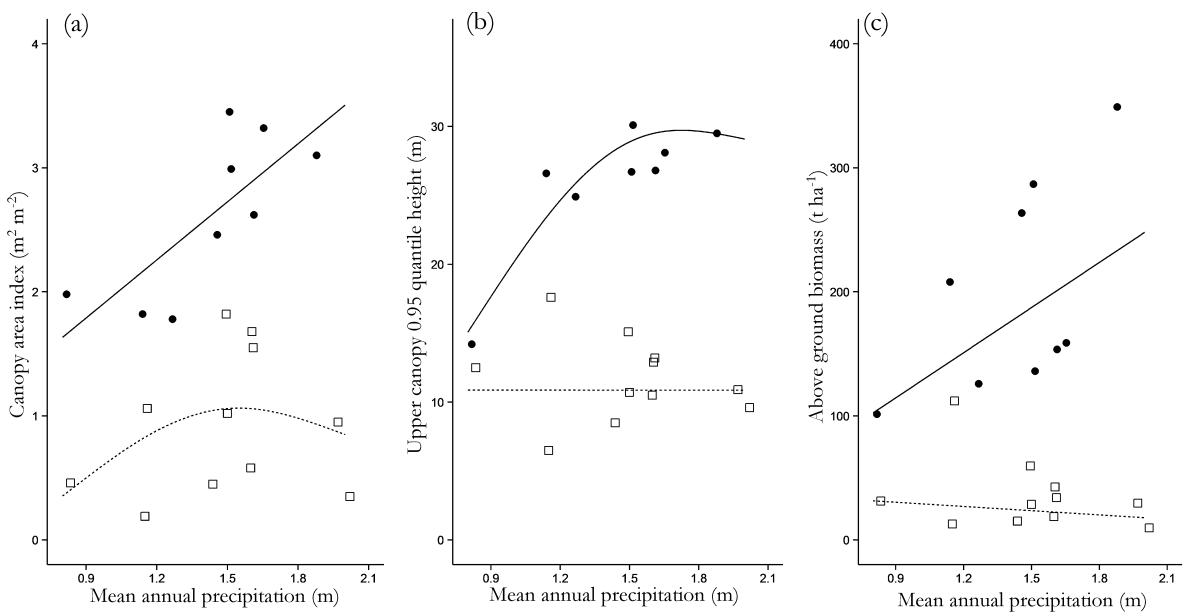

Figure 4. Variations in canopy structural properties in relation to precipitation and vegetation formation type (a) canopy area index, (b) upper 0.95 quantile height and (c) above-ground biomass. (•) Forest plots; ( $\square$ ) savanna plots. Fitted curves (solid for forest plots, dashed for savanna) represent generalised additive model fits.

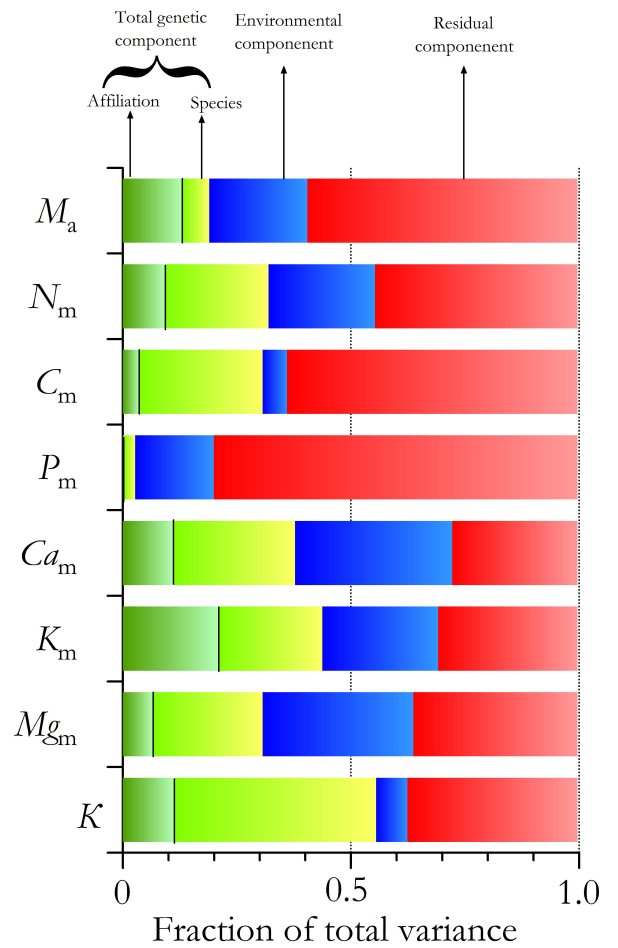

Figure 5. Partitioning of the total variance for mass-based foliar properties into genetic (green), environmental (blue) and residual (red) components with the genetic component further divided into the variations between versus within vegetation formation affiliation (each species having being identified as principally associated with either forest or savanna). $M_{\mathrm{a}}$ denotes mass per unit area and $K$ represents leaf construction costs. Other symbols represent the elemental composition of the leaves on a dry-mass (subscript "m") basis.
$\mathrm{C}_{\mathrm{m}}, \mathrm{Mg}_{\mathrm{m}}$, and $K$ all having savanna species mean values all within $20 \%$ of the forest species' mean) but with $\mathrm{Ca}_{\mathrm{m}}$ and $\mathrm{K}_{\mathrm{m}}$ showing much larger differences (savanna affiliated species showing reductions of 34 and $39 \%$, respectively, as compared to forest species: Table S3).

\subsubsection{Mass-based trait variation in relation to vegetation type and precipitation}

Across the precipitation gradient, leaves of trees within savanna formations $(\mathbb{S}$ ) had consistently higher leaf mass per unit area than those where the dominant species mix consisted of forest species ( $\mathbb{F}$; Fig. 6a). From the generalised additive model fit (Eq. 5), this overall $\left\langle M_{\mathrm{a}}\right\rangle$ difference $(\alpha=$ $32 \pm 9 \mathrm{~g} \mathrm{~m}^{-2}$ ) was significant at $p=0.001$. Overall, the $P_{\mathrm{A}}$ dependencies observed were highly significant at $p<0.001$ for both $\mathbb{V}$, but the differing fitted trends were not so significant ( $p=0.183$ ); i.e. little credence should be placed on the greater difference between the two vegetation formation types at the highest $P_{\mathrm{A}}$.

For stand-level leaf nitrogen there was also an obvious difference in overall concentrations between the two $\mathbb{V}(\mathbb{F}-\mathbb{S}=$ $6.0 \pm 1.5 \mathrm{mg} \mathrm{g}^{-1} ; p=0.001$; Fig. $6 \mathrm{~b}$ ) with the fitted precipitation dependencies showing an increase with declining $P_{\mathrm{A}}$ significant at $p<0.001$ and $p=0.065$ for $\mathbb{F}$ and $\mathbb{S}$, respectively. As for $\left\langle M_{\mathrm{a}}\right\rangle$ there was, however, no difference in the fitted $P_{\mathrm{A}}$ dependencies for $\left\langle\mathrm{N}_{\mathrm{m}}\right\rangle$ once differences in absolute values were taken into account $(p=0.588)$. Thus, after accounting for differences in intercept both forest and savanna can be considered as showing similar increases in $\left\langle\mathrm{N}_{\mathrm{m}}\right\rangle$ with declining $P_{\mathrm{A}}$.

For $\left\langle\mathrm{P}_{\mathrm{m}}\right\rangle$ there was no effect of $\mathbb{V}$ on overall leaf concentrations (Fig. 6c: $p=0.283$ ), nor was there any difference in the fitted $P_{\mathrm{A}}$ response patterns $(p=0.098)$. 

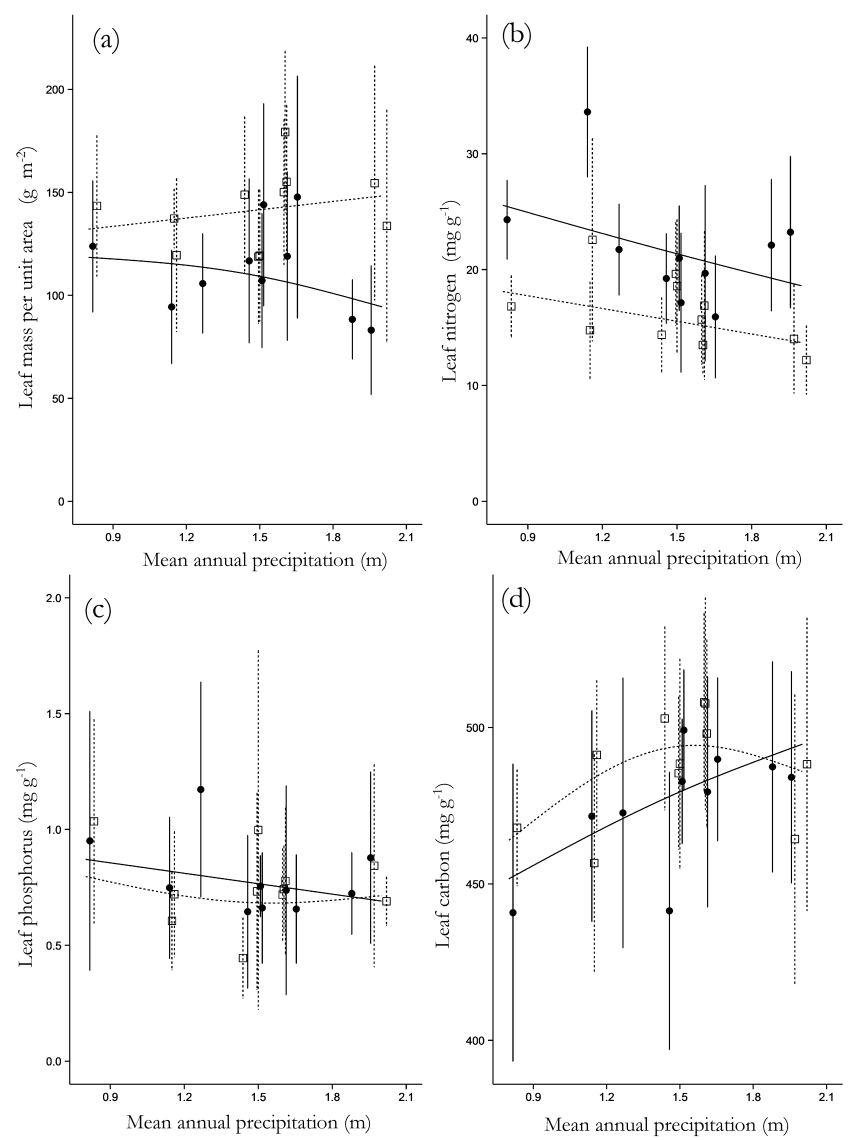

Figure 6. Variations in community-abundance-weighted mean foliar properties in relation to precipitation and vegetation formation type (a) leaf mass per unit area, (b) leaf nitrogen (dry-mass basis), (c) leaf phosphorus (dry-mass basis) and (d) carbon (dry-mass basis). (•) Forest plots; ( $\square$ ) savanna plots. Fitted curves (solid for forest plots, dashed for savanna) represent generalised additive model fits. Error bars represent the community-abundance-weighted SD.

A similar lack of any effect of vegetation formation type was also observed for leaf carbon concentrations (Fig. 6d) where although $\left\langle\mathrm{C}_{\mathrm{m}}\right\rangle$ were $11 \mathrm{mg} \mathrm{g}^{-1}$ higher for $\mathbb{S}$ plots this effect was significant only at $p=0.091$. The fitted $P_{\mathrm{A}}$ dependencies were, nevertheless, significant at $p<0.001$ in both cases, but also not different in pattern to each other $(p=0.687)$.

Despite the $\left\langle\mathrm{Ca}_{\mathrm{m}}\right\rangle$ differences between $\mathbb{F}$ and $\mathbb{S}$ plots at lower $P_{\mathrm{A}}$, the overall contrast $(\mathbb{F}-\mathbb{S})$ of $1.4 \mathrm{mg} \mathrm{g}^{-1}$ was only significant at $p=0.161$, presumably a consequence of significant overlap between the two $\mathbb{V}$ at around $P_{\mathrm{A}}=1.5 \mathrm{~m}$ and the high variance of the community-weighted means at higher overall $\left\langle\mathrm{Ca}_{\mathrm{m}}\right\rangle$, especially for forest plots at low $P_{\mathrm{A}}$ (Fig. 7a). The fitted $P_{\mathrm{A}}$ dependencies were highly significant in both cases $(p<0.001)$, but with overall patterns not different $(p=0.687)$.

For $\left\langle\mathrm{K}_{\mathrm{m}}\right\rangle, \mathbb{F}$ and $\mathbb{S}$ values were significantly different overall $(p=0.015)$ with savanna plots being estimated as, on
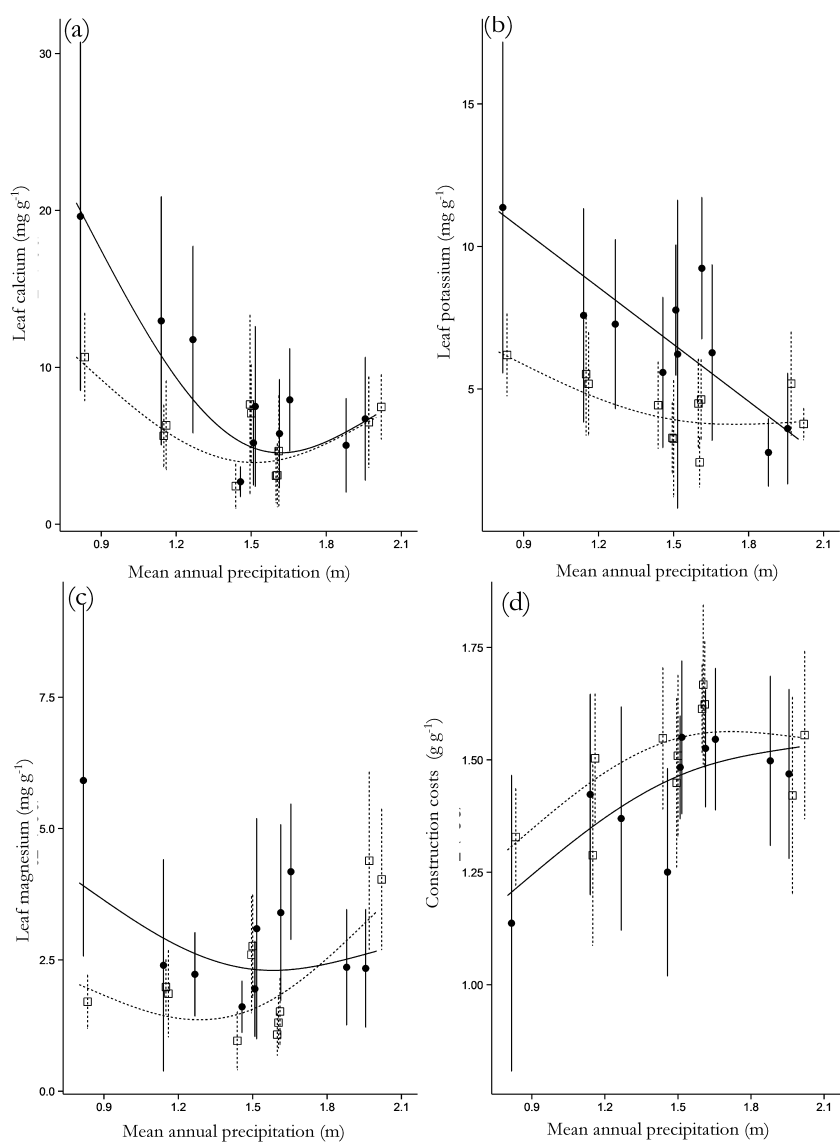

Figure 7. Variations in community-abundance-weighted mean foliar properties in relation to precipitation and vegetation formation type (a) leaf calcium (dry-mass basis), (b) leaf potassium (drymass basis), (c) leaf magnesium (dry-mass basis) and (d) leaf construction costs. (•) Forest plots; $(\square)$ savanna plots. Fitted curves (solid for forest plots, dashed for savanna) represent generalised additive model fits. Error bars represent the community-abundanceweighted SD.

average, $1.8 \pm 0.7 \mathrm{mg} \mathrm{g}^{-1}$ less than forest (Fig. 7b). Overall fitted $P_{\mathrm{A}}$ dependency patterns - which were significant at $p<0.001$ and $p=0.025$ for $\mathbb{F}$ and $\mathbb{S}$, respectively - were also appreciably different from each other $(p=0.010)$. Thus for $\left\langle\mathrm{K}_{\mathrm{m}}\right\rangle$ we can conclude that for $\mathbb{F}$ the rate of increase with declining precipitation was more or less constant across the transect. This is opposed to $\mathbb{S}$ where the increase in $\left\langle\mathrm{K}_{\mathrm{m}}\right\rangle$ with declining $P_{\mathrm{A}}$ was more moderate, also occurring only towards the drier end of the transect.

Overall, the $0.67 \mathrm{mgg}^{-1}$ lower $\left\langle\mathrm{Mg}_{\mathrm{m}}\right\rangle$ observed for the savanna plots (Fig. 7c) did not make them appreciably different to their forest counterparts $(p=0.155)$ with no difference between the two $\mathbb{V}$ in the nature of their $P_{\mathrm{A}}$ dependencies $(p=0.192)$, which were themselves both significant ( $p=0.001$ and $p=0.047$ for $\mathbb{F}$ and $\mathbb{S}$, respectively). As for $\left\langle\mathrm{Ca}_{\mathrm{m}}\right\rangle$ and $\left\langle\mathrm{K}_{\mathrm{m}}\right\rangle$, within-plot variation at the lowest $P_{\mathrm{A}}$ forest plot (TUC-01) was exceptionally high. 
Leaf construction costs showed a slight overall dependence on $\mathbb{V}$ with $\langle K\rangle$ for $\mathbb{S}$ being on average $0.077 \pm$ $0.037 \mathrm{mg}$ glucose $\mathrm{g}^{-1} \mathrm{DW}$ higher than $\mathbb{F}(p=0.053)$. Although the individually fitted curves are different in form for $\mathbb{F}$ vs. $\mathbb{S}$ (Fig. 7d) this difference in shape is not of consequence $(p>0.999)$.

Although a lack of knowledge for many of the species studied prevents rigorous inferences of trends in leaf habit, from those species for which this information was available (Table S2), it can be confidently stated that at the driest Tucavaca sites in Bolivia that all species were deciduous (both forest and savanna) with semi-deciduous and brevideciduous and then evergreen species becoming more common as precipitation increased. At all sites other than $\mathrm{Tu}-$ cavaca, evergreen species were more common in the forests and purely deciduous species more common in the savanna.

\subsubsection{Vegetation-soil nutrient associations}

Estimates on canopy nutrient contents (Eq. 2) as a function of soil exchangeable nutrient contents (Eq. 1) showed no clear relationship for calcium $\left(\mathrm{Ca}_{\mathrm{C}}\right.$; Fig. 8a), magnesium $\left(\mathrm{Mg}_{\mathrm{C}}\right.$; Fig. $8 \mathrm{~b}$ ) and phosphorus $\left(\mathrm{P}_{\mathrm{C}}\right.$; Fig. $\left.8 \mathrm{~d}\right)$, but with some association being more clear for potassium $\left(\mathrm{K}_{\mathrm{C}} ;\right.$ Fig. $\left.8 \mathrm{c}\right)$. Using a robust regression procedure (relatively immune to outliers), significance levels as estimated through a dispersion test were $p=0.062,0.266,0.026$ and 0.402 for $\mathrm{Ca}_{\mathrm{C}}, \mathrm{Mg}_{\mathrm{C}}$, $\mathrm{K}_{\mathrm{C}}$, and $\mathrm{P}_{\mathrm{C}}$, respectively.

As the graphs of Fig. 8 express both plant and soil nutrients on the same per unit ground area basis, they provide a ready means to evaluate the relative amounts of any nutrient in the foliage vs. the soil. Here we then see that, as approaching the asymptote, $\mathrm{Ca}_{\mathrm{C}} \simeq 0.1[\mathrm{Ca}]_{\mathrm{sa}}, \mathrm{Mg}_{\mathrm{C}} \simeq 0.1[\mathrm{Mg}]_{\mathrm{sa}}$ and $\mathrm{P}_{\mathrm{C}} \simeq 0.08[\mathrm{P}]_{\mathrm{sa}}$, but for $\mathrm{K}_{\mathrm{C}}:[\mathrm{K}]_{\mathrm{sa}}$ there is no real flattening out, with canopy potassium contents quite similar to those of calcium and magnesium despite much lower soil concentrations; i.e. relative to the amount of soil nutrient present, there is much less $\mathrm{K}$ in the canopy foliage than is the case for $\mathrm{Ca}$ and $\mathrm{Mg}$. This is in addition to a much clearer relationship between the nutrient stocks in the canopy vs. soil pools for $\mathrm{K}$ than for the other cations examined. For phosphorus the generally overall lower canopy foliar contents of savanna plots are not associated with a lower $[\mathrm{P}]_{\mathrm{sa}}$.

\subsection{Photosynthesis and related traits}

\subsubsection{Variance partitioning (area-based traits)}

In contrast to the mass-based traits, in no case was the proportion of the total data set variance in light and $\mathrm{CO}_{2}$ saturated assimilation rates $\left(A_{\max }\right)$, area-based nitrogen and phosphorus concentrations $\left(\mathrm{N}_{\mathrm{a}}\right.$ and $\mathrm{P}_{\mathrm{a}}$, respectively), photosynthetic $\mathrm{N}$ and $\mathrm{P}$ use efficiencies ( $A_{\mathrm{N}}$ and $A_{\mathrm{P}}$, respectively) and foliar $\delta^{13} \mathrm{C}$ attributable to species affiliation per se. But still - with the exception of $\mathrm{P}_{\mathrm{a}}$, and to a lesser extent $\delta^{13} \mathrm{C}-$
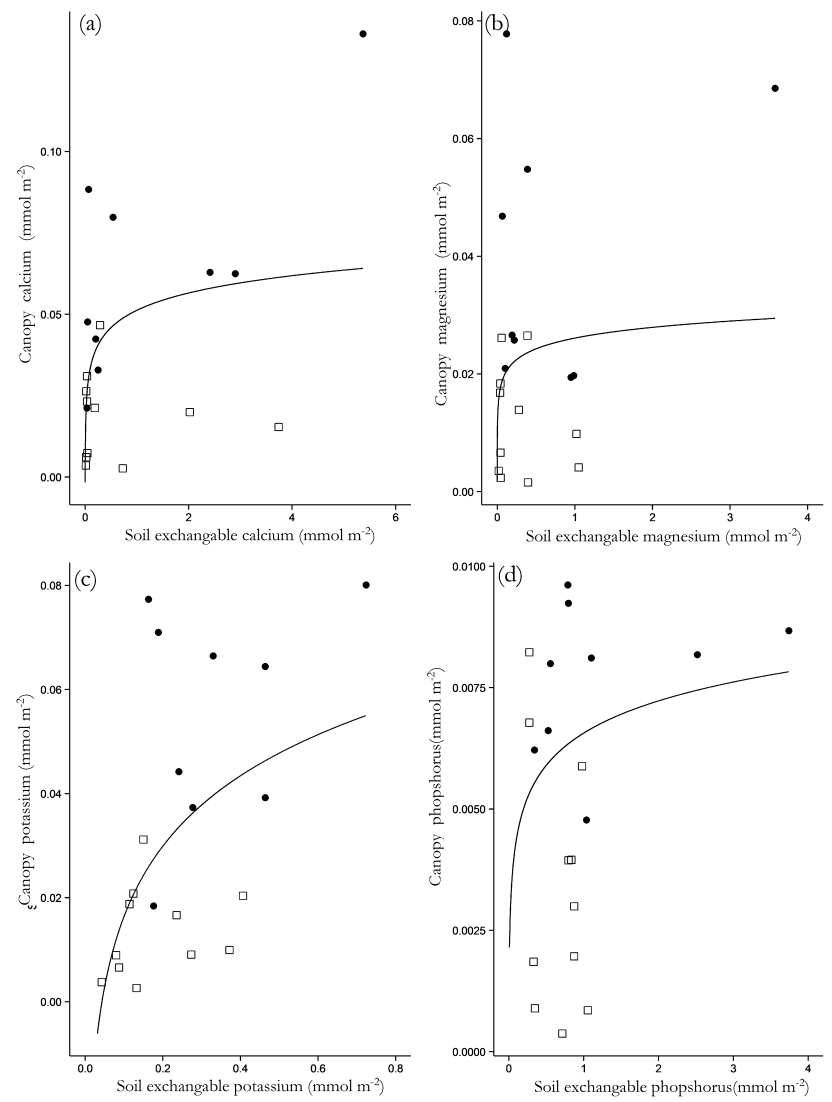

Figure 8. Relationships between soil and community-abundanceweighed foliar nutrient concentrations with both expressed on a ground area basis. (a) Calcium, (b) magnesium, (c) potassium and (d) phosphorus. (•) Forest plots; $(\square)$ savanna plots. The curves shown are log-linear, viz. $y=a+b \log (x)$, fitted using a robust nonparametric procedure.

a notable portion of the explained variance was attributable to species identity. Plot identity as estimated through the environmental components was also an appreciable source of variation in all cases, especially for $\delta^{13} \mathrm{C}$ and - in relative terms - also for $\mathrm{P}_{\mathrm{a}}$.

\subsubsection{Area-based trait variation in relation to vegetation type and precipitation}

Stand-level species-abundance-weighted maximum $\mathrm{CO}_{2}$ assimilation rates (Fig. 10a) did not vary overall between the two $\mathbb{V}(p=0.851)$, nor - despite their fitted slopes being of a different sign - did their precipitation dependencies differ $(p=0.302)$. Amongst this general "noise" of note, however, are two noticeably high $\left\langle A_{\max }\right\rangle$ plots: the relatively low precipitation forest OTT-01 and the mid-precipitation savanna LFB-03.

Contrasting to $\left\langle\mathrm{N}_{\mathrm{m}}\right\rangle$, there was no overall difference between $\mathbb{F}$ and $\mathbb{S}$ in $\left\langle\mathrm{N}_{\mathrm{a}}\right\rangle$ across the data set (Fig. 10b), though with very different patterns in terms of their $P_{\mathrm{A}}$ dependen- 


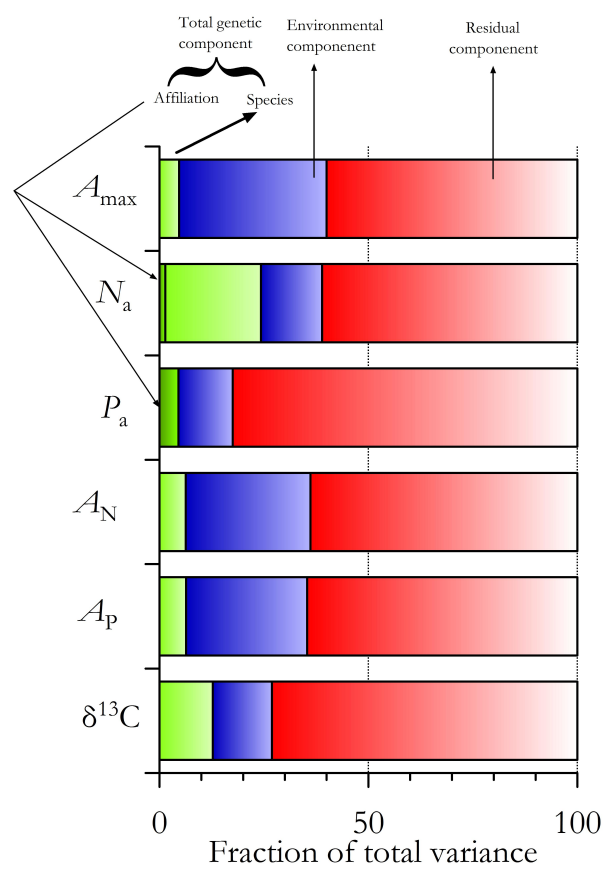

Figure 9. Partitioning of the total variance for photosynthesisassociated foliar properties into genetic (green), environmental (blue) and residual (red) components with the genetic component further divided into the variations between versus within vegetation formation affiliation (each species having being identified as principally associated with either forest or savanna). $A_{\max }$ denotes light and $\mathrm{CO}_{2}$ saturated (maximum) $\mathrm{CO}_{2}$ assimilation rate; $\mathrm{N}_{\mathrm{a}}$ and $\mathrm{Pa}$ represent the nitrogen and phosphorus composition of the leaves on an area (subscript "a") basis; $A_{\mathrm{N}}$ and $A_{\mathrm{P}}$ represent the photosynthetic nitrogen and phosphorus-use efficiencies (viz. $A_{\max } / \mathrm{N}_{\mathrm{a}}$ and $A_{\max } / \mathrm{P}_{\mathrm{a}}$ ) with $\delta{ }^{13} \mathrm{C}$ a measure of the leaf ${ }^{13} \mathrm{C} /{ }^{12} \mathrm{C}$ composition.

cies $(p=0.006)$. Specifically, there was virtually no systematic variation of $\left\langle\mathrm{N}_{\mathrm{a}}\right\rangle$ with precipitation for the savanna plots, but with an increase in forest plot $\left\langle\mathrm{N}_{\mathrm{a}}\right\rangle$ as $P_{\mathrm{A}}$ decreased $(p<0.001)$.

For $\left\langle\mathrm{P}_{\mathrm{a}}\right\rangle$ there was a small effect of $\mathbb{V}$ on mean values (Fig. 10c) with savanna plots typically being $0.022 \mathrm{~g} \mathrm{~m}^{-2}$ higher than their forest counterparts. As for $\left\langle A_{\max }\right\rangle$ and $\left\langle\mathrm{N}_{\mathrm{a}}\right\rangle$, opposing patterns of variations with $P_{\mathrm{A}}$ were observed, here with a decline in $\left\langle\mathrm{P}_{\mathrm{a}}\right\rangle$ coinciding with an increase in precipitation for $\mathbb{F}$, but with less pattern observed for $\mathbb{S}$.

Finally, we note the clear contrasting patterns in $\left\langle\delta^{13} \mathrm{C}\right\rangle$ observed for $\mathbb{F}$ vs. $\mathbb{S}$ with a more or less constant decline with increasing precipitation observed for the forest plots, but with this pattern only being replicated for savanna plots at lower $P_{\mathrm{A}}$ (Fig. 10d). Here the fitted curves were both significant at $p<0.001$ and statistically different to each other $(p=0.011)$.
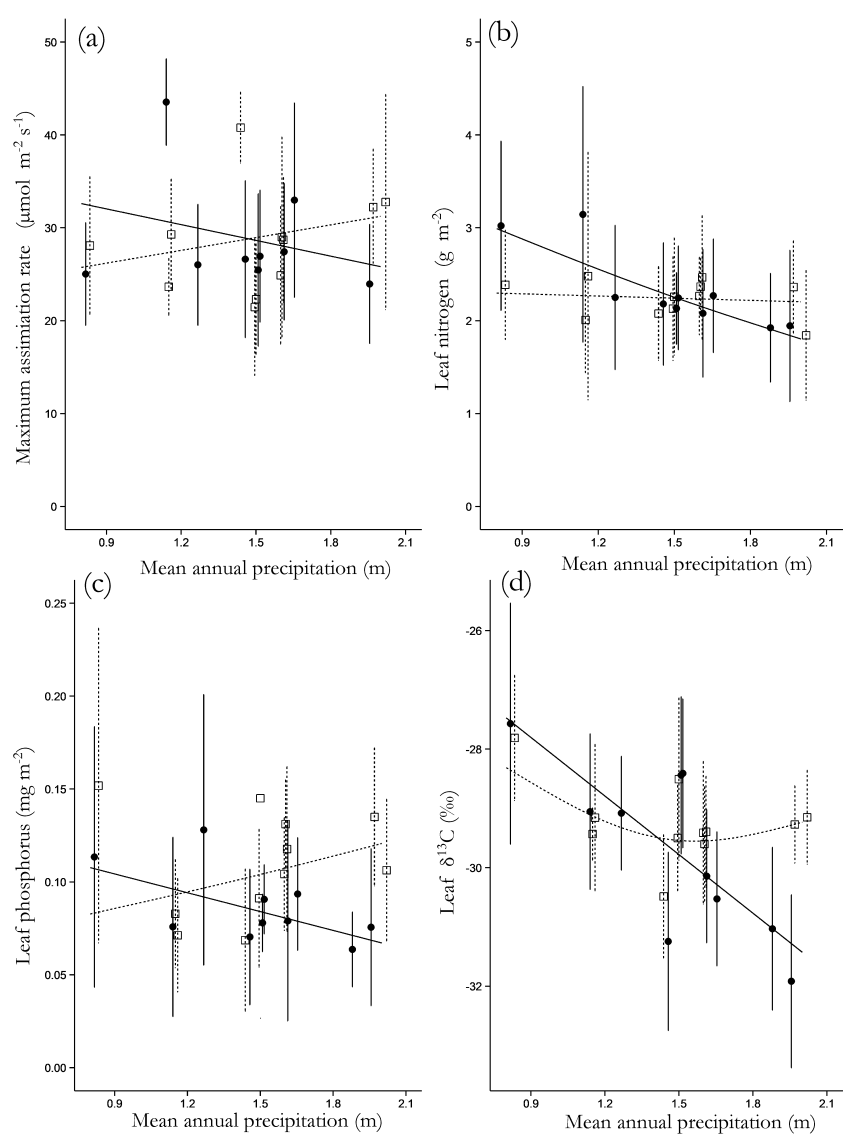

Figure 10. Variations in community-abundance-weighted mean foliar properties in relation to precipitation and vegetation formation type (a) light and $\mathrm{CO}_{2}$ saturated (maximum) $\mathrm{CO}_{2}$ assimilation rate, (b) leaf nitrogen (area basis), (c) leaf phosphorus (area basis) and (d) leaf ${ }^{13} \mathrm{C} /{ }^{12} \mathrm{C}$ composition. (•) Forest plots; ( $\square$ ) savanna plots. Fitted curves (solid for forest plots, dashed for savanna) represent generalised additive model fits. Error bars represent communityabundance-weighted SD.

\subsubsection{Identifying key drivers of variation in $\left\langle A_{\max }\right\rangle$ and $\left\langle\delta^{13} \mathrm{C}\right\rangle$}

With Fig. 10 suggesting broad-scale interacting patterns of variations in $\left\langle A_{\max }\right\rangle$ with $\mathbb{V}$ and $P_{\mathrm{A}}$ quite similar in form to $\left\langle\mathrm{N}_{\mathrm{a}}\right\rangle$ and $\left\langle\mathrm{P}_{\mathrm{a}}\right\rangle$, Kendall's non-parametric regression coefficients $(\tau)$ were calculated for these and other stand-level properties of interest (Table 1). This shows that, contrary to expectation, the only significant univariate correlation with $\left\langle A_{\max }\right\rangle$ at $p<0.05$ was a negative one with soil potassium. Consequently $[\mathrm{K}]_{\mathrm{sa}}$ also exhibited strong positive correlations with a range of stand-level structural properties such as crown area index and canopy height (both mean and 0.95 quantile) as well as $\left\langle\delta^{13} \mathrm{C}\right\rangle$.

Building on this negative $\left\langle A_{\max }\right\rangle:[\mathrm{K}]_{\mathrm{sa}}$ association through the development of a OLS multivariate regression model using a forward regression procedure, a best-fit linear- 
Table 1. Kendall's bivariate correlation coefficients for stand-level photosynthetic capacity $\left\langle A_{\max }\right\rangle$, photosynthetic nitrogen use efficiency $\left\langle A_{\mathrm{N}}\right\rangle$, photosynthetic phosphorus-use efficiency $\left\langle A_{\mathrm{P}}\right\rangle$ and their association with a range of canopy, soil and climatic factors, viz. communityweighted means of area-based leaf nitrogen $\left\langle\mathrm{N}_{\mathrm{a}}\right\rangle$ and phosphorus $\left\langle\mathrm{P}_{\mathrm{a}}\right\rangle$ concentrations; leaf carbon stable isotopic composition $\left\langle\delta^{13} \mathrm{C}\right\rangle$; total woody canopy area index $C_{\mathrm{W}}$; upper 0.95 quantile upper-canopy height $\left\langle H_{\mathrm{U}}\right\rangle$; community-weighted mean upper-canopy height $H^{*}$; areabased measures of soil nutrient availability for calcium, potassium and magnesium, viz. $[\mathrm{Ca}]_{\mathrm{sa}},[\mathrm{K}]_{\mathrm{sa}}$ and $[\mathrm{Mg}]_{\mathrm{sa}}$; soil carbon/nitrogen ratio $(\mathrm{CN})$, and mean annual precipitation $\left(P_{\mathrm{A}}\right)$. Values significant at $p<0.05$ are shown in bold.

\begin{tabular}{|c|c|c|c|c|c|c|c|c|c|c|c|c|c|}
\hline \multicolumn{14}{|l|}{$\left\langle A_{\max }\right\rangle$} \\
\hline 0.65 & $\left\langle A_{\mathrm{N}}\right\rangle$ & & & & & & & & & & & & \\
\hline 0.43 & 0.54 & $\left\langle A_{\mathrm{P}}\right\rangle$ & & & & & & & & & & & \\
\hline 0.17 & -0.18 & -0.12 & $\left\langle N_{\mathrm{a}}\right\rangle$ & & & & & & & & & & \\
\hline-0.12 & -0.26 & -0.7 & 0.22 & $\left\langle\mathrm{P}_{\mathrm{a}}\right\rangle$ & & & & & & & & & \\
\hline-0.09 & -0.27 & -0.29 & 0.25 & 0.31 & $\left\langle\delta^{13} \mathrm{C}\right\rangle$ & & & & & & & & \\
\hline-0.07 & -0.02 & 0.11 & 0.08 & -0.2 & 0.01 & $C_{\mathrm{W}}$ & & & & & & & \\
\hline 0.01 & 0.08 & 0.20 & 0.16 & -0.25 & 0.02 & 0.74 & $\left\langle H_{\mathrm{U}}\right\rangle$ & & & & & & \\
\hline-0.01 & 0.06 & 0.22 & 0.16 & -0.26 & 0.02 & 0.73 & 0.86 & $H^{*}$ & & & & & \\
\hline-0.13 & -0.3 & -0.15 & 0.20 & 0.05 & 0.53 & 0.13 & 0.13 & 0.18 & {$[\mathrm{Ca}]_{\mathrm{sa}}$} & & & & \\
\hline-0.37 & -0.42 & -0.15 & 0.20 & 0.01 & 0.32 & 0.42 & 0.37 & 0.42 & 0.53 & {$[\mathrm{~K}]_{\mathrm{sa}}$} & & & \\
\hline-0.15 & -0.29 & -0.09 & 0.19 & -0.03 & 0.38 & 0.12 & 0.10 & 0.16 & 0.85 & 0.54 & {$[\mathrm{Mg}]_{\mathrm{sa}}$} & & \\
\hline-0.05 & -0.12 & 0.03 & 0.12 & -0.1 & 0.31 & 0.14 & 0.08 & 0.17 & $\mathbf{0 . 5 0}$ & 0.52 & $\mathbf{0 . 5 3}$ & {$[\mathrm{P}]_{\mathrm{Sa}}$} & \\
\hline 0.15 & 0.22 & -0.07 & -0.07 & 0.28 & -0.2 & -0.05 & -0.16 & -0.15 & -0.53 & -0.41 & -0.56 & -0.38 & $\mathrm{CN}_{\mathrm{s}}$ \\
\hline 0.2 & 0.35 & 0.05 & -0.13 & 0.16 & -0.25 & 0.06 & 0.03 & -0.01 & -0.46 & -0.37 & -0.59 & -0.43 & -0.85 \\
\hline
\end{tabular}

$\log$ relationship of $\left\langle A_{\max }\right\rangle$ with $[\mathrm{K}]_{\mathrm{sa}},[\mathrm{P}]_{\mathrm{sa}},\left\langle\mathrm{N}_{\mathrm{a}}\right\rangle$ and $\left\langle H_{\mathrm{U}}\right\rangle$ was found, details of which are given in Table $2 \mathrm{a}$. Here, along with unstandardised coefficients, standardised values are also given together with the appropriate collinearity statistics, the latter giving $\mathrm{VIF}<10$ (tolerance $>0.1$ ), which suggests that cross-correlations between predictor variables were not an issue in the model fit. From the standardised coefficients we can conclude that the dominant effect is, indeed, the negative $[\mathrm{K}]_{\mathrm{sa}}$ association and the other three positive factors, viz. $[\mathrm{P}]_{\mathrm{sa}},\left\langle\mathrm{N}_{\mathrm{a}}\right\rangle$ and $\left\langle H_{\mathrm{U}}\right\rangle$ all contributing to a lesser degree. The reasons for the complex multivariate association can be seen in Fig. 11, where $\left\langle A_{\max }\right\rangle$ is individually plotted as a function of each of $[\mathrm{K}]_{\mathrm{sa}},[\mathrm{P}]_{\mathrm{sa}},\left\langle\mathrm{N}_{\mathrm{a}}\right\rangle$ and $\left\langle H_{\mathrm{U}}\right\rangle$. Here, for example, although the forest plot OTT-01 is a clear outlier when considered just in terms of $[\mathrm{K}]_{\mathrm{sa}}$, this apparently anomalously high $\left\langle A_{\max }\right\rangle$ can, however, be explained in terms of a very high $\left\langle\mathrm{N}_{\mathrm{a}}\right\rangle$. The lower precipitation forest plot TUC-01 also has a high $\left\langle\mathrm{N}_{\mathrm{a}}\right\rangle$, but in this case $[\mathrm{K}]_{\mathrm{sa}}$ is very high and $\left\langle H_{\mathrm{U}}\right\rangle$ relatively low: these factors then combine (at least according to the model) to give a relatively low $\left\langle A_{\max }\right\rangle$. For the savanna plot LFB-03, the main contributing factor to its high $\left\langle A_{\max }\right\rangle$ is suggested by the model to arise through a very low $[\mathrm{K}]_{\mathrm{sa}}$ combined with a reasonably high $[\mathrm{P}]_{\mathrm{sa}}$.

Given the relatively strong association between soil exchangeable $\mathrm{K}$ and the other base cations (Table 1), it was of interest to see if these could substitute for potassium as a predictor of $\left\langle A_{\max }\right\rangle$ with other potentially important soil properties, such as $\mathrm{pH}$ and soil and clay content, also being tested. This analysis confirmed potassium as the defining soil predictor, with the best alternative predictor, as detected through a substitution of the $[\mathrm{K}]_{\mathrm{sa}}$ term in the model of Table $2 \mathrm{a}$, being the $[\mathrm{Mg}]_{\mathrm{sa}}$ term with an $r^{2}$ of only of 0.15 (cf. 0.71 for $\left.[\mathrm{K}]_{\mathrm{sa}}\right)$. This "best alternative model" had an Akaike's information criterion (AIC) of 117.6 as compared to 98.4 for the equation in Table $2 \mathrm{a}$.

Soil potassium status was also negatively related to species-abundance-weighted photosynthetic nitrogen use efficiency; $\left\langle A_{\mathrm{N}}\right\rangle=\left\langle A_{\max } / N_{\mathrm{a}}\right\rangle$; indeed, following a similar procedure as for $\left\langle A_{\max }\right\rangle$, significant associations at $p<0.05$ were again found for $[\mathrm{K}]_{\mathrm{sa}},[\mathrm{P}]_{\mathrm{sa}}$ and $\left\langle H_{\mathrm{U}}\right\rangle$ with soil exchangeable potassium again the dominant (negatively associated) predictor variable (Table $2 \mathrm{~b}$ ). As for $\left\langle A_{\max }\right\rangle$, alternative soil predictors gave a markedly inferior fit, the "best alternative model" again being with $[\mathrm{Mg}]_{\text {sa }}$ but with an $r^{2}$ only of 0.15 (cf. 0.68 for $[\mathrm{K}]_{\mathrm{sa}}$ ). This model had an AIC of 87.1 as compared to 68.7 for the equation in Table $2 \mathrm{~b}$. In both the above cases, substituting either the soil $[\mathrm{K}]_{\text {sa }}$ variable with its canopy equivalent $\left\langle\mathrm{K}_{\mathrm{a}}\right\rangle$ and/or the soil $[\mathrm{P}]_{\text {sa }}$ variable with its canopy equivalent $\left\langle\mathrm{P}_{\mathrm{a}}\right\rangle$ also gave rise to a markedly inferior fit (data not shown).

This was similar in the case of a fit of species-abundanceweighted photosynthetic phosphorus-use efficiency; $\left\langle A_{\mathrm{P}}\right\rangle=$ $\left\langle A_{\max } / \mathrm{P}_{\mathrm{a}}\right\rangle$, where soil $\mathrm{C}: \mathrm{N}$ was a significantly better predictor than $\left\langle\mathrm{N}_{\mathrm{a}}\right\rangle$ with $[\mathrm{K}]_{\mathrm{sa}}$ and $\left\langle H_{\mathrm{U}}\right\rangle$ again included in the best-fit model (Table 2c). Here again, other soil properties could not be substituted for $[\mathrm{K}]_{\mathrm{sa}}$ with the best alternative predictor being $[\mathrm{Ca}]_{\mathrm{sa}}$ giving an AIC of 226.7 as compared to 222.8 for the equation in Table $2 \mathrm{c}$.

Soil exchangeable potassium also showed a relatively high Kendall's $\tau$ when considered as a univariate predictor of $\left\langle\delta^{13} \mathrm{C}\right\rangle$ (Table 1 ); indeed, a model consisting of $[\mathrm{K}]_{\mathrm{sa}}$ and $\left\langle H_{\mathrm{U}}\right\rangle$ provided a statistically reasonable model fit, with an increase in $[\mathrm{K}]_{\mathrm{sa}}$ or a decrease in $\left\langle H_{\mathrm{U}}\right\rangle$ predicted to cause higher (less negative) $\left\langle\delta^{13} \mathrm{C}\right\rangle$. It is also of note, however, that in this case soil calcium (ground-area basis) turns out to be a better predictor of $\left\langle\delta^{13} \mathrm{C}\right\rangle$ when taken in conjunction with 
Table 2. Multivariate regression statistics relating estimates of community-weighted canopy-level average maximum $\mathrm{CO}_{2}$ assimilation rates, nitrogen use efficiency, phosphorus-use efficiency and foliar ${ }^{13} \mathrm{C} /{ }^{12} \mathrm{C}$ to canopy and soil variables. Abbreviations: [K] $]_{\mathrm{sa}}-$ soil potassium $\left(\mathrm{mmol} \mathrm{m}^{-2}\right),[\mathrm{P}]_{\mathrm{sa}}\left(\mu \mathrm{molm} \mathrm{m}^{-2}\right),\left\langle\mathrm{N}_{\mathrm{a}}\right\rangle$ - species-abundance-weighted area-based leaf nitrogen $\left(\mathrm{g} \mathrm{m}^{-2}\right),\left\langle H_{\mathrm{U}}\right\rangle-$ average canopy height $($ trees $>$ $0.1 \mathrm{~m}$ diameter at beast height, in $\mathrm{m}), \mathrm{CN}_{\mathrm{S}}$ - soil $\mathrm{CN}$ ratio $\left(\mathrm{g} \mathrm{g}^{-1}\right)$ and $\mathrm{VIF}$ - variance inflation factor. In all cases predictor variates have been centred with the unstandardised intercept giving then the predicted value when all predictor variables are at their mean values. In the standardised case, all variables have been centred and scaled by their SD.

\begin{tabular}{|c|c|c|c|c|c|c|c|c|c|}
\hline \multicolumn{10}{|c|}{ Coefficients } \\
\hline & \multicolumn{2}{|c|}{ Unstandardised coefficients } & \multicolumn{3}{|c|}{ Standardised } & \multicolumn{2}{|c|}{0.95 confidence interval for $b$} & \multicolumn{2}{|c|}{ Collinearity statistics } \\
\hline & $b$ & SE & $\beta$ & $t$ & $p$ & Lower & Upper & Tolerance & VIF \\
\hline \multicolumn{10}{|c|}{ a. Light $/ \mathrm{CO}_{2}$ saturated assimilation rate $\left(\mu \mathrm{molCO} \mathrm{m}^{-2} \mathrm{~s}^{-1}\right): r^{2}=0.71, p=0.0004$} \\
\hline Intercept & 28.73 & 0.74 & - & 38.74 & 0.000 & 27.07 & 30.53 & - & - \\
\hline $\log _{\mathrm{e}}[\mathrm{K}]_{\mathrm{sa}}$ & -6.98 & 1.19 & -1.212 & -5.86 & 0.000 & -11.04 & -4.75 & 0.387 & 2.59 \\
\hline $\log _{\mathrm{e}}[\mathrm{P}]_{\mathrm{sa}}$ & 3.80 & 0.83 & 0.630 & 3.67 & 0.003 & 0.75 & 6.00 & 0.575 & 1.73 \\
\hline $\log _{\mathrm{e}}\left\langle\mathrm{N}_{\mathrm{a}}\right\rangle$ & 3.62 & 1.98 & 0.660 & 4.58 & 0.001 & 0.87 & 5.21 & 0.875 & 1.14 \\
\hline $\log _{\mathrm{e}}\left\langle H_{\mathrm{U}}\right\rangle$ & 2.44 & 0.98 & 0.425 & 2.50 & 0.027 & 1.39 & 5.45 & 0.604 & 1.65 \\
\hline \multicolumn{10}{|c|}{ b. Photosynthetic nitrogen use efficiency $\left(\mu \mathrm{molCO} 2 \mathrm{~g}^{-1} \mathrm{Ns}^{-1}\right): r^{2}=0.68, p=0.0003$} \\
\hline Intercept & 12.81 & 0.33 & - & 38.72 & 0.000 & 11.86 & 13.28 & - & - \\
\hline $\log _{\mathrm{e}}[\mathrm{K}]_{\mathrm{sa}}$ & -3.16 & 0.52 & -1.393 & -6.12 & 0.000 & -4.88 & -2.41 & 0.411 & 2.43 \\
\hline $\log _{\mathrm{e}}[\mathrm{P}]_{\mathrm{sa}}$ & 1.59 & 0.44 & 0.630 & 3.67 & 0.003 & 0.574 & 2.72 & 0.585 & 1.71 \\
\hline $\log _{\mathrm{e}}\left\langle H_{\mathrm{U}}\right\rangle$ & 1.04 & 0.44 & 0.463 & 2.40 & 0.031 & 0.326 & 2.10 & 0.607 & 1.65 \\
\hline \multicolumn{10}{|c|}{ c. Photosynthetic phosphorus-use efficiency $\left(\mu \mathrm{molCO} \mathrm{Cg}^{-1} \mathrm{Ps}^{-1}\right): r^{2}=0.30, p=0.0469$} \\
\hline Intercept & 312.4 & 23.90 & - & 13.07 & 0.000 & 258.3 & 354.1 & - & - \\
\hline $\log _{\mathrm{e}}[\mathrm{K}]_{\mathrm{sa}}$ & -91.59 & 33.61 & -0.857 & -2.73 & 0.016 & -173.0 & -31.8 & 0.507 & 1.97 \\
\hline $\log _{\mathrm{e}}\left(\mathrm{CN}_{\mathrm{s}}\right)$ & -58.78 & 27.53 & -0.542 & -2.13 & 0.051 & -126.1 & -3.48 & 0.754 & 1.33 \\
\hline $\log _{\mathrm{e}}\left\langle H_{\mathrm{U}}\right\rangle$ & 71.34 & 31.50 & 0.586 & 2.27 & 0.040 & 11.6 & 129.3 & 0.610 & 1.64 \\
\hline \multicolumn{10}{|c|}{ d. Foliar ${ }^{13} \mathrm{C} /{ }^{12} \mathrm{C}(\% o): r^{2}=0.26, p=0.040$} \\
\hline Intercept & -29.37 & 0.170 & - & -180 & 0.000 & -29.61 & -28.93 & - & - \\
\hline $\log _{\mathrm{e}}[\mathrm{K}]_{\mathrm{sa}}$ & 0.592 & 0.219 & 0.787 & 3.63 & 0.016 & 0.301 & 1.143 & 0.609 & 1.64 \\
\hline $\log _{\mathrm{e}}\left\langle H_{\mathrm{U}}\right\rangle$ & -0.526 & 0.225 & -0.604 & -2.88 & 0.034 & -0.974 & -0.133 & 0.609 & 1.64 \\
\hline
\end{tabular}

$\left\langle H_{\mathrm{U}}\right\rangle\left(r^{2}=0.383\right)$ giving an AIC of 40.7 as compared to 44.1 for the equation in Table 2c.

Especially as $P_{\mathrm{A}}$, on its own showed a reasonably strong correlation with $[\mathrm{K}]_{\mathrm{sa}}$ (Table 1); mean annual precipitation was also tested as a predictor variable for $\left\langle A_{\max }\right\rangle,\left\langle A_{\mathrm{N}}\right\rangle,\left\langle A_{\mathrm{P}}\right\rangle$ and $\left\langle\delta^{13} \mathrm{C}\right\rangle$. But in no case, either on its own or in conjunction with the other predictor variables in Table 2, did it give rise to an $r^{2}$ even closely approximating $[\mathrm{K}]_{\mathrm{sa}}$ (data not shown).

\subsection{Predicting canopy structural properties}

In addition to an important role as a modulator of leaf-level photosynthetic properties, Table 1 also suggests a strong association between $[\mathrm{K}]_{\mathrm{sa}}$ and $C_{\mathrm{W}}$ and both canopy height measures. With $C_{\mathrm{W}}$ relating directly to both leaf area index and fractional canopy cover (Veenendaal et al., 2015) and both providing commonly used measures of woody plant plenteousness in tropical ecosystems (Lloyd et al., 2008; Hirota et al., 2011; Staver et al., 2011; Murphy and Bowman, 2012; Torello-Raventos et al., 2013; Veenendaal et al., 2015), we therefore first applied a simple OLS log-log model re- lating $C_{\mathrm{W}}$ to $[\mathrm{K}]_{\mathrm{sa}}$. And indeed, even when simply considered on its own, this area-based soil potassium measure accounted for 0.31 of the total $C_{\mathrm{W}}$ data set variation (Model 1: Table 3a). Although this was substantially more than when precipitation was considered on its own $\left(r^{2}=0.00\right)$, when $P_{\mathrm{A}}$ was considered along with $\log [\mathrm{K}]_{\mathrm{sa}}$ as a predictor of $\log \left(C_{\mathrm{W}}\right)$, a substantial improvement in the model fit was achieved (Model 2: Table 4b; $r^{2}=0.57 ; \Delta \mathrm{AIC}=-8.6$ ). Further, although the simple addition of plant available soil water storage capacity $\left(\theta_{\mathrm{P}}\right.$; see Table $\left.\mathrm{S} 1\right)$ did not improve the model fit (Model 3: Table 3c), addition of a $P_{\mathrm{A}} \times \theta_{\mathrm{P}}$ interaction term gave rise to a substantial model improvement (Model 4: Table 3d; $r^{2}=0.68 ; \Delta \mathrm{AIC}=-5.3$ ). However, in this model, the $P_{\mathrm{A}}$ term is significant at only $p=0.553$ and with very high VIF (low tolerances) for the $\theta_{\mathrm{P}}$ and $P_{\mathrm{A}} \times \theta_{\mathrm{P}}$ terms as well. Removal of the $P_{\mathrm{A}}$ term from Model 4, but with all other variables retained (including the interaction), resulted in a model that was just as good, if not even better (Model 5: Table 3e; $r^{2}=0.71 ; \Delta$ AIC $=-1.9$ ). 
Table 3. Multivariate regression statistics relating canopy area index $\left(C_{\mathrm{W}}\right)$, mean upper stratum canopy height $\left\langle H_{\mathrm{U}}\right\rangle$, and above-ground biomass $\left(B_{\mathrm{U}}\right)$ to soil and climatic variables. From (a) to (d) occur increasingly complex models for the prediction of $C_{\mathrm{W}}$; (e) represents an application of model (d) to $\left\langle H_{\mathrm{U}}\right\rangle$ and (f) is model (d) but applied to $B_{\mathrm{U}}$. Other abbreviations: $[\mathrm{K}]_{\mathrm{sa}}-$ soil potassium $\left(\mathrm{mmolm}^{-2}\right), P_{\mathrm{A}}$ mean annual precipitation $(\mathrm{m})$, VIF - variance inflation factor. In all cases predictor variates have been centred with the unstandardised intercept giving then the predicted value when all predictor variables are at their mean values. In the standardised case, all variables have been centred and scaled by their SD.

\begin{tabular}{|c|c|c|c|c|c|c|c|c|c|}
\hline \multicolumn{10}{|c|}{ Coefficients } \\
\hline & \multicolumn{2}{|c|}{ Unstandardised coefficients } & \multicolumn{3}{|c|}{ Standardised } & \multicolumn{2}{|c|}{0.95 confidence interval for $b$} & \multicolumn{2}{|c|}{ Collinearity statistics } \\
\hline & $b$ & SE & $\beta$ & $t$ & $p$ & Lower & Upper & Tolerance & VIF \\
\hline \multicolumn{10}{|c|}{ (a) $\log _{\mathrm{e}}$ [Crown area index] (Model 1): $r^{2}=0.31, p=0.010$, AIC $=42.43$} \\
\hline Intercept & 1.42 & 0.457 & - & 3.12 & 0.007 & 0.456 & 2.40 & - & - \\
\hline $\log _{\mathrm{e}}[\mathrm{K}]_{\mathrm{sa}}$ & 0.748 & 0.258 & 0.573 & 2.91 & 0.010 & 0.204 & 1.30 & - & - \\
\hline \multicolumn{10}{|c|}{ (b) $\log _{\mathrm{e}}$ [Crown area index] (Model 2): $r^{2}=0.57, p=0.000, \mathrm{AIC}=34.70$} \\
\hline Intercept & -0.55 & 0.701 & - & 1.70 & 0.794 & -2.04 & 0.945 & - & - \\
\hline $\log _{\mathrm{e}}[\mathrm{K}]_{\mathrm{sa}}$ & 1.14 & 0.236 & 0.874 & 5.15 & 0.000 & 0.640 & 1.645 & 0.740 & 1.35 \\
\hline$P_{\mathrm{A}}$ & 1.78 & 0.542 & 0.633 & 3.47 & 0.001 & 0.623 & 2.93 & 0.740 & 1.35 \\
\hline \multicolumn{10}{|c|}{ (c) $\log _{\mathrm{e}}[$ Crown area index $]\left(\right.$ Model 3): $r^{2}=0.58, p=0.001$, AIC $=35.19$} \\
\hline Intercept & -0.926 & 0.774 & - & -1.17 & 0.111 & -2.58 & 0.733 & - & - \\
\hline $\log _{\mathrm{e}}[\mathrm{K}]_{\mathrm{sa}}$ & 1.121 & 0.235 & 1.022 & 4.77 & 0.000 & 0.618 & 1.624 & 0.735 & 1.36 \\
\hline$P_{\mathrm{A}}$ & 1.775 & 0.539 & 0.686 & 3.30 & 0.005 & 0.620 & 2.930 & 0.740 & 1.35 \\
\hline$\theta \mathrm{P}$ & 0.827 & 0.743 & 0.140 & 1.13 & 0.285 & -0.767 & 2.421 & 0.991 & 1.00 \\
\hline \multicolumn{10}{|c|}{ (d) $\log _{\mathrm{e}}\left[\right.$ Crown area index] $\left(\right.$ Model 4): $r^{2}=0.72, p=0.000$ AIC $=28.27$} \\
\hline Intercept & 1.821 & 1.140 & - & 0.67 & 0.498 & -0.643 & 4.289 & - & - \\
\hline $\log _{\mathrm{e}}[\mathrm{K}]_{\mathrm{sa}}$ & 0.949 & 0.199 & 0.726 & 4.76 & 0.000 & 0.518 & 1.380 & 0.670 & 1.49 \\
\hline$P_{\mathrm{A}}$ & -0.372 & 0.863 & 0.931 & 4.99 & 0.886 & -2.234 & 1.492 & 0.189 & 5.27 \\
\hline$\theta_{\mathrm{P}}$ & -9.274 & -2.610 & 0.281 & 2.16 & 0.050 & -16.95 & $-1 / 598$ & 0.028 & 35.10 \\
\hline$\theta \mathrm{P} \times P_{\mathrm{A}}$ & 7.090 & 2.458 & 0.445 & 2.89 & 0.012 & 1.780 & 12.400 & 0.026 & 37.85 \\
\hline \multicolumn{10}{|c|}{ (e) $\log _{\mathrm{e}}\left[\right.$ Crown area index] $\left(\right.$ Model 5): $r^{2}=0.74, p=0.000 \mathrm{AIC}=26.52$} \\
\hline Intercept & 1.362 & 0.395 & - & 2.05 & 0.030 & 0.515 & 2.21 & - & - \\
\hline $\log _{\mathrm{e}}[\mathrm{K}]_{\mathrm{sa}}$ & 0.992 & 0.167 & 0.643 & 5.94 & 0.000 & 0.634 & 1.35 & 0.896 & 1.11 \\
\hline$\theta_{\mathrm{P}}$ & -7.975 & 1.819 & -1.404 & -4.39 & 0.001 & -11.88 & -4.07 & 0.102 & 9.77 \\
\hline$\theta_{\mathrm{P}} \times P_{\mathrm{A}}$ & 6.177 & 0.326 & 1.673 & 5.12 & 0.000 & 3.59 & 8.77 & 0.103 & 9.68 \\
\hline \multicolumn{10}{|c|}{ (f) $\log _{\mathrm{e}}$ [Mean canopy height]: $r^{2}=0.41, p=0.016$} \\
\hline Intercept & 2.926 & 0.329 & - & 8.90 & 0.000 & 2.221 & 3.631 & - & - \\
\hline $\log _{\mathrm{e}}[\mathrm{K}]_{\mathrm{sa}}$ & 0.503 & 0.139 & 0.766 & 3.62 & 0.003 & 0.205 & 0.802 & 0.897 & 1.12 \\
\hline$\theta_{\mathrm{P}}$ & -2.113 & 1.514 & 1.286 & -1.39 & 0.184 & -5.361 & 1.134 & 0.102 & 9.77 \\
\hline$\theta_{\mathrm{P}} \times P_{\mathrm{A}}$ & 1.702 & 1.004 & -1.102 & 1.70 & 0.112 & -0.451 & 3.857 & 0.103 & 9.69 \\
\hline \multicolumn{10}{|c|}{ (g) $\log _{\mathrm{e}}$ [Woody biomass]: $r^{2}=0.47, p=0.007$} \\
\hline Intercept & 5.614 & 0.725 & - & 7.75 & 0.000 & 4.06 & 7.168 & - & - \\
\hline $\log _{\mathrm{e}}[\mathrm{K}]_{\mathrm{sa}}$ & 1.238 & 0.307 & 0.637 & 4.03 & 0.001 & 0.581 & 1.896 & 0.897 & 1.11 \\
\hline$\theta_{\mathrm{P}}$ & -3.228 & 3.339 & -0.528 & -0.96 & 0.350 & -10.38 & 3.933 & 0.102 & 9.77 \\
\hline$\theta_{\mathrm{P}} \times P_{\mathrm{A}}$ & 3.004 & 2.214 & 0.695 & 1.35 & 0.197 & -1.745 & 7.753 & 0.103 & 9.68 \\
\hline
\end{tabular}

Overall, predictions of $C_{\mathrm{W}}$ according to Model 5 were of acceptable fidelity (Fig. 12a) with the wide range of savanna $C_{\mathrm{W}}$ well predicted, in particular by this simple mixture of soil chemical and hydrological properties. Some differentiation of the forest plots would also seem to have been achieved by the model. Nevertheless, there was a tendency for the model to under-predict forest $C_{\mathrm{W}}$ and vice versa for savanna plots.

To illustrate how Model 5 works, the input data are presented in the ordinal space of the interacting $P_{\mathrm{A}}$ and $\theta_{\mathrm{P}}$ terms in Fig. 12b. Here the colour of the symbols relate to $C_{\mathrm{W}}$ and 

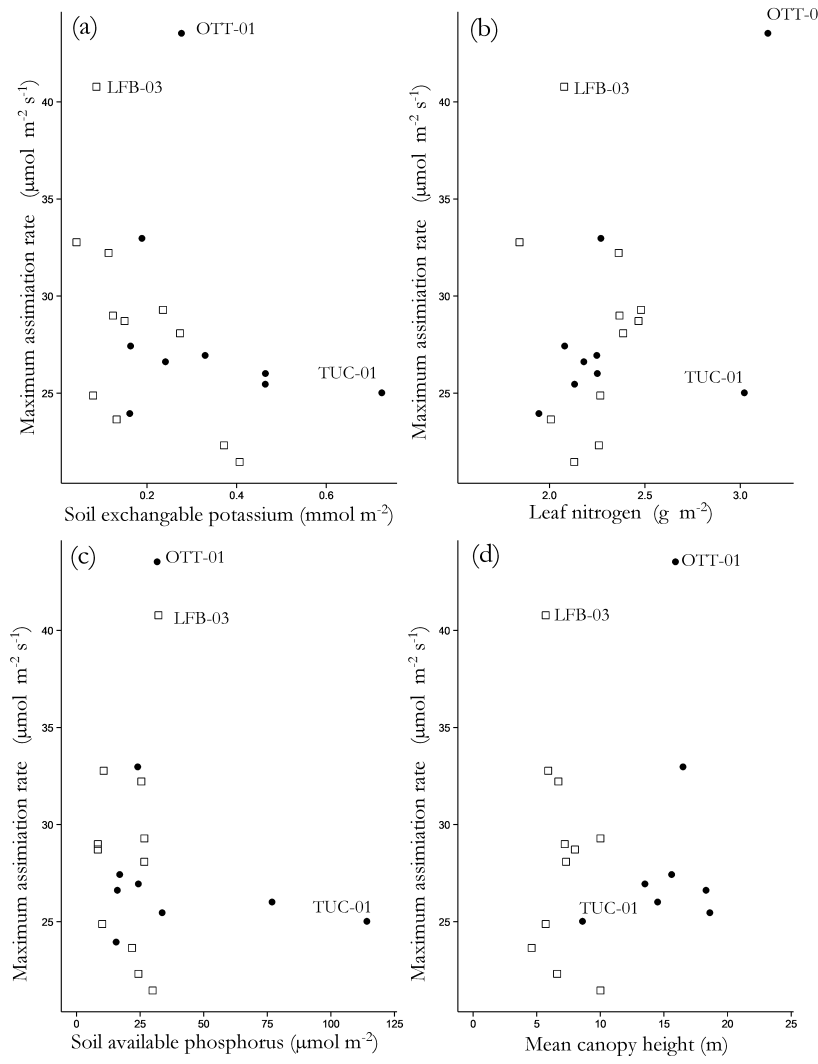

Figure 11. Relationships of community-abundance-weighted mean maximum $\mathrm{CO}_{2}$ assimilation rates to (a) soil exchangeable potassium, community-abundance-weighted foliar nitrogen concentrations (area basis), (c) soil available phosphorus and (d) mean canopy height. Selected plots (specifically mentioned in the text) are also shown. (•) Forest plots; $(\square)$ savanna plots.

the symbol size relates to $[\mathrm{K}]_{\mathrm{sa}}$. From Fig. $12 \mathrm{~b}$ it can be seen that in any one region of the plot that the smaller symbols (lower $[\mathrm{K}]_{\mathrm{sa}}$ ) tend to be of a redder hue (lower $C_{\mathrm{W}}$ ), and consideration of similarly sized symbols shows a tendency for increased greenness (higher $C_{\mathrm{W}}$ ) as one moves along the main diagonal. Reddish symbols (of low $C_{\mathrm{W}}$ ) are typically smaller (of lesser $[\mathrm{K}]_{\mathrm{sa}}$ ) at higher $P_{\mathrm{A}}$, although the pattern of variation with $\theta_{\mathrm{P}}$ is less systematic.

As an illustration, model predictions of canopy area index $\left(\hat{C}_{\mathrm{W}}\right)$ variations as a function of $[\mathrm{K}]_{\mathrm{sa}}$ are shown in Fig. $12 \mathrm{c}$ for $P_{\mathrm{A}}=1.0 \mathrm{ma}^{-1}$ and $P_{\mathrm{A}}=1.5 \mathrm{ma}^{-1}\left(\theta_{\mathrm{P}}=0.5 \mathrm{~m}\right)$. This shows the model to be especially responsive to $[\mathrm{K}]_{\mathrm{sa}}$ below about $0.2 \mathrm{~mol} \mathrm{~m}^{-2}$ with a greater sensitivity of $\hat{C}_{\mathrm{W}}$ to $[\mathrm{K}]_{\mathrm{sa}}$ at higher $P_{\mathrm{A}}$. Thus, in relative terms, $\hat{C}_{\mathrm{W}}$ is modelled to become most sensitive to $P_{\mathrm{A}}$ at low $[\mathrm{K}]_{\mathrm{sa}}$.

Figure $12 \mathrm{~d}-\mathrm{f}$ show how the $P_{\mathrm{A}} \times \theta_{\mathrm{P}}$ interaction affects $\hat{C}_{\mathrm{W}}$ at three different $[\mathrm{K}]_{\mathrm{sa}}$. Here (where white areas are for $\hat{C}_{\mathrm{W}}<0$ and for which we therefore assume in practice $C_{\mathrm{W}}=0$ ) we see first for Fig. $12 \mathrm{~d}$ that at a very low $[\mathrm{K}]_{\mathrm{sa}}$ of $0.1 \mathrm{~mol} \mathrm{~m}^{-2}$ the model suggests that any sort of woody leaf area is simply not possible for $P_{\mathrm{A}}<1.5 \mathrm{~m} \mathrm{a}^{-1}$, and even then only when $\theta_{\mathrm{P}}$ is relatively high. As $P_{\mathrm{A}}$ increases, the $\theta_{\mathrm{P}}$ for which $\hat{C}_{\mathrm{W}} \geqslant 0$ increases, with a $\hat{C}_{\mathrm{W}}$ of around $2 \mathrm{~m}^{2} \mathrm{~m}^{-2}$ at the highest $P_{\mathrm{A}}-\theta_{\mathrm{P}}$ combination examined considered possible.

At double potassium availability with $[\mathrm{K}]_{\mathrm{sa}}=$ $0.2 \mathrm{~mol} \mathrm{~m}^{-2}$, the response observed is very different (Fig. 12e). Here, by comparison with Fig. 12d, we can again see the generally higher $\hat{C}_{\mathrm{W}}$ anticipated for the higher $P_{\mathrm{A}}-\theta_{\mathrm{P}}$ combinations. But at around $P_{\mathrm{A}} \simeq 1.3 \mathrm{ma}^{-1}$, the area delineated by the $\hat{C}_{\mathrm{W}}=0$ shifts from a concave to a convex form; i.e. the model then predicts that for $P_{\mathrm{A}} \lesssim 1.3 \mathrm{~m} \mathrm{a}^{-1}$, rather than an increase $C_{\mathrm{W}}$ should decline with increasing $\theta_{\mathrm{P}}$.

At an even higher $[\mathrm{K}]_{\mathrm{sa}}$ of $0.4 \mathrm{molm}^{-2}$ the general concave-convex pattern is maintained (Fig. 12f) with higher $\hat{C}_{\mathrm{W}}$ at all $P_{\mathrm{A}}-\theta_{\mathrm{P}}$ combinations. The domain for which $\hat{C}_{\mathrm{W}} \geqslant 0$ is also shifted compared to Fig. 12e with additional combinations of lower $P_{\mathrm{A}} /$ higher $\theta_{\mathrm{P}}$ also deemed possible. At the lowest simulated $P_{\mathrm{A}}$ of $0.8 \mathrm{ma}^{-1}, \hat{C}_{\mathrm{W}} \geqslant 0$ is now modelled as possible for all $\theta_{\mathrm{P}}$ less than about $0.5 \mathrm{~m}$.

Application of Model 5 to other structural variables also gave rise to a reasonable fit. For example, as shown in Table $3 \mathrm{f}$, a reasonable fit of $r^{2}=0.41$ was found when $\left\langle H_{\mathrm{U}}\right\rangle$ was substituted as the dependent variable. Above-ground biomass $\left(B_{\mathrm{U}}\right)$ was also reasonably well predicted by the model (Table 5g: $r^{2}=0.47$ ), in both cases with a role for potassium still evident at $p=0.001$.

When taken in conjunction with $P_{\mathrm{A}}$ and $\theta_{\mathrm{P}},[\mathrm{K}]_{\mathrm{sa}}$ further proved to be a much better predictor for each of the three structural variables examined than any other measured soil property. For example, the next-best alternative to $[\mathrm{K}]_{\mathrm{sa}}$ as a co-predictor for $C_{\mathrm{W}}$ in Model 5 was $[\mathrm{Mg}]_{\mathrm{sa}}$, which gave a $r^{2}=0.65$ and an AIC $=31.9$ as compared to $r^{2}=0.74$ and $\mathrm{AIC}=26.5$ for $[\mathrm{K}]_{\mathrm{sa}}$ (Table 2e). For both $\left\langle H_{\mathrm{U}}\right\rangle$ and $B_{\mathrm{U}}$ it also emerged that $[\mathrm{Mg}]_{\mathrm{sa}}$ was the next-best substitute for $[\mathrm{K}]_{\mathrm{sa}}$, but in both cases with the differences between the two cations in their statistical efficacy much less marked with $\Delta \mathrm{AIC}=-0.4$ for $\left\langle H_{\mathrm{U}}\right\rangle$ and -1.9 for $B_{\mathrm{U}}$.

\subsection{Soil water simulations}

Given the results of Sect. 3.5, where the statistical modelling of $C_{\mathrm{W}},\left\langle H_{\mathrm{U}}\right\rangle$ and $B_{\mathrm{U}}$ in terms of climate and soil factors suggested a significant interaction between mean annual precipitation and soil water storage (Fig. 12), we conducted numerical simulations of soil water balances investigating the specific proposition that a low $\theta_{\mathrm{P}}$ arising through the existence of some sort of impermeable layer close to the soil surface could actually have a positive effect on ecosystem annual water balances at low $P_{\mathrm{A}}$ : this occurring as a consequence of reductions in vertical water flow to depths below the rooting zone (Appendix B). Indeed, as is detailed is Sect. B3, it turns out that, due to reductions in drainage not necessarily being offset by high runoff rates, restricted root zones need not always be considered as having a detrimental effect on 

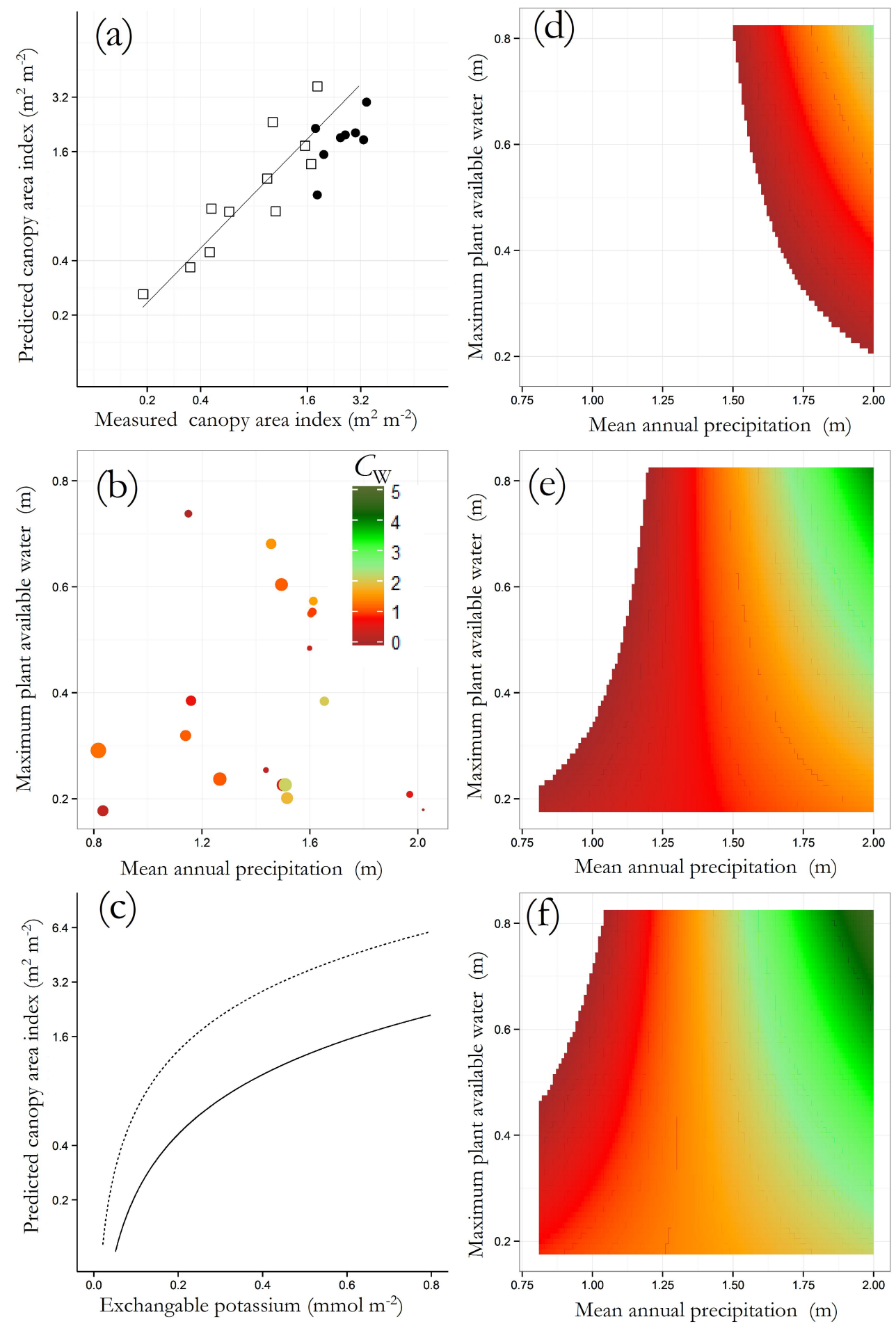

Figure 12. Modelling of canopy area index $\left(C_{\mathrm{W}}\right)$ in relation to mean precipitation $\left(P_{\mathrm{A}}\right)$, maximum plant available soil water storage $\left(\theta_{\mathrm{p}}\right)$ and area-based soil potassium $[\mathrm{K}]_{\mathrm{sa}}$. (a) Modelled versus observed $C_{\mathrm{W}}$ as predicted by Model 4 of Table 3 with a $1: 1$ line also shown; (b) location of sample plots in terms of $P_{\mathrm{A}}$ and $\theta_{\mathrm{p}}$. Here symbol size is in proportion to $[\mathrm{K}]_{\mathrm{sa}}$ with the colouring in accordance with the $C_{\mathrm{W}}$ colour scale shown; (c) model predictions of the relationship between $C_{\mathrm{W}}$ and $[\mathrm{K}]_{\mathrm{sa}}$ for $P_{\mathrm{A}}=1.0 \mathrm{ma}^{-1}$ (solid line) and $P_{\mathrm{A}}=1.5 \mathrm{ma}{ }^{-1}$ (dashed line). In both cases $\theta_{\mathrm{p}}$ has been held constant at $0.5 \mathrm{~m}$; Model predictions of $C_{\mathrm{W}}$ in relation to $P_{\mathrm{A}}$ and $\theta_{\mathrm{p}}$ for $(\mathbf{d})[\mathrm{K}]_{\mathrm{sa}}=0.1 \mathrm{mmol} \mathrm{m}{ }^{-2},(\mathbf{e})$ $0.2 \mathrm{mmol} \mathrm{m}^{-2}$ and (f) $[\mathrm{K}]_{\mathrm{sa}}=0.4 \mathrm{mmol} \mathrm{m}^{-2}$. 
plant water relations; in fact, in many cases potentially the opposite occurs and this is more likely to be the case where $P_{\mathrm{A}}$ is low.

\section{Discussion}

Utilising the relatively novel situation found in South America where two distinct tropical vegetation formation types $(\mathbb{V})$ occur in close proximity across a wide precipitation range, we have demonstrated here systematic differences between forest $(\mathbb{F})$ and savanna $(\mathbb{S})$ in terms of soil, vegetation structure and some of the sampled physiologically relevant foliar characteristics. Further, we have shown that the large contrasts in structure between forest and savanna (Figs. 2 and 4) can be explained with a simple statistical model based on "effective plant available soil water" $\theta_{\mathrm{P}}$ and upper layer exchangeable potassium concentrations $[\mathrm{K}]_{\mathrm{sa}}$ (Table 3 ).

In terms of our relatively unusual situation of forestsavanna contrasts existing over such a wide precipitation range, the underlying reasons seem well understood in terms of underlying geomorphology and past landscape evolution (Cole, 1960, 1986). In short (as well as a gross simplification) outside the Amazon forest region proper, forests tend to be found on slopes and escarpments with reasonably young and hence fertile (but often shallow) soils, with cerrado-type savannas on plateaus and other planation surfaces characterised by deep and usually heavily weathered soils. These differences in soil parent material, landscape position and/or soil age (degree of weathering) then lead to differences in soil properties (Fig. 3, Table S1), which - as has already been noted by others (Cochrane, 1989; Silva et al., 2006; Cochrane and Cochrane, 2010) - are intimately associated with the different vegetation types found across the landscape mosaic.

At larger scales than in this study, an important role for soil cations as a modulator of tropical vegetation structure and function has already been implied, for example from the canonical correspondence analysis (CCA) of vegetation distributions across the Amazon Basin, where - in addition to $P_{\mathrm{A}}-$ effective soil cation exchange capacity (ECEC), and sub-soil texture were found to be important determinants of vegetation type with vegetation formations characterised by a higher $C_{\mathrm{W}}$ tending to be found at higher ECEC (Lloyd et al., 2009). Similarly, taking interpolated estimates of total exchangeable bases $\left(\Sigma_{\mathrm{B}}=[\mathrm{Ca}]_{\mathrm{ex}}+[\mathrm{Mg}]_{\mathrm{ex}}+\right.$ $[\mathrm{K}]_{\mathrm{ex}}+[\mathrm{Na}]_{\mathrm{ex}}$ ) as a measure of "soil fertility", Lehmann et al. (2011) found a significant positive effect of inclusion of $\Sigma_{\mathrm{B}}$ into a precipitation-based model of global savanna distribution. Using a crude water balance metric $(W)$, Veenendaal et al. (2015) found that both intra- and inter-continental differences in transition zone $W$ were related to differences in $[\mathrm{Ca}]_{\mathrm{ex}}+[\mathrm{Mg}]_{\mathrm{ex}}+[\mathrm{K}]_{\mathrm{ex}}$ (drier transition zones typically having higher cation status) with that study (of which the soil and vegetation data here form a subset) also finding significant cation-soil moisture interactions.
It would thus seem that the identification of factors underlying the clear effects of soil on tropical vegetation structure, as evident using our precipitation transect extending across savanna-forest transition zones as in the current study, may be of a general and wide relevance. Nevertheless, we do emphasise that some trends, such as increases in soil cation status with declining rainfall, are much more likely to be due to changes in soil parent material than to climate. Thus, although it may be reasonable to infer that the only reason we were able to find forest at the lowest $P_{\mathrm{A}}$ was that there were soils there of a very high cation status; it is by no means a corollary that soil and/or plant cation status should always tend to increase with declining $P_{\mathrm{A}}$, or even that there might be a general trend in that direction (regionally, globally or otherwise).

\subsection{Mass-related trait variations in relation to species, soils and climate}

In terms of stand-level forest-savanna trait comparisons, data interpretation is facilitated by there being almost no species overlap between the two vegetation types anywhere along the precipitation gradient (Torello-Raventos et al., 2013) - hence our ability to refer to "forest" and "savanna" species. Within each vegetation type there is, however, significant species sharing between plots. But interestingly, although forest plot species composition systematically changes in accordance with changes in precipitation regime (Torello-Raventos et al., 2013), when examined at the community level changes in mean trait values as precipitation declined were, with the exception of the cations and $\delta^{13} \mathrm{C}$, surprisingly small (Figs. 6, 7 and 10). This is especially the case when compared to the dramatic changes in forest stand-level canopy cover, tree height and biomass characteristics (Figs. 2 and 4). This is even all the more surprising in so much as there was also a clear change in leaf deciduousness along the transect, with almost all the forest species deciduous at the lowest $P_{\mathrm{A}}$ TUC01 and mostly evergreen at the highest $P_{\mathrm{A}}$ TAP-123 and TAP-04 sites (Table S2). Moreover, as is evident from the relatively modest "environmental component" in the variance partitioning of Fig. 3 and the error bars of Figs. 6, 7 and 10, within-plot variability - a reasonable portion of which could be attributed to species identity (Fig. 3) - accounted for much more of the variation in trait characteristics than soil or climate. This then suggests that, at least within the one vegetation type, species differences in leaf-level traits, such as $M_{\mathrm{a}}$, $\mathrm{N}_{\mathrm{m}}$ and $\mathrm{P}_{\mathrm{m}}$, are more or less irrelevant in terms of any habitat filtering that might be occurring.

Some changes in savanna species composition along the transect also occurred, though with this being to a lesser extent than for the forest species (Torello-Raventos et al., 2013), with the changes in community level trait values generally more muted for $\mathbb{S}$ than was the case for $\mathbb{F}$. For example, there was no appreciable effect of precipitation on community-averaged savanna $M_{\mathrm{a}}$ (Fig. 6a) as was also ob- 
served by Schrodt et al. (2014) in West Africa, which is contrary to the generally accepted dogma that $M_{\mathrm{a}}$ should increase with declining rainfall (Poorter et al., 2009). We suggest a similar explanation for this lack of a precipitation response as detailed by Schrodt et al. (2014); that is to say, this lack of precipitation response of $M_{\mathrm{a}}$ to annual rainfall amount may be due to our study being located in the strongly seasonal tropics where there is a tendency towards an increased rainfall seasonality (shorter growing season) as precipitation declines.

An overall higher $M_{\mathrm{a}}$ (Fig. 6a) and lower $\mathrm{N}_{\mathrm{m}}$ (Fig. 6b) of savanna trees was also noted by Schrodt et al. (2014), and has been observed similarly in tropical Australia by Bloomfield et al. (2014) and in the phylogenetically controlled Brazilian cerrado vs. gallery forest comparison of Hoffmann et al. (2005). This suggests a consistent difference and, as is discussed in the next section, a tendency for leaf nitrogen concentrations to increase with decreasing rainfall also seems to be a consistent pattern, and is probably related to reductions in canopy leaf areas as $P_{\mathrm{A}}$ declines. Also involved might be lesser $\mathrm{N}$ lixiviation and denitrification at lower rainfall (Robertson, 1989).

Differences between $\mathbb{F}$ and $\mathbb{S}$ in mass-based phosphorus concentrations are less consistent across studies with Schrodt et al. (2014) finding no difference in West Africa (as was the case here - Fig. 6d), but with Bloomfield et al. (2014) finding lower values in their Australian savanna species. Nevertheless for all studies, at least within ZOT, any difference between vegetation types disappears when $\mathrm{P}$ is considered on a leaf area basis (Sect. 4.2).

It was, in any case, the cations for which the most dramatic changes with $P_{\mathrm{A}}$ we observed and for which the differences between $\mathbb{F}$ and $\mathbb{S}$ were the greatest. Again these trends and differences are similar as was found for West Africa, but with the case of higher savanna $K_{m}$ at low rainfall in that study not being associated with increases in soil cation availability as was the case here (Fig. 3a). As discussed by Schrodt et al. (2014), given its prime role as an osmotically active cation (Leigh and Wyn Jones, 1984), it seems reasonable to assume that leaves of trees exposed to a lower $P_{\mathrm{A}}$ regime should have a higher potassium content than their higher rainfall counterparts due to the more negative osmotic potentials required to survive more extended rain-free periods (also likely to be times of higher than average evaporative demand) during the dry season. Such a notion is consistent with results from a recent literature survey where it was found that the leaves of "tropical-dry" woody species tend to have more negative osmotic potentials than their "tropical-wet" counterparts (Bartlett et al., 2012).

The West African study of Schrodt et al. (2014) similarly found lower $\mathrm{K}_{\mathrm{m}}$ for savanna as compared to forest plots, which - although also related to a lower potassium availability in the savanna soils within ZOT - was further attributable to a different species composition. This is also the case in this study because re-running Eq. (2) but with the affilia- tion term treated as fixed rather than random gave an intrinsic savanna-forest difference of $3.0 \pm 0.7 \mathrm{mg} \mathrm{g}^{-1}$ (Table S3f); i.e. it is not only the different soil chemistry of the forest vs. savanna plots that leads to their lower $\left\langle\mathrm{K}_{\mathrm{m}}\right\rangle$, but also intrinsically lower $\mathrm{K}_{\mathrm{m}}$ for savanna species contributing. Specifically, our model predicts $\mathrm{K}_{\mathrm{m}}$ to be - on average - only 0.6 that of their forest counterparts under identical edaphic conditions. Also inferred to be intrinsically lower for savanna species were both $\mathrm{Ca}_{\mathrm{m}}$ (Table S3e) and (more marginally) $\mathrm{Mg}_{\mathrm{m}}$ (Table S3g), and as discussed by Schrodt et al. (2014) underlying this forest-savanna difference may be typically contrasting plant strategies in terms of leaf construction costs, with the tendency for low $M_{\mathrm{a}}$ in leaves of high mineral content. This is presumably attributable to a low tissue density associated with thinner, less lignified cell walls with the higher cation content presumably also balanced by higher levels of organic acids, which are, themselves, of a relatively low $\mathrm{C}$ content. Generally with a lower $\mathrm{C}_{\mathrm{m}}$ as well, forest leaves thus have lower overall construction costs especially at low $P_{\mathrm{A}}$ (Fig. 7d; Table S3g).

As noted in Sect. 3.3.3 there was a tendency towards increased deciduousness as $P_{\mathrm{A}}$ declined; indeed, with a simple ANOVA on the data in Table S2 (data not shown) we find lower construction costs for deciduous species as compared to evergreen species and the semi- and brevi-deciduous types as defined in Sect. $2.4(p<0.01)$, but only for forest species. The lower average construction costs for trees in forest plots is not therefore associated with a greater dominance of deciduous species per se; indeed, if anything the opposite occurs with more evergreen-type species in the transitional forests (Sect. 3.3.3).

\subsection{Area-based trait variations}

Despite individual estimates of $A_{\max }$ at the leaf level varying more than twofold across the data set, little of this variation appeared systematic in terms of differences in $\left\langle A_{\max }\right\rangle$ between $\mathbb{F}$ and $\mathbb{S}$ plots, or in relation to variations in $P_{\mathrm{A}}$ (Fig. 10a). This lack of any rainfall dependence was also observed for savanna plot $\left\langle\mathrm{N}_{\mathrm{a}}\right\rangle$ and $\left\langle\mathrm{P}_{\mathrm{a}}\right\rangle$. There was, however, a slight and significant tendency for forest plot $\left\langle\mathrm{N}_{\mathrm{a}}\right\rangle$ and $\left\langle\mathrm{P}_{\mathrm{a}}\right\rangle$ to increase with declining rainfall (in a general pattern similar to the non-significant $\left\langle A_{\mathrm{a}}\right\rangle$ trend) consistent with the idea that leaves functioning at lower $P_{\mathrm{A}}$ should have a higher photosynthetic capacity than at high $P_{\mathrm{A}}-$ also operating a lower ratio of intercellular to ambient $\left[\mathrm{CO}_{2}\right], \mathrm{C}_{\mathrm{i}} / \mathrm{C}_{\mathrm{a}}$ (Buckley et al., 2002; Farquhar et al., 2002). The latter effect would be expected to be detectable through such leaves having a higher (less negative) $\delta^{13} \mathrm{C}$ as was indeed observed to be the case for forest plots across the transect (Fig. 10d). It was, however, only at the lowest $P_{\mathrm{A}}$ savanna site that $\left\langle\delta^{13} \mathrm{C}\right\rangle$ was increased for savanna trees. This lack of a community-level savanna $\delta^{13} \mathrm{C}$ response has also been observed along a precipitation gradient in Australia where it has been assumed that the pattern is due to "species switching" (Schulze et al., 
1998; Miller et al., 2001); i.e. as $P_{\mathrm{A}}$ declines, species that are increasingly adapted to more severe and/or extended soil water deficits replace those whose physiological characteristics are better suited to more mesic conditions; presumably one important factor here being that the former has intrinsically higher roots, i.e. shoot ratios (Schenk and Jackson, 2002; Mokany et al., 2006; Zerihun et al., 2006).

Taking savanna and forest together, simple linear multivariate modelling (Table 2) showed changes in $\left\langle\mathrm{N}_{\mathrm{a}}\right\rangle$ to be positively correlated with higher $\left\langle A_{\max }\right\rangle$. This is as would be expected on the basis of leaf-level studies (Domingues et al., 2010, 2014; Bloomfield et al., 2014) but here with the soilassociated $[\mathrm{P}]_{\mathrm{sa}}$ rather than the community-weighted foliar $\left\langle\mathrm{P}_{\mathrm{a}}\right\rangle$ being the better predictor in terms of stand-level phosphorus status. Moreover, in addition to a positive effect of mean canopy height $\left\langle H_{\mathrm{U}}\right\rangle$ on $\left\langle A_{\max }\right\rangle(p<0.01)$, also detected was a very strong negative effect of soil exchangeable potassium $[\mathrm{K}]_{\mathrm{sa}}$.

Taking the phosphorus effect first, one likely explanation for soil concentrations being better predictors than those of the foliage itself is that - at the individual leaf level $-\mathrm{N}$ and $\mathrm{P}$ may not be simple additive constraints on photosynthetic capacity. But rather - and depending on their relative concentrations - either one of these two elements can be limiting and both forms of limitation often existing within the one stand (Domingues et al., 2010, 2014). The higher the $[\mathrm{P}]_{\mathrm{sa}}$ the less the chance of a given tree having its photosynthetic rate limited by $\mathrm{P}_{\mathrm{a}}$. Nevertheless, this would then mean that a soil phosphorus effect as shown here should be evident, but not necessarily with a community-level trait metric such as $\left\langle\mathrm{P}_{\mathrm{a}}\right\rangle$ being the relevant measure.

But what of the canopy height and soil potassium effects? First, with regard to $\left\langle H_{\mathrm{U}}\right\rangle$, although there is a strong tendency for taller trees with a greater probability of access to full sunlight to have higher area-based nutrient concentrations and associated higher $\mathrm{CO}_{2}$ assimilation capacities (Kenzo et al., 2006; Lloyd et al., 2010), this effect applies only within individual stands and there is no reason why that phenomenon should readily translate to differences in mean canopy height between different stands. Moreover, with $\left\langle\mathrm{N}_{\mathrm{a}}\right\rangle$ also included in the multivariate model (Table 2a), that means that it is also the mean photosynthetic $\mathrm{N}$ use efficiency, which is modelled to decline with decreasing $\left\langle H_{\mathrm{U}}\right\rangle$. With the $\left\langle H_{\mathrm{U}}\right\rangle$ of forest plots showing a clear negative dependence on $P_{\mathrm{A}}$, especially at the drier end of the transect (and savanna plots being less variable; Figs. $4 \mathrm{~b}$ and 11d); perhaps then this effect relates to concurrent changes on other stand properties which also correlate with $\left\langle H_{\mathrm{U}}\right\rangle$. For example, an increase in forest species deciduousness is associated with the shorter growing season as noted in Sect. 4.1. Here for example, to facilitate rapid leaf and shoot expansion during the limited periods of plant water availability at sites such as TUC-01, we might reasonably expect relatively large amounts of nitrogen to be allocated away from photosynthesis and towards amino acid production (Funk et al., 2013), with increased allocation to
$\mathrm{N}$-based plant defence strategies also expected for the inevitably short-lived leaves (Stamp, 2003) on trees growing in - as is strongly suggested by their soil and leaf $\delta^{15} \mathrm{~N}(\mathrm{Nar}-$ doto et al., 2013) - a relatively replete nitrogen environment.

Although at first sight the negative correlation between soil potassium and both leaf-area-based photosynthetic capacities as well as the photosynthetic nutrient efficiencies of both $\mathrm{N}$ and $\mathrm{P}$ may seem surprising, this association is broadly consistent with previous work in the forest-savanna transition zone in both Africa and Australia, where savanna species as was the case here typically found on lower potassium status soils than their forest counterparts - have been observed to have greater $A_{\max }$ and/or $A_{\mathrm{N}}$ than their forest counterparts (Domingues et al., 2010, 2014; Bloomfield et al., 2014). Indeed, undertaking simple non-parametric correlations between photosynthetic capacity and a range of climatic and edaphic conditions for a (combined) data set of nearly 200 forest and savanna tree measurements in Far North Queensland (Australia), Bloomfield et al. (2014) also found soil exchangeable potassium to be the best predictor of photosynthetic properties with a negative relationship as found here.

In interpreting this relationship between community-level mean trait values and soil properties, it is important to remember that edaphic effects may be mediated via intrinsic differences in the physiological characteristics of the various species making up the different plant communities (Fyllas et al., 2012), this being in addition to any direct effects of the soil property on the physiological traits of the species making up that community per se. In this respect, there is some indication that both these effects are likely to be important, with Fig. 9 suggesting that equivalent amounts of the explained variance in the data set are attributable to both species and environment for $A_{\max }$ and $A_{\mathrm{N}}$. Akin with this may then be that, associated with the typically lower cation status, low $[\mathrm{K}]_{\mathrm{sa}}$ soils are typically slower growing species, which on average have less of their $\mathrm{N}$ allocated to defence or amino acids as growth reserves as compared to the faster growing species. Also related to differences in leaf nitrogen chemistry may be the tendency for tropical trees on higher cation status soils to use as their primary source $\mathrm{NO}_{3}^{-}$, which is subsequently assimilated in the foliage as opposed to root assimilated $\mathrm{NH}_{4}^{+}$ (Stewart et al., 1988; Schmidt and Stewart, 1998; Aidar et al., 2003). This could affect photosynthesis and photosynthetic nitrogen efficiency in two ways. First, with the leaves of trees on higher nutrient status soil having the main site of nitrogen processing in leaves as opposed to roots on more dystric soils, more N-containing compounds not directly associated with $\mathrm{CO}_{2}$ assimilation would inevitably be present in the foliage, thus leading to a lower $A_{\mathrm{N}}$. Second, with some of the $\mathrm{NO}_{3}^{-}$reduction reactions of such trees occurring in the chloroplast (Halliwell, 1981), it is also possible there could be direct competition with the photosynthetic carbon reduction cycle for the reducing equivalents ATP and NADPH. 
But how does one specifically invoke a role for soil potassium in the above scheme? Especially as differing forms of nitrogen uptake observed on eutric vs. dystric soils are generally considered to largely reflect differences in the relative availabilities of $\mathrm{NO}_{3}^{-}$and $\mathrm{NH}_{4}^{+}$(Britto and Kronzucker, 2013), which in turn relate to $\mathrm{pH}$ sensitivities of ammoniaoxidising bacteria and archaea (Yao et al., 2011). It is, however, now clear that other edaphic factors may influence soil nitrification rates at low $\mathrm{pH}$ (de Gannes et al., 2014) including a likely role for potassium (Norman and Barrett, 2014). Moreover, when one considers that a likely reason for nitrogen assimilation occurring mostly in the roots at low $\mathrm{pH}$ is through the prevention of ammonium toxicity in the stem and leaf tissues (Givan, 1979) and with alleviation of $\mathrm{NH}_{4}^{+}$toxicity by $\mathrm{K}^{+}$supply well documented (Mengel et al., 1976; Britto and Kronzucker, 2013), then a specific role of soil potassium in influencing leaf photosynthetic characteristics through a range of interactions with plant nitrogen utilisation characteristics seems likely, especially given the close linkages between nitrogen and potassium in the modulation of numerous plant signalling pathways as discovered in recent years (Tsay et al., 2011). It has also been suggested that there may be advantages to storing $\mathrm{C}$ as organic acids (rather than sugars/starch) when it is to be subsequently used for the assimilation and/or used for $\mathrm{N}$ (Xu et al., 2012), which may also be related to potassium's likely role as a balancing cation for organic anions (see Sect. 4.1).

\subsection{Soil-vegetation-climate relationships}

In both managed and natural ecosystems, physiologically relevant reductions in soil nutrient availability can be expected as most likely to be manifested either through changes in tissue nutrient concentrations and/or reductions in the extent of standing biomass (for example reductions in leaf area); therefore through Eq. (3) we have attempted to see which of our studied nutrients was likely to be more limiting by examining the relationships between total canopy and soil amounts when both are expressed on a ground area basis (Fig. 8). When looked at this way, suggestions of any sort of relationship were, however, found only for calcium (Fig. 8a) and potassium (Fig. 8c) with - in marked contrast to the wetter forests of the Amazon Basin (Quesada and Lloyd, 2015) - no relationship being found between canopy and soil phosphorus amounts. It is accepted of course that Eq. (3) is an approximation: ignoring for example nutrients in boles, branches and roots as well as in grasses and understorey shrubs. Nevertheless, with their fast foliage turnover times and a general equivalence between fine-root and leaf concentrations in tropical ecosystems (Vitousek and Sanford, 1986), such plots should still give a general indication of the relationship between ecosystem nutrient stocks/uptake rates and therefore the lack of any sort of relationship for magnesium and phosphorus remains particularly telling. It is also clear that whilst there are typically fivefold higher concentrations of calcium in the soil as compared to potassium (see also Fig. 3a), differences in the total amount of foliar nutrient per unit ground area are much less marked (Fig. 8a and c). This - along with the non-saturating relationship of Fig. $8 \mathrm{c}$ then suggests - at least when considered in terms of vegetation requirements in relation to soil availability - that of the nutrients examined it is potassium that is the more likely candidate in terms of a nutrient constraint on ecosystem function.

Further evidence pointing in this direction comes from the observation that, as well as being associated with a range of different foliar properties, such as photosynthetic nitrogen and phosphorus-use efficiencies, and varying systematically between forest and savanna stands, as a univariate predictor, $[K]_{\text {sa }}$ was the only edaphic or climatic variable significantly correlated with $C_{\mathrm{W}}$ at $p<0.05$ (Table 1) and with none of $[\mathrm{Mg}]_{\mathrm{sa}},[\mathrm{Ca}]_{\mathrm{sa}}, \mathrm{pH}$, sand or clay content nearly as good a predictor of $C_{\mathrm{W}}$, when considered either on their own or when considered in conjunction with $P_{\mathrm{A}}$ and $\theta_{\mathrm{P}}$ (Sect. 3.5). Thus we postulate not only that low soil potassium availability serves to decrease leaf areas, though with this effect somewhat offset by higher photosynthetic capacities per unit leaf area, but also - with this response also mimicking what is expected under conditions of increasingly more severe water deficits (Buckley et al., 2002; Farquhar et al., 2002) - that potassium may somehow be involved in the signalling of the latter. Although such a strong effect, attributable to a single cation, may be surprising, especially in terms of generally assumed belief that nitrogen and/or phosphorus are the two factors likely to be limiting plant productivity - and through the associated modulation of $\mathrm{C}$ supply also controlling other attributes such as leaf area and stand-level biomass (Ostle et al., 2009; Scheiter and Higgins, 2009; Mercado et al., 2011; Alvarez-Clare et al., 2013; Pavlick et al., 2013) - in the agricultural literature the importance of potassium for crop yields is particularly well appreciated (Römheld and Kirkby, 2010; Wang et al., 2013; Zörb et al., 2014). This is especially the case under conditions of soil water deficit where a range of factors have been implicated: these including an improved soil and/or plant potassium status being associated with enhanced root longevities, reductions in stress-associated reactive oxygen species production and the maintenance of tissue water relations through increases in leaf and/or root osmotic potential. In addition, positive effects of potassium on photosynthetic carbon acquisition through stimulation of both stomatal and chloroplast metabolism have also been noted. (Mengel and Arneke, 1982; Egilla et al., 2001, 2005; Umar, 2006; Lebaudy et al., 2008; El-Mesbahi et al., 2012; Wang et al., 2013; Shabala and Pottosin, 2014). Further, an important role of potassium as a prime signaller of plant responses to abiotic stresses has also recently been postulated by several groups (Osakabe et al., 2013; Ahmad and Maathuis, 2014; Anschütz et al., 2014; Hafsi et al., 2014; Shabala and Pottosin, 2014), which - along with a previously unrecognised likely role for potassium as an osmoticum in woody stem tissues capable of high water storage (Braun et al., 
1968; Hart, 1984; Borchert and Pockman, 2005; PinedaGarcia et al., 2013; Hietz et al., 2014; Spicer, 2014) - all point to this element as a key chemical in soil water deficit signalling and response.

An active involvement of potassium in modulating plant responses to soil water deficit is also consistent with the additional involvement of mean annual precipitation and total plant available water as key factors modulating canopy structural properties (Table 3): in particular as a determinant of $C_{\mathrm{W}}$ for which $\theta_{\mathrm{P}}$ seems just as important as $P_{\mathrm{A}}$ in accounting for the variations observed (Fig. 12d-f). Although perhaps surprising, numerical simulations have shown that this should indeed be the case. For example, the theoretical study of Feng et al. (2012) showed that along with seasonality, the key factor controlling ecosystem evaporation rates - themselves expected to link broadly to differences in plant productivity (Beer et al., 2009) - was $\gamma=\theta_{P} / \dot{P}$, where $\dot{P}$ is the mean precipitation depth per event. The dimensionless nature of $\gamma$ itself immediately points to an interaction between precipitation and soil water storage as detected here and is also, as expected on the basis of maximum rooting depth, increasing with mean annual rainfall in water-limited ecosystems (Collins and Bras, 2007; Schenk, 2008). Moreover, as one might intuitively expect, the study of Feng et al. (2012) also served to show that lower values of $\gamma$ provide increasingly greater constraints on annual ecosystem evaporation rates as precipitation seasonality increases. Thus in less seasonal environments than those investigated here, it may well be that $\theta_{\mathrm{P}}$ is less important a factor in the modulation of precipitation effects than as found for the current study.

Nevertheless, none of the above considerations can account for our fitted model prediction that for $P_{\mathrm{A}} \leq 1.5 \mathrm{~m}$ a decline in $\theta_{\mathrm{P}}$ may actually be associated with an increase in $C_{\mathrm{W}}$. But as is verified numerically in Appendix B, this phenomenon does become readily understandable when it is considered that - with the exception of only a few sites - lower values of $\theta_{\mathrm{P}}$ for the current study arose through the presence of some physical barrier restricting the depth below which roots could penetrate (Table S1). We suggest that because such layers are also effectively impermeable to water flow, then associated with a lower $\theta_{\mathrm{P}}$ is also less drainage and thus with more water generally being available for plant water use above that layer. Of course, if any such layer were not to be present, then roots could still access water below that depth, but presumably with this also involving additional structural carbon investment as compared to the restricted root zone case: the maximum rooting depth on that case presumably reflecting the point at which the marginal carbon cost of adding deeper roots is balanced by the marginal carbon benefit of the increased transpiration then made possible (Guswa, 2008).

As characterised through the forest-savanna species dichotomy, a strong influence of soil physical and chemical properties on tropical vegetation structure as detected here are also indicative of a significant edaphic influence on woody plant community composition consistent with nu- merous regional studies where landscape-scale variations in vegetation structure/floristics have been related to effects of landscape position, underlying geology and/or soil texture, as for example, in Brigalow woodland in Central Queensland (Australia; Dowling et al., 1986), Mopane Woodland in Botswana (Mlambo, 2007), for Nylsvley Nature Reserve (Coetzee et al., 1976), Kruger National Park (Fraser et al., 1987; Ben-Shahar, 1991; Baldeck et al., 2014; Scholtz et al., 2014), northern Transvaal (O'Connor, 1992) and Klaserie Nature Reserve (Witkowski and O'Connor, 1996) in South Africa, for the southern Kalahari Desert (Botswana, Namibia and South Africa; Werger, 1978), in Etosha National Park in Namibia (Le Roux et al., 1988), for the Turkana District in Kenya (Coughenour and Ellis, 1993), across northern Yucatan Peninsula in Mexico (White and Hood, 2004), at Assis Ecological Station in southeast Brazil (de Assis et al., 2011), in W Regional Park in southwest Niger (Diouf et al., 2012), in the Zambesi Valley (Guy, 1977), at Malilangwe Wildlife Reserve (Clegg and O'Connor, 2012) and Gonarezhou National Park (Gandiwa et al., 2014) in Zimbabwe, and for Emas National Park in central Brazil (Dantas et al., 2015). At larger scales, soil-specific texture and depth effects on vegetation structure have also been noted for Zimbabwe (Dye and Walker, 1980) and, in conjunction with rainfall variations for Australia (Williams et al., 1996), Botswana (Skarpe, 1986; Ringrose et al., 2003) and Sudan (Smith, 1951).

Although it has been suggested that one general theme emerging from the above studies is the importance of soil texture, with heavy textured soil generally having a lower woody vegetation density than coarser textured soils, apparently due to lower infiltration rates associated with the swelling of 2: 1 minerals (Clegg and O'Connor, 2012), high clay contents are also possible for even the most highly weathered soils dominated by $1: 1$ clays for which water infiltration and retention properties are, if anything, more favourable than more coarsely textured soils (Sanchez, 1976; Hodnett and Tomasella, 2002; Quesada et al., 2011; Quesada and Lloyd, 2015). Moreover, variations in both soil organic matter and silt fraction also contribute importantly to differences in plant available soil volumetric water content (Rawls et al., 2003; Collins and Bras, 2007; Shukla, 2013). This means that, along with variations in rooting depth (as potentially affected by physical limitations), simple measures of upper-soil sand and clay content are likely to be only broadly reflective of the $\theta_{\mathrm{P}}$ parameter as identified here. Although our estimates of $\theta_{\mathrm{P}}$ were based simply on observations of maximum rooting depth and translating the categorised soil texture for each depth increment to a water holding capacity using a simple look up table (Hodnett and Tomasella, 2002), this clearly provides an improved estimate of soil moisture storage and buffering as compared to simple measures of upper surface clay and/or sand content as seems to have been the generally employed metric to date (Williams et al., 1996; Sankaran et al., 2005, 2008; Lehmann et al., 2014). It is, however, important to note that the fitted $P_{\mathrm{A}}: \theta_{\mathrm{P}}$ interaction term 
should not be independent of precipitation seasonality (Good and Caylor, 2011; Feng et al., 2012) with any (presumably small) changes in seasonality with $P_{\mathrm{A}}$ incorporated into our fitted regression coefficients.

Although a few of the above studies demonstrating strong effects of soil physical properties and landscape position of vegetation structure did also measure soil nutrients, prior to this study little attempt had been made to ascertain if variations in tropical vegetation structure could be explained on the basis of differences in soil chemistry: either in isolation or in addition to the soil physical effects interacting with water supply as described above. One exception is the interesting recent study of Mills et al. (2013) who found that for measures of woody cover on 364 plots at 20 sites in Namibia $C_{\mathrm{W}}$ tended to peak at intermediate nutrient contents. They interpreted their data as indicating that at the highest soil nutrient availabilities the "metabolic power" of grasses exceeded that of woody plants. Noting significant differences on several foliar traits between species growing in a "seasonally dry forest" vs. a "cerradão" (closed savanna woodland) stand in south-eastern Brazil, Viani et al. (2014) pointed out a low $\mathrm{pH}$ (as opposed to a low $[\mathrm{K}]_{\mathrm{sa}}$ ) in the latter as the main factor driving differences in stand structure between the two vegetation formation types. But, as was found here (Fig. 7b), foliar potassium concentrations in that study were also markedly higher in the forest species as compared to their savanna counterparts with similar large contrasts in soil exchangeable cations (Fig. 3) between the two vegetation types (Viani et al., 2011). In terms of model fits, we found $\mathrm{pH}$ to be a far inferior predictor when substituted with $[\mathrm{K}]_{\text {sa }}$ with $r^{2}<0.1$ for all multivariate predictor combinations as presented in Table 3. Indeed, as was the case for the photosynthetic properties examined, when considered in association with the appropriate covariates, no other soil parameter came even close to potassium in terms of its efficacy as a predictor of $C_{\mathrm{W}}$ with the best alternative, viz. $[\mathrm{Mg}]_{\mathrm{sa}}$, yielding a $\triangle \mathrm{AIC}$ of -5.4 (Sect. 3.5).

But, especially with nearly half the sites of the current study being classified as savanna and hence having an appreciable axylale layer, is it also necessary to implicitly take into account tree-grass competition when considering our observed potassium effect? To some extent, that depends on the view one takes as to which grasses are "passive" occupiers of open areas not occupied by woody vegetation versus active competitors for water and nutrient resources. But in any case, with their typically lower stature and characteristically lower rates of transpiration per unit leaf area (Grace et al., 1998), many of the explanations given above for the underlying basis of the potassium effect of woody vegetation might reasonably be expected to be less of a consideration for grasses and herbs. This would be especially the case should one of the prime roles of potassium be in association with the transport of water to height and/or short-term alleviation of leaf water deficits through provision of xylem parenchyma storage reservoirs in woody tissue root and stem.
It is, of course, possible that rather it being potassium itself, it might be that some unmeasured trace element who's availability in the soil is strongly correlated with $[\mathrm{K}]_{\mathrm{sa}}$ that is really the basis of the underlying strong correlations observed between $[\mathrm{K}]_{\mathrm{sa}}$ and the wide range of woody plant traits as reported here (Mills et al., 2013). Yet, although it is true that many univalent and divalent cation trace elements are at relatively low concentrations in the more highly weathered tropical soils such as were found to occur in all but the lowest precipitation regions of the current study (Marques et al., 2004), it is also the case that - as compared to "typical" temperate soils for example - relative trace element concentrations are reduced by less than an order of magnitude in even the most highly weathered tropical soils (Marques et al., 2004). This is a situation very much different to that for the major cations (and especially potassium) where estimates of exchangeable concentrations are several fold lower in the more heavily weathered soils of the tropics as opposed to those typical of the temperate zone (Sanchez, 1976; Quesada et al., 2011). This contrast is perhaps due to retention of trace element cations in the even most strongly weathered tropical soil types through organic matter adsorption and iron oxides also potentially being important in trace element retention in such soils (Rieuwerts, 2007).

\subsection{Implications}

Obviously there is much work to be done in terms of verifying what might be termed the combined water and potassium (CWAK) concept in terms of its applicability to other tropical systems. But, nevertheless, the idea that variations in canopy structure both within and between different forest and savanna vegetation formation types can be explained through a simple concurrent consideration of water and nutrients does not sit comfortably with most current theories of tropical vegetation structure where notions of disturbance and the existence of alternative stable states (ASS) as mediated by fire (or herbivory) as the prime drivers of structural and floristic variations in tropical ecosystems have assumed dogma status over recent years (Warman and Moles, 2009; Hirota et al., 2011; Lehmann et al., 2011, 2014; Staver et al., 2011; Favier et al., 2012; Hoffmann et al., 2012; Murphy and Bowman, 2012). Nevertheless, observational evidence for ASS is at best circumstantial (Veenendaal et al., 2015).

The CWAK hypothesis, of course, does not require there to be no effect of fire on tropical vegetation structure. But rather, that fire be more a passive response to the presence of flammable $\mathrm{C}_{4}$ grasses (Lloyd et al., 2008) as opposed to fire being a major factor accounting for differences in savanna structure and the nature of forest-savanna transitions per se (Bond, 2008). Indeed, when examined in this context, recent results do actually point to the "passive response hypothesis being correct" (Diouf et al., 2012; Dantas et al., 2014), although interacting effects of fire on long-term soil nutrient availabilities and physical properties cannot be discounted 
(Cook, 1994; Mills and Fey, 2004; Cawson et al., 2012; Oliveras et al., 2013; Kugbe et al., 2014).

In terms of an apparent lack of edaphic effects on tropical vegetation structure, although some researchers have argued that the spatial scale of variability in soil chemical properties is insufficient to account for observed spatial patterns in vegetation structure (Lehmann et al., 2011; Favier et al., 2012) this would seem, as much as anything else, to simply reflect a basic misunderstanding of the purpose of large-scale soil maps such as are generally employed at the national or continental scale (levels 4 and 5 in Table 6.1 of Dent and Young, 1981) and now widely available on-line. Such maps were never constructed with the intention of providing an indication of the exact soil resource at any location, but rather to simply provide a broad overview of the soil resource at national or regional levels, this often being as a first step to more detailed mapping for future land use planning (Young, 1980; Dent and Young, 1981). Indeed, due to practical limits in the number of field observations possible when mapping at medium to high resolution, the hectare-scale soil-vegetation associations as mentioned above in Sect. 4.3 often end up being one important factor in the generation of the smaller-scale soil map itself (Trapnell et al., 1950; Young, 1980; Breimer et al., 1986; Nyamapfene, 1988). As noted by Guy (1977) working in the Zambesi Valley: "The very close relationships between vegetation types and soils is well illustrated.... Because of this close relationship it is not hard to see why that structure of each vegetation type changes over short distances where pockets of soils unlike those surrounding them occur".

Of course, we are by no means suggesting that all observed variations in tropical vegetation structure should be explainable on the simple basis of the CWAK hypothesis. For example, there are numerous cases where poor drainage may be the reason for savanna vegetation types under conditions otherwise suitable for forest (Cole, 1960, 1986; Haase and Beck, 1989; Cronje et al., 2008; Mantlana et al., 2008; Cochrane and Cochrane, 2010), and it also seems reasonable to speculate that in some cases woody savanna tree extent could be constrained by supra-low calcium concentrations in the subsoil (Cochrane, 1989). Also, with sodium capable of replacing potassium in many of its physiological functions when available at moderate concentrations (Wakeel et al., 2011; Kronzucker et al., 2013), of considerable interest in terms of refinement of the CWAK hypothesis is the existence of very high biomass stands of Colophospermum mopane (J.Kirk ex Benth.) J.Kirk ex J.Léonard and Acacia harophylla F. Muell. in southern Africa and north-eastern Australia, respectively: in both cases sometimes at low precipitation $\left(<0.8 \mathrm{ma}^{-1}\right)$ but also on soils with a high exchangeable sodium content and often also some form of physical constraint at depth (Russell et al., 1967; Guy, 1977, 1981; Dye and Walker, 1980; Dowling et al., 1986). Whatever the case, as has also recently been shown for the Amazon forests at a basin-wide scale (Quesada et al., 2012), it is clear that a simple sampling and/or consideration of soils for a few selected parameters such as upper surface sand and clay content can in no way allow for a reasonable assessment of likely edaphic effects of tropical vegetation structure and function to have been achieved.

\section{Conclusions}

Irrespective of rainfall regime, savannas are found on soils of a consistently lower cation status than their forest counterparts: these soils also being characterised by lower phosphorus concentrations and higher $\mathrm{C} / \mathrm{N}$ ratios. Leaves of trees growing within savanna stands are also typically of lower $\mathrm{N}$ and $\mathrm{K}$ concentrations (dry-mass basis) than for forest stands, but with little systematic difference in other elements (including phosphorus) or photosynthetic capacity. Contrasts between forest and savanna in the magnitude of their canopy cover for any given precipitation regime are appreciably greater than any differences in leaf-area-based physiological traits.

Especially for savannas, canopy cover is not closely associated with mean annual rainfall. But when considered in conjunction with soil water storage capacity and mean annual precipitation, soil exchangeable $\mathrm{K}$ (expressed on an area basis) emerges as an excellent predictor of canopy cover. Soil exchangeable $\mathrm{Mg}$, or $\mathrm{Ca}, \mathrm{pH}$ or texture metrics are much less well associated. Soil exchangeable potassium is also well associated with a range of structural and photosynthesisassociated traits with, in almost all cases, other cations, $\mathrm{pH}$ or soil texture metrics again of an inferior predictive ability.

For canopy cover and other stand-level structural traits, such as mean canopy height and standing live biomass, this potassium effect is modulated by variations in soil water availability as evidenced by a co-occurring soil water storage/precipitation interaction term in OLS multivariate predictive model fits. This modelled interaction is complex, and although the intuitive increase in canopy cover with increasing soil water storage capacity is simulated to occur at relatively high rates of mean annual precipitation $\left(P_{\mathrm{A}} \gtrsim 1 / 5 \mathrm{ma}^{-1}\right)$, the opposite is observed for $P_{\mathrm{A}} /$ $\gtrsim 1.5 \mathrm{~m} \mathrm{a}^{-1}$. With most of the variation in soil water storage capacity in the current data set being attributable to differences in rooting zone depth as opposed to plant available water storage per unit soil volume, it was confirmed through numerical simulation that the presence of an impermeable layer close to the soil surface can potentially have a beneficial effect on annual water balances in a strongly seasonal environment. This unexpected effect arises as a consequence of reduced drainage rates out of the shallow rooting zone more than offsetting any higher runoff rates associated with extreme rainfall events. 
Appendix A: List of symbols and abbreviations (with

typical units as appropriate)

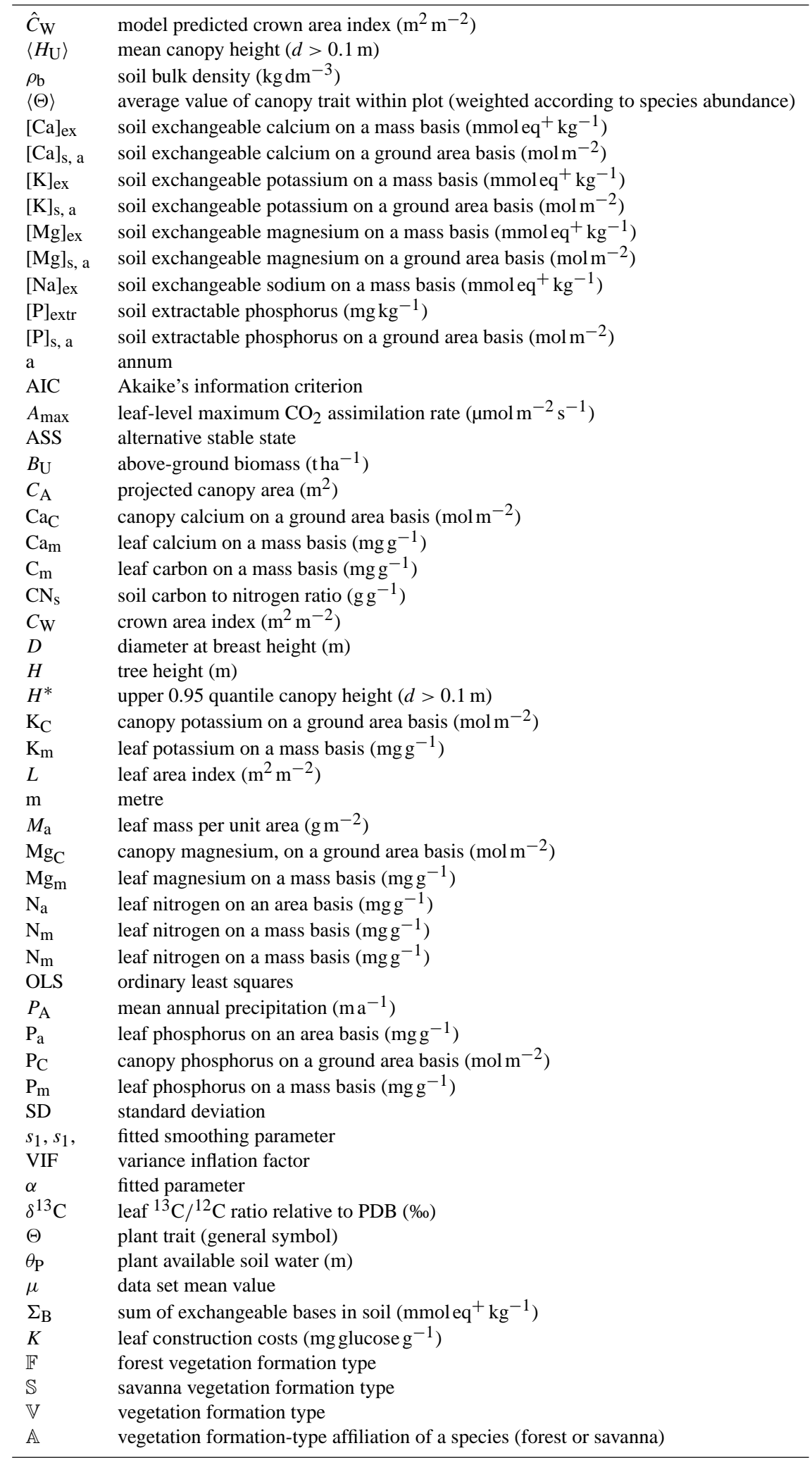




\section{Appendix B: Numerical demonstration of potential beneficial effects of restricted root zones}

Given the results of Sect. 6, with our best-fit statistical model predicting that, other things being equal, a reduced water storage capacity is more associated with higher canopy leaf areas than is the case for deeper soils under low rainfall conditions $\left(P_{\mathrm{A}} \lesssim 1.5 \mathrm{~m} \mathrm{a}^{-1}\right)$, but with the opposite being true under higher rainfall regimes, we investigate here the nature of this soil water storage - - precipitation interaction using a simple water balance model as described on pp. 136-138 of Moene and van Dam (2014) with and without a physical barrier in the upper soil layers.

\section{B1 Model description}

The model is constructed by first considering all in- and outflowing water amounts, viz.

$\Delta W=(P-E-R-D) \Delta t$,

where $W$ is the amount of water stored in the soil column $(\mathrm{m}), P$ denotes the precipitation rate $\left(\mathrm{md}^{-1}\right), E$ is the evaporation rate $\left(\mathrm{m} \mathrm{d}^{-1}\right), R$ is surface runoff $\left(\mathrm{m} \mathrm{d}^{-1}\right), D$ is drainage or deep percolation rate $\left(\mathrm{md}^{-1}\right)$ and $\Delta t$ is the considered time interval $(d)$.

Here the soil is considered as a uniform reservoir of depth $Z_{\mathrm{t}}$, which can be filled with precipitation and which gradually releases water to the vegetation and the sub-soil. All precipitation is assumed to infiltrate unless the reservoir is saturated, in which case surplus precipitation flows away as surface runoff.

Reduction of potential evaporation $E_{\mathrm{P}}$ is assumed to occur when the soil moisture content drops below a critical value $\theta_{\mathrm{C}}$ according to

$E(\theta)=\beta_{\mathrm{W}}(\theta) E_{\mathrm{P}}$ with $\beta_{\mathrm{W}}= \begin{cases}1 & \text { for } \theta_{\mathrm{C}} \leq \theta<\theta_{\mathrm{S}} \\ \frac{\theta-\theta_{\mathrm{W}}}{\theta_{\mathrm{C}}-\theta_{\mathrm{W}}} & \text { for } \theta_{\mathrm{W}} \leq \theta<\theta_{\mathrm{C}}, \\ 0 & \text { for } \theta=\theta_{\mathrm{W}}\end{cases}$

where $E$ denotes the actual evapotranspiration, $\theta$ is the soil reservoir moisture content $\left(\mathrm{m}^{3} \mathrm{~m}^{-3}\right), \beta_{\mathrm{W}}$ is a reduction coefficient for transpiration (dimensionless) and $\theta_{\mathrm{S}}, \theta_{\mathrm{C}}$ and $\theta_{\mathrm{W}}$ are the saturated, critical and wilting point moisture contents $\left(\mathrm{m}^{3} \mathrm{~m}^{-3}\right)$, respectively.

In the absence of any restriction to vertical water flow, percolation is described with free drainage below the soil reservoir using a hydraulic conductivity function:

$D=k_{\mathrm{h}}(\theta)$,

where $k_{\mathrm{h}}\left(\mathrm{m} \mathrm{h}^{-1}\right)$ is the soil hydraulic conductivity, the moisture dependence of which is described here according to the Brooks and Corey (1964) model as applied to the conductivity equation of Mualem (1976) by Tomasella and Hodnett
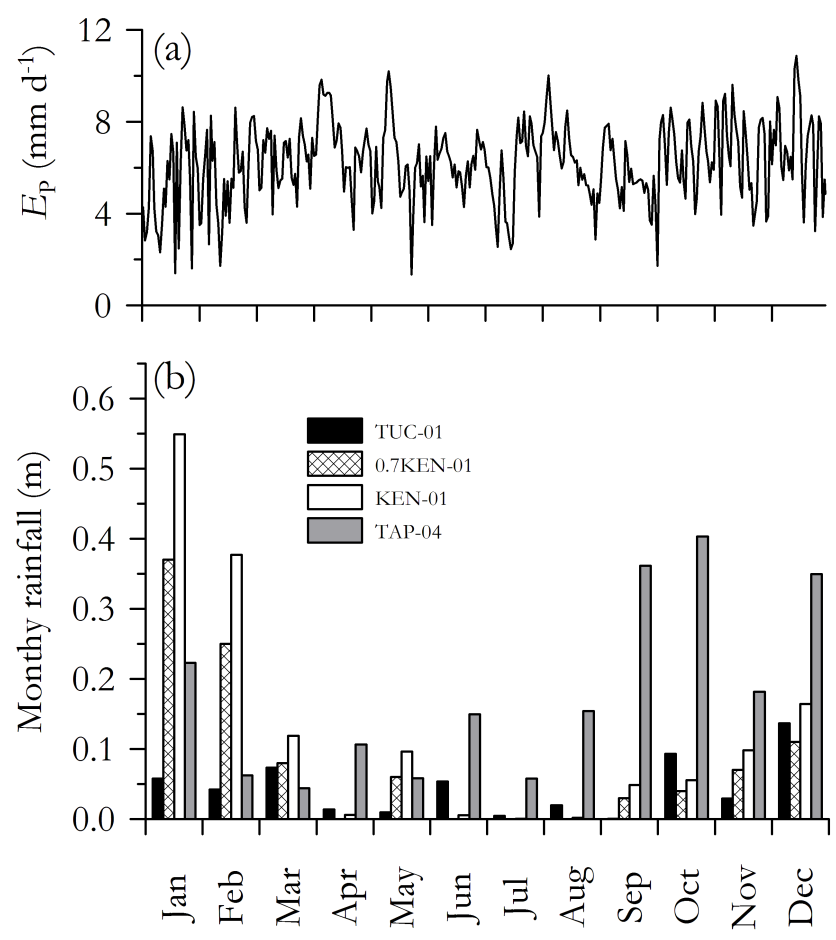

Month of Year

Figure B1. Key temporally varying inputs as used in the simulations (a) potential evapotranspiration (shown as daily totals) and (b) precipitation (shown as monthly sum).

(1997), viz.

$k_{\mathrm{h}}=k_{\mathrm{sat}}\left(\frac{\theta-\theta_{\mathrm{W}}}{\theta_{\mathrm{S}}-\theta_{\mathrm{W}}}\right)^{\eta}$,

where $k_{\text {sat }}$ is the saturated soil hydraulic conductivity $\left(\mathrm{m} \mathrm{h}^{-1}\right)$ and $\eta$ is a function of parameter $b$ in the water release curve retention mode of Brooks and Corey (1964), denoted herein as $b_{\mathrm{BC}}$ according to

$\eta=\eta_{1} b_{\mathrm{BC}}+\eta_{2}$.

To estimate $k_{\text {sat }}$ we utilise the Ahuja et al. (1984) generalisation of the Kozeny-Caraman equation as applied by Tomasella and Hodnett (1997), viz.

$k_{\mathrm{sat}}=B \phi_{\mathrm{e}}^{n}$,

where $\phi_{\mathrm{e}}$ is the effective porosity of the soil, defined as the total porosity $(\phi)$ minus the water content at a matric potential $(\psi)$ of $-33 \mathrm{kPa}$, and $B$ and $n$ are fitted parameters.

To relate $\psi$ to $\theta$ we used the tropical soil van Genuchten (VG) pedotransfer function as applied to tropical soil by Hodnett and Tomasella (2002). The VG function is

$\theta=\theta_{\mathrm{R}}+\frac{\theta_{\mathrm{S}}-\theta_{\mathrm{R}}}{\left[1+(\alpha / \psi)^{a}\right]^{b}}$, 
Table B1. Effect of presence of restricted soil layer on simulated total duration of low aeration $\left(\phi>0.1 \mathrm{~m}^{3} \mathrm{~m}^{-3}\right)$ or low soil moisture status $\left(\theta<\theta_{\mathbf{C}}\right)$ for the four precipitation scenarios shown in Fig. B1. In all cases the evapotranspiration rate refers to that estimated for a soil with a restricted layer at $0.3 \mathrm{~m}$ depth with the number of days calculated and compared (with in brackets) that predicted to be the case in simulations giving the same annual evapotranspiration rate but with no restricted layer present: KEN- $01^{*}$ is all rainfall events at KEN-01 multiplied by 0.7 . (see text)

\begin{tabular}{lrrrr}
\hline $\begin{array}{l}\text { Weather site } \\
\text { station }\end{array}$ & $\begin{array}{r}\text { Precipitation } \\
\left(\mathrm{m} \mathrm{a}^{-1}\right)\end{array}$ & $\begin{array}{r}\text { Evapotranspiration } \\
\left(\mathrm{m} \mathrm{a}^{-1}\right)\end{array}$ & $\begin{array}{r}\text { Days } \\
\left(\phi>0.1 \mathrm{~m}^{3} \mathrm{~m}^{-3}\right)\end{array}$ & $\begin{array}{r}\text { Days } \\
\left(\theta<\theta_{\mathrm{C}}\right)\end{array}$ \\
\hline TUC-01 & 0.54 & 0.52 & $0(0)$ & $342(350)$ \\
KEN-01* & 1.01 & 0.71 & $28(0)$ & $284(303)$ \\
KEN-01 & 1.51 & 0.87 & $94(0)$ & $248(285)$ \\
TAP-04 & 2.15 & 1.51 & $62(0)$ & $168(215)$ \\
\hline
\end{tabular}

where $\theta_{\mathrm{R}}$ is the "residual" water content and $\alpha, a$ and $b$ are empirical constants (for which $b$ is generally taken to be equal to $1-1 / a$ ). To avoid confusion with the Brooks and Corey (BC) equation (whose parameters are used in Eq. B4b), we hereafter denote $a$ and $b$ of Eq. (B6) as $a_{\mathrm{VG}}$ and $b_{\mathrm{VG}}$ also noting the numerical equivalences between the parameters of these two different equations (Morel-Seytoux et al., 1996).

To define the required parameters for the running of the model, we first must specify a specific soil type; the one chosen here being the soil below the stunted forest at TUC01; a silty loam at the driest end of the transect. On the basis of that texture classification, the five parameter values of the pedotransfer functions of Hodnett and Tomasella (2002) were obtained, these being $\alpha=0.191 \mathrm{kPa}^{-1}, a_{\mathrm{VG}}=1.644$, $b_{\mathrm{VG}}=0.391, \theta_{\mathrm{R}}=0.223 \mathrm{~m}^{3} \mathrm{~m}^{-3}$ and $\theta_{\mathrm{S}}=0.601 \mathrm{~m}^{3} \mathrm{~m}^{-3}$. Soil water content at field capacity $\theta_{\mathrm{FC}}$ was then estimated using Eq. (B6) with $\psi=-33 \mathrm{kPa}$ yielding a value of $\theta_{\mathrm{R}}=$ $0.336 \mathrm{~m}^{3} \mathrm{~m}^{-3}$. This then allowed $\phi_{\mathrm{e}}$ (Eq. B5) to be estimated according to (Shukla, 2013)

$\phi_{\mathrm{e}}=1-\frac{\rho}{2.65}-\theta_{\mathrm{FC}}$,

with $\rho$ being the measured average soil bulk density $\left(1.47 \mathrm{~g} \mathrm{~cm}^{-3}\right)$ and 2.65 representing a (default) soil particle density. To obtain values of $B$ and $n$ for inclusion into Eq. (B5), we took the values obtained by Tomasella and Hodnett (1997) as derived from a regression of $\log \left(k_{\text {sat }}\right)$ on $\log \left(\phi_{e}\right)$ across a range of tropical soil types, viz. $B=56540$ and $n=4.5359$ yielding $k_{\text {sat }}=26.40 \mathrm{~mm} \mathrm{~h}^{-1}$. The soil moisture dependence of the soil hydraulic conductivity was then estimated through Eq. (B4), with $\eta_{1}=3.701$ and $\eta_{2}=1.843$ as suggested by Tomasella and Hodnett (1997), this with $b_{\mathrm{BC}}=0.644$ then yielding $\eta=4.89$.
To obtain an estimate of $\beta_{\mathrm{W}}$ in Eq. (B2), we took $\theta_{\mathrm{W}}=\theta_{R}$ and $\theta_{\mathrm{W}}=0.3 \theta_{\mathrm{FC} *}$ (Dunin and Aston, 1984) where $\theta_{\mathrm{FC} *}$ is a slightly modified field capacity to that used in Eq. (B7), being taken at $\psi=-10 \mathrm{kPa}$ (Moene and van Dam, 2014), this then yielding $\theta_{\mathrm{FC} *}=0.445 \mathrm{~m}^{3} \mathrm{~m}^{-3}$. 


\section{B2 Driving variables and model progression}

To drive the model, we first used meteorological data collected as part of a study into Amazon forest productivity at the dry margin of the Amazon Basin in Bolivia (AraujoMurakami et al., 2014; Doughty et al., 2014). We took data from the first year of measurements and estimated on a halfhourly basis values of $E_{\mathrm{P}}$ for input into Eq. (B2) according to the FAO Penman method (Allen et al., 1998), viz.

$E_{\mathrm{P}}=\frac{0.408\left(R_{\mathrm{n}}-G\right)+\gamma \frac{900}{T_{\mathrm{K}}} u_{2}\left(e_{\mathrm{s}}-e_{\mathrm{a}}\right)}{\Delta+\gamma\left(1+0.34 u_{2}\right)}$,

where $E_{\mathrm{P}}$ is the reference (potential) evapotranspiration $\left(\mathrm{mmd}^{-1}\right), \quad R_{\mathrm{n}}$ is the net radiation at the crop surface $\left(\mathrm{MJ} \mathrm{m}^{-2} \mathrm{~d}^{-1}\right), G$ is the soil heat flux density $\left(\mathrm{MJ} \mathrm{m}^{-2} \mathrm{day}^{-1}\right), T_{\mathrm{K}}$ is the mean daily air temperature at $2 \mathrm{~m}$ height $(\mathrm{K}), u$ is the wind speed at $2 \mathrm{~m}$ height $\left(\mathrm{m} \mathrm{s}^{-} 1\right), e_{\mathrm{s}}$ is the saturation vapour pressure $(\mathrm{kPa}), e$ is actual vapour pressure $(\mathrm{kPa}), \Delta$ is the slope of the vapour pressure/temperature curve $\left(\mathrm{kPa}^{\circ} \mathrm{C}^{-1}\right)$ and $\gamma$ is the psychometric constant $\left(\mathrm{kPa}^{\circ} \mathrm{C}^{-1}\right)$.

Even with measurements of incoming solar radiation, $Q$, neither $R_{\mathrm{n}}$ nor $G$ had been directly determined at the KEN-01 site. By estimating the $\left(R_{\mathrm{n}}-G\right)$ term in Eq. (B8), we therefore made the simple assumption that $G=0.1 R_{\mathrm{n}}$ (Moene and van Dam, 2014) as well as assuming $R_{\mathrm{n}}=0.8 Q$ (Miranda et al., 1997). On a half-hourly basis (the resolution of the provided meteorological data) the estimation of $E_{\mathrm{P}}$ then allowed for an estimate of the change of soil moisture with time in the absence a relatively impenetrable layer to be made, viz.

$$
\frac{\mathrm{d} \theta}{\mathrm{d} t}=\frac{1}{Z_{\mathrm{r}}}\left[P-\beta E_{\mathrm{P}}-k_{\mathrm{sat}}\left(\frac{\theta-\theta_{\mathrm{W}}}{\theta_{\mathrm{S}}-\theta_{\mathrm{W}}}\right)^{\eta}\right] .
$$

To simulate the effects of an impenetrable layer, the $k_{\text {sat }}$ term in Eq. (B9) above was set to $1.0 \mathrm{~mm} \mathrm{~s}^{-1}$; a value in the range of those reported for an almost totally impermeable layer in the sub-soil of an Amazon Plinthosol (de Moraes et al., 2006).
We then undertook two sets of analyses with water supply and demand as described as above, but with varying $k_{\text {sat }}$. For both scenarios simulations were undertaken for a range of soil depths by repeated model runs with the effective rooting depth $Z_{\mathrm{r}}$ increasing from 0.08 to $2.40 \mathrm{~m}$ in $10 \mathrm{~mm}$ increments.

As well as being evaluated at the KEN-01, we also investigated the effect of different precipitation regimes through substitution of the KEN-01 precipitation values $\left(P_{\mathrm{A}}=1.51 \mathrm{~m} \mathrm{a}^{-1}\right)$ with the hourly record of a site close to TUC-01 and made in an apparently very dry year (Steininger et al., 2013) $\left(P_{\mathrm{A}}=0.54 \mathrm{~m} \mathrm{a}^{-1}\right)$ and the wettest year of an hourly 6-year record from a site in the Amazon forest region proper (TAP-04), as provided by Kim et al. (2012) $\left(P_{\mathrm{A}}=\right.$ $2.15 \mathrm{ma}^{-1}$ ). Providing a fourth (so as to provide a series of precipitation regimes in approximately $0.5 \mathrm{~m}$ increments) we also generated an artificial regime of $P_{\mathrm{A}}=1.1 \mathrm{~m} \mathrm{a}^{-1}$ by simply multiplying each KEN-01 precipitation event by 0.7 .

Figure A1 shows the seasonality of these four precipitation patterns are shown along with the simulated potential evaporation rate (as obtained using input radiation, wind speed, temperature and humidity data from KEN-01 and held as invariant across all four sites). 


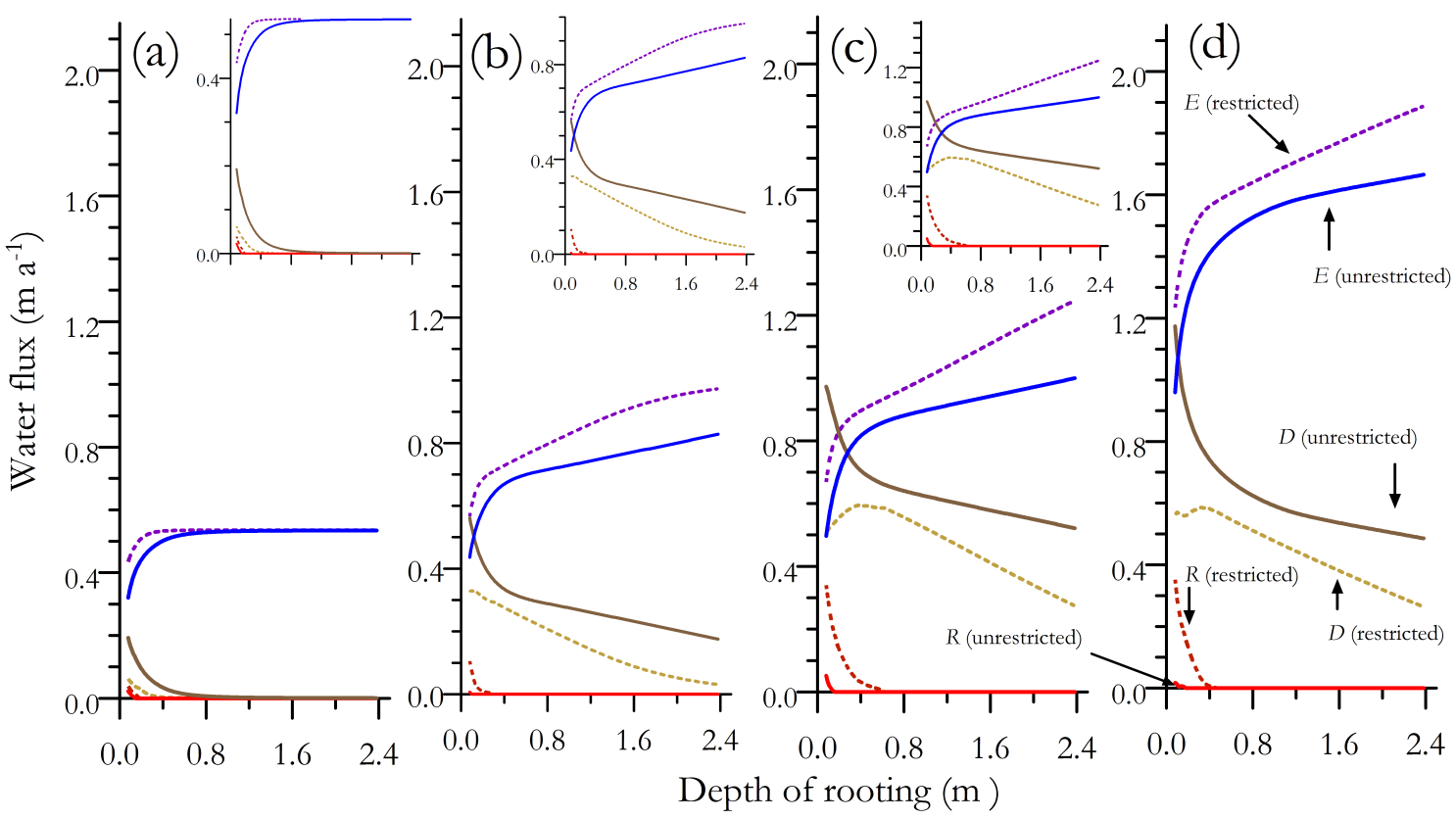

Figure B2. Simulated effects of the presence or absence or impermeable layer on soil water budgets across a range of rooting soil depths as affected by the precipitation regimes $\left(P_{\mathrm{A}}\right)$ of Fig. B1b. (a) $P_{\mathrm{A}}=\mathrm{TUC}-01$, (b) $P_{\mathrm{A}}=0.7 \mathrm{KEN}-01$, (c) $P_{\mathrm{A}}=\mathrm{KEN}-01$ and (d) $P_{\mathrm{A}}=\mathrm{TAP}-04$. In all cases the main $y$ axis has been scaled with a maximum value equal to the mean annual precipitation at TAP-04 $\left(P_{\mathrm{A}}=2.15 \mathrm{ma} \mathrm{a}^{-1}\right)$. Insets in (a-c) show same data, but with the $y$ axis according to $P_{\mathrm{A}}$ at the site in question. Shown are model predictions for evapotranspiration $(E)$, drainage $(D)$ and runoff $(R)$ as (1) a function of rooting depth where for the restricted case maximum rooting depth $\left(Z_{\max }\right)$ is assumed to be restricted by an impermeable layer at the same depth ("restricted" case) and (2) where there is no imposed restriction on $Z_{\max }$ ("unrestricted" case). 


\section{B3 Simulation results}

Figure B2 shows the simulated dependencies of all water fluxes into and out of the soil according to the model as dependent on the rooting depth $\left(Z_{\mathrm{r}}\right)$, where for the "restricted" case it is assumed that an impermeable layer constrains the depth to which the supported vegetation can extract water. In the case of "unrestricted" rooting, free drainage is allowed to occur below $Z_{\mathrm{r}}$, which then reflects - in some sort of crude way - the ecological strategy of the vegetation above in terms of its below-ground carbon investment directed towards water acquisition.

Starting with the lowest precipitation regime (Fig. B2a: TUC-01), it can clearly be seen that in neither case is extending $Z_{\mathrm{r}} \gtrsim 0.8 \mathrm{~m}$ likely to be of any profit for the vegetation (with both drainage and runoff being zero beyond this value). The water flux through evapotranspiration does, however, increase with $Z_{\mathrm{r}}$ up until around $0.6 \mathrm{~m}$, but with a far more rapid increase in $E$ with $Z_{\mathrm{r}}$ occurring for $Z_{\mathrm{r}} \gtrsim 0.2 \mathrm{~m}$ in the restricted case. This can be seen because of much less drainage than the unrestricted case at low $Z_{\mathrm{r}}$; something which is only offset to a minor degree by the marginally increased runoff.

At the ca. $100 \%$ higher precipitation regime of Fig. B2b, very different patterns emerge with an increase in $E$ with $Z_{\mathrm{r}}$ up until at least $2.4 \mathrm{~m}$ in both cases. Though with this dependency in both cases distinctly non-linear and, for the lowest rainfall regime, with the restricted case showing a much more rapid rise in vegetation water use as rooting depth increases up until about $0.25 \mathrm{~m}$ and, at any given $Z_{\mathrm{r}}$, always with high $E$ predicted for the restricted vs. unrestricted case. The latter effect can be attributed to the reduction in drainage associated with the impeded layer being less than offset by the higher runoff.

A broadly similar pattern is observed at a higher rainfall of about $1.5 \mathrm{~m} \mathrm{a}^{-1}$ (KEN-01: Fig. B2c) though here drainage fluxes for the restricted case show a different pattern: first increasing then decreasing with increased $Z_{\mathrm{r}}$. This can be regarded as a consequence of $R$ declining faster than $E$ as the restricted layer depth decreases; the implication being that of the extra water infiltrating the soil as rooting depth increases at lower $Z_{\mathrm{r}}$, only some of it can be used by the vegetation above, the rest necessarily going as drainage. Beyond $Z_{\mathrm{r}} \cong 0.6 \mathrm{~m}$ - this also being the minimum soil depth for which $R$ is modelled to be zero - the expected decline in $D$ with increased $Z_{\mathrm{r}}$ occurs, this being complemented entirely by increased $E$.

Under the highest examined precipitation regime of TAP$04\left(P=2.15 \mathrm{ma}^{-1}\right)$, a broadly similar pattern to KEN-01 is observed, but with the more rapid increase in $E$ with $Z_{\mathrm{r}}$ in the restricted case now extending to about $0.6 \mathrm{~m}$. Beyond this depth, there is simulated to be little effect of the higher precipitation regime on $D$ for either the restricted or unrestricted cases as compared to KEN-01, with all the extra rainfall being utilised by the vegetation in both cases (Fig. B2d).
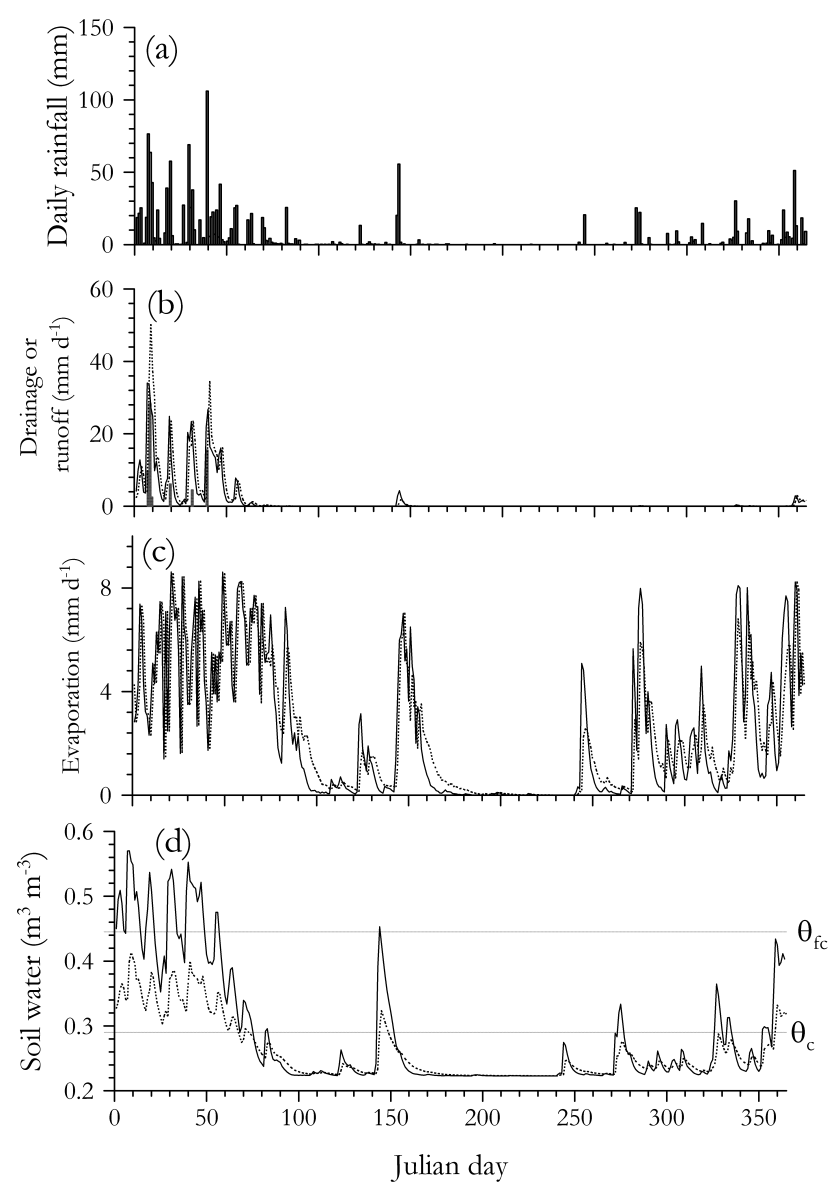

Figure B3. Simulated soil water budget components as affected by the presence of an impermeable layer at KEN-01. (a) Precipitation, (b) drainage and runoff, (c) ecosystem transpiration and (d) soil water content. Solid lines: impermeable layer at $0.3 \mathrm{~m}$ depth. Dashed lines: with the same annual evaporation; but with no barrier to vertical water flow (rooting depth of $0.7 \mathrm{~m}$ ). Red bar in (b) shows simulated daily runoff totals (impermeable layer only). Also shown in (d) are the prescribed minimum (critical) soil water content for plant water uptake $\left(\theta_{\mathrm{c}}\right)$ and field capacity $\left(\theta_{\mathrm{c}}\right)$.

Overall, Fig. B2 suggests that, according to these simulations at least - as hypothesised - a restricted root zone may be beneficial in at least some situations - at least when compared to the unrestricted case at the same $Z_{\mathrm{r}}$. Yet, it is also important to bear in mind that when compared at the same $E$, there are very different temporal patterns for the two cases examined here. This is shown in Table B1, where for each of the four precipitation regimes examined in Fig. B2, we have calculated both the numbers of days at which $\theta<\theta_{\mathrm{C}}$ (indicating some degree of simulated effect of soil water deficit on $E$ as modulated by the $\beta_{\mathrm{W}}$ term in Eq. B2) and those for which the air filled porosity $(\phi)$ was modelled as being less than $0.1 \mathrm{~m}^{3} \mathrm{~m}^{-3}$, this being one general indicator of potentially waterlogged conditions (Wesseling et al., 1957). Here for each $P_{\mathrm{A}}$ regime, the unrestricted-restricted comparison is 
at the same simulated $E$ as that found for the restricted case with $Z_{\mathrm{r}}=0.3 \mathrm{~m}$. For all four $P_{\mathrm{A}}$, the equivalent $Z_{\mathrm{r}}$ for the unrestricted case is just over $0.7 \mathrm{~m}$.

This shows that for all four $P_{\mathrm{A}}$ regimes there are no simulated indications of any water logging in the well-drained case but with up to 3 months of unfavourable conditions of soil aeration predicted with a restricted layer present. On the other hand, time spent under conditions of some sort of soil water deficit is reduced by the presence of the restricting layer with differences of nearly 50 days under the highest TAP-04 rainfall regime examined.
This effect is probed further in Fig. B3 where the simulated annual patterns (daily values) of $P, R, D, E$ and $\theta$ are shown for KEN-01 with the yearly total evapotranspiration in both cases equal to the $Z_{\mathrm{r}}=0.3 \mathrm{~m}$ restricted case. Here the higher runoff of the restricted case can be seen, with the unrestricted soil showing a corresponding lagged drainage response immediately after high precipitation periods (Fig. B3a and b). This general "buffering" in the absence of any root zone restriction is also seen in both the $E$ and $\theta$ responses during periods of soil water depletion or refill (Fig. B3c and d) with, most noticeably, $\theta$ always at a much lower value for the unrestricted case - even during the wet season when $E$ is clearly not limited by soil water availability. 


\section{B4 Caveats}

It must be emphasised that in many ways the model applied here is a crude one. For example - in terms of defects - see also page 138 of Moene and van Dam (2014):

1. It assumes that runoff occurs only when a soil becomes saturated; in reality runoff will also occur when the precipitation flux is higher than the maximum infiltration flux into the soil. In savannas that bias may potentially be a large one because of hydrophobicity caused by fire (DeBano, 2000); furthermore, this is also the case for more strongly seasonal environments with extreme drywetting events: the limited rapid infiltration of water into very dry soils being especially an issue for soils of a relatively abundant clay content (Shukla, 2013; Moene and van Dam, 2014).

2. The critical moisture content $\theta_{\mathrm{C}}$ is merely an assumed one, defined on the basis of one Australian study (Dunin and Aston, 1984). Most likely it would also vary according to variations in $Z_{\mathrm{r}}$ and in response to the presence/absence of any restrictive layer (Guswa, 2010).

3. Likewise in both cases we have assumed that $\beta_{\mathrm{W}}$ (a dimensionless coefficient relating $E$ to $E_{\mathrm{P}}-$ see Eq. B2) is dependent only upon the soil water content. In practice it will vary with other factors, such as leaf area index, which also vary seasonally, therefore giving rise to a more linear $E$ vs. $\theta$ relationship than that prescribed here (Quesada et al., 2008). As an example, with the restricted $Z_{\mathrm{r}}=0.3 \mathrm{~m}$ soil most likely supporting a deciduous forest under KEN-01 conditions (Torello-Raventos et al., 2013), the simulated out of season vegetation water uptake around day 150 would be most unlikely to actually occur due to an absence of leaves. It might also be expected that if $Z_{\mathrm{r}}$ is restricted, the supported vegetation would have a more aggressive water use strategy than would otherwise be the case, therefore depleting the root zone more quickly - subsequently creating space to absorb the next rain(s) (Guswa, 2010).
4. Any evaporation direct from the soil surface has been ignored.

5. Vertical variations in root distributions have not been accounted for.

6. Capillary rise has not been considered.

7. The simulated pattern in $E_{\mathrm{P}}$ comes from a single site (KEN-01). Thus, for example, anti-correlations between precipitation amount and potential evaporation rates (due to reduced radiation inputs and low vapour pressure deficits on wetter, cloudy days) have been broken for the TUC-01 and TAP-04 simulations.

Nevertheless, whilst the above means that little emphasis should be placed on the precise nature of the various individual predictions, the general principles as established by the simulations still remain valid. 


\section{The Supplement related to this article is available online at doi:10.5194/bg-12-6529-2015-supplement.}

Acknowledgements. We gratefully acknowledge the many generous individuals who took part in the making of this work either in the field or in the UK. Shiela Lloyd assisted with manuscript preparation and anger management. This work was funded as part of the UK Natural Environment Research Council TROBIT Consortium project (Award NE/D005590/1). We gratefully acknowledge to CNPq to the productivity grant and "Ciência sem Fronteiras" grant from $\mathrm{CNPq}$ to $\mathrm{BH}$ Marimon Junior and BS Marimon. Jon Lloyd was supported by a Royal Society of London Wolfson Research Merit Award. Meteorological data for KEN-01 as used in Appendix B was kindly provided by C. Doughty and Y. Malhi (University of Oxford) with data for TAP-04 having been made available by M. Goulden (University of California, Irvine). Original data as presented here available through the TRY plant trait database (www.try-db.org/).

Edited by: T. Keenan

\section{References}

Ahmad, I. and Maathuis, F. J. M.: Cellular and tissue distribution of potassium: physiological relevance, mechanisms and regulation, J. Plant Physiol., 171, 708-714, doi:10.1016/j.jplph.2013.10.016, 2014.

Ahuja, L., Naney, J., Green, R., and Nielsen, D.: Macroporosity to characterize spatial variability of hydraulic conductivity and effects of land management, Soil Sci. Soc. Am. J., 48, 699-702, 1984.

Aidar, M., Schmidt, S., Moss, G., Stewart, G., and Joly, C.: Nitrogen use strategies of neotropical rainforest trees in threatened Atlantic Forest, Plant Cell Environ., 26, 389-399, 2003.

Allen, R. G., Pereira, L. S., Raes, D., and Smith, M.: Crop Evapotranspiration - Guidelines for Computing Crop Water Requirements - FAO Irrigation and Drainage Paper 56, FAO, Rome, 300, 6541, 1998.

Alvarez-Clare, S., Mack, M., and Brooks, M.: A direct test of nitrogen and phosphorus limitation to net primary productivity in a lowland tropical wet forest, Ecology, 94, 1540-1551, 2013.

Anderson, J. M. and Ingram, J. S. I.: Tropical Soil Biology and Fertility: a Handbook of Methods, CAB International, Wallingford, UK, 1-221, 1993.

Anschütz, U., Becker, D., and Shabala, S.: Going beyond nutrition: regulation of potassium homoeostasis as a common denominator of plant adaptive responses to environment, J. Plant Physiol., 171, 670-687, doi:10.1016/j.jplph.2014.01.009, 2014.

Araujo-Murakami, A., Doughty, C. E., Metcalfe, D. B., SilvaEspejo, J. E., Arroyo, L., Heredia, J. P., Flores, M., Sibler, R., Mendizabal, L. M., and Pardo-Toledo, E.: The productivity, allocation and cycling of carbon in forests at the dry margin of the Amazon forest in Bolivia, Plant Ecol. Divers., 7, 55-69, 2014.

Askew, G., Moffatt, D., Montgomery, R., and Searl, P.: Interrelationships of soils and vegetation in the savanna-forest boundary zone of North-Eastern Mato Grosso, Geogr. J., 136, 370-376, 1970.

Avenard, J.-M. and Tricart, J.: Le contact forêt-savane: rôle des régimes hydriques des sols dans l'Ouest de la Côte-d'Ivoire, Ann. Geogr., 81, 421-450, 1972.

Baldeck, C. A., Colgan, M. S., Féret, J. B., Levick, S. R., Martin, R. E., and Asner, G. P.: Landscape-scale variation in plant community composition of an African savanna from airborne species mapping, Ecol. Appl., 24, 84-93, doi:10.1890/130307.1, 2014.

Bartlett, M. K., Scoffoni, C., and Sack, L.: The determinants of leaf turgor loss point and prediction of drought tolerance of species and biomes: a global meta-analysis, Ecol. Lett., 15, 393-405, doi:10.1111/j.1461-0248.2012.01751.x,, 2012.

Bates, D., Mächler, M., Bolker, B., and Walker, S.: Fitting Linear Mixed-Effects Models Using lme4, Journal of Statistical Software 67(1), doi:10.18637/jss.v067.i01, 2015.

Beer, C., Ciais, P., Reichstein, M., Baldocchi, D., Law, B., Papale, D., Soussana, J. F., Ammann, C., Buchmann, N., and Frank, D.: Temporal and among-site variability of inherent water use efficiency at the ecosystem level, Global Biogeochem. Cy., 23, 1-13, 2009.

Ben-Shahar, R.: Abundance of trees and grasses in a woodland savanna in relation to environmental factors, J. Veg. Sci., 2, 345350, doi:10.2307/3235926, 1991 .

Bevington, P. R. and Robinson, D. K.: Data Reduction and Error Analysis for the Physical Sciences, McGraw-Hill, New York, 336 pp., 1969.

Bird, M. I., Veenendaal, E. M., and Lloyd, J. J.: Soil carbon inventories and $\delta^{13} \mathrm{C}$ along a moisture gradient in Botswana, Glob. Change Biol., 10, 342-349, doi:10.1046/j.13652486.2003.00695.x, 2004.

Bloomfield, K. J.: The Nature of Photosynthetic Phosphorus Limitations for Tropical Tree Species, Ph.D. thesis, School of Geography, University of Leeds, 160 pp., 2012.

Bloomfield, K. J., Domingues, T. F., Saiz, G., Bird, M. I., Crayn, D. M., Ford, A., Metcalfe, D. J., Farquhar, G. D., and Lloyd, J.: Contrasting photosynthetic characteristics of forest vs. savanna species (Far North Queensland, Australia), Biogeosciences, 11, 7331-7347, doi:10.5194/bg-11-7331-2014, 2014.

Bond, W. J.: What limits trees in $\mathrm{C}_{4}$ grasslands and savannas?, Annu. Rev. Ecol. Evol. S., 39, 641-659, 2008.

Bond, W. J.: Do nutrient-poor soils inhibit development of forests? A nutrient stock analysis, Plant Soil, 334, 47-60, doi:10.1007/s11104-010-0440-0, 2010.

Borchert, R. and Pockman, W. T.: Water storage capacitance and xylem tension in isolated branches of temperate and tropical trees, Tree Physiol., 25, 457-466, doi:10.1093/treephys/25.4.457, 2005.

Braun, H. J., Versteegh, C., and Böhme, H.: Holz-Bautypen tropischer Bäume und ihre Einordnung in die Organisation des Hydrosystems, Holzforschung, 22, 16-21, 1968.

Breimer, R. F., Van Kekem, A., and Van Reuler, H.: Guidelines for soil survey and land evaluation in ecological research, Unesco, 125 pp., 1986.

Briggs, R. D.: Site Classification Field Guide, Maine Agriculture and Forest Experiment Station, 15 pp., 1994. 
Britto, D. T. and Kronzucker, H. J.: Ecological significance and complexity of N-source preference in plants, Ann. Bot.-London, 112, 957-963, doi:10.1093/aob/mct157, 2013.

Brooks, R. and Corey, A.: Hydraulic properties of porous media, Hydrology Papers, Colorado State University, 37 pp., 1964.

Buckley, T. N., Miller, J. D., and Farquhar, G. D.: The mathematics of linked optimisation for water and nitrogen use in a canopy, Silva Fenn., 36, 639-669, 2002.

Cawson, J., Sheridan, G., Smith, H., and Lane, P.: Surface runoff and erosion after prescribed burning and the effect of different fire regimes in forests and shrublands: a review, Int. J. Wildland Fire, 21, 857-872, 2012.

Cernusak, L. A., Hutley, L. B., Beringer, J., Holtum, J. A., and Turner, B. L.: Photosynthetic physiology of eucalypts along a sub-continental rainfall gradient in northern Australia, Agr. Forest Meteorol., 151, 1462-1470, 2011.

Clegg, B. and O'Connor, T.: The vegetation of Malilangwe Wildlife Reserve, south-eastern Zimbabwe, Afr. J. Range For. Sci., 29, 109-131, 2012.

Cleveland, C. C., Townsend, A. R., Taylor, P., Alvarez-Clare, S., Bustamante, M. M. C., Chuyong, G., Dobrowski, S. Z., Grierson, P., Harms, K. E., Houlton, B. Z., Marklein, A., Parton, W., Porder, S., Reed, S. C., Sierra, C. A., Silver, W. L., Tanner, E. V. J., and Wieder, W. R.: Relationships among net primary productivity, nutrients and climate in tropical rain forest: a pantropical analysis, Ecol. Lett., 14, 939-947, doi:10.1111/j.14610248.2011.01658.x, 2011.

Cochrane, T. T.: Chemical properties of native savanna and forest soils in central Brazil, Soil Sci. Soc. Am. J., 53, 139-141, 1989.

Cochrane, T. T. and Cochrane, T. A.: Amazon Forest and Savanna lands: A Guide to the Climates, Vegetation, Landscapes and Soils of Central Tropical South America, CreateSpace, 188 pp., 2010.

Coetzee, B., Meulen, F., Zwanziger, S., Gonsalves, P., and Weisser, P.: A phytosociological classification of the Nylsvley Nature Reserve, Bothalia, 12, 137-160, 1976.

Cole, M. M.: Cerrado, Caatinga and Pantanal: the distribution and origin of the savanna vegetation of Brazil, Geogr. J., 126, 168$179,1960$.

Cole, M. M.: The Savannas, Biogeography and Geobotany, Academic Press, 438 pp., 1986.

Collins, D. B. G. and Bras, R. L.: Plant rooting strategies in water-limited ecosystems, Water Resour. Res., 43, W06407, doi:10.1029/2006WR005541, 2007.

Comins, H. and McMurtrie, R.: Long-term response of nutrientlimited forests to $\mathrm{CO}_{2}$ enrichment; equilibrium behavior of plantsoil models, B. Ecol. Soc. Am., 3, 666-681, 1993.

Cook, G.: The fate of nutrients during fires in a tropical savanna, Aust. J. Ecol., 19, 359-365, 1994.

Coughenour, M. B. and Ellis, J. E.: Landscape and climatic control of woody vegetation in a dry tropical ecosystem: Turkana District, Kenya, J. Biogeogr., 20, 383-398, 1993.

Cronje, H. P., Panagos, M. D., and Reilly, B. K.: The plant communities of the Andover Game Reserve, South Africa: original research, Koedoe: African Protected Area Conservation and Science, 50, 184-201, 2008.

Daly, D. C. and Mitchell, J. D.: Lowland vegetation of tropical South America - an overview, in: Imperfect Balance Landscape Transformations in the Pre-Columbian Americas, edited by: Lentz, D., Columbia University Press, New York, 391-454, 2000.

Dantas, V. D. L., Batalha, M. A., França, H., and Pausas, J. G.: Resource availability shapes fire-filtered savannas, J. Veg. Sci., 26, 395-403, doi:10.1111/jvs.12247, 2015.

de Assis, A., Coelho, R., da Silva Pinheiro, E., and Durigan, G.: Water availability determines physiognomic gradient in an area of low-fertility soils under Cerrado vegetation, Plant Ecol., 212, 1135-1147, doi:10.1007/s11258-010-9893-8, 2011.

DeBano, L. F.: The role of fire and soil heating on water repellency in wildland environments: a review, J. Hydrol., 231, 195-206, 2000.

de Gannes, V., Eudoxie, G., and Hickey, W. J.: Impacts of edaphic factors on communities of ammonia-oxidizing archaea, ammonia-oxidizing bacteria and nitrification in tropical soils, Plos One, 9 (2), e89568, doi:10.1371/journal.pone.0089568, 2014.

de Moraes, J. M., Schuler, A. E., Dunne, T., Figueiredo, R. D. O., and Victoria, R. L.: Water storage and runoff processes in plinthic soils under forest and pasture in eastern Amazonia, Hydrol. Process., 20, 2509-2526, doi:10.1002/hyp.6213, 2006.

Dent, D. and Young, A.: Soil Survey and Land Evaluation, George Allen \& Unwin., 278 pp., 1981.

Diouf, A., Barbier, N., Lykke, A. M., Couteron, P., Deblauwe, V., Mahamane, A., Saadou, M., and Bogaert, J.: Relationships between fire history, edaphic factors and woody vegetation structure and composition in a semi-arid savanna landscape (Niger, West Africa), Appl. Veg. Sci., 15, 488-500, doi:10.1111/j.1654109X.2012.01187.x, 2012.

Domingues, T. F., Berry, J. A., Martinelli, L. A., Ometto, J. P. H. B., and Ehleringer, J. R.: Parameterization of canopy structure and leaf-level gas exchange for an Amazonian tropical rain forest (Tapajós National Forest, Pará, Brazil), Earth Interact., 9, 1-23, doi:10.1175/EI149.1, 2005.

Domingues, T. F., Meir, P., Feldpausch, T. R., Saiz, G., Veenendaal, E. M., Schrodt, F., Bird, M., Djagbletey, G., Hien, F., Compaore, H., Diallo, A., Grace, J., and Lloyd, J.: Co-limitation of photosynthetic capacity by nitrogen and phosphorus in West Africa woodlands, Plant Cell Environ., 33, 959-980, doi:10.1111/j.1365-3040.2010.02119.x, 2010.

Domingues, T. F., Ishida, F. Y., Feldpausch, T. R., Grace, J., Meir, P., Saiz, G., Sene, O., Schrodt, F., Sonké, B., Taedoumg, H., Veenendaal, E. M., Lewis, S. L., and Lloyd, J.: Biome-specific effects of nitrogen and phosphorus on the photosynthetic characteristics of trees at a forest-savanna boundary in Cameroon, Oecologia, 178, 659-672, doi:10.1007/s00442-015-3250-5, 2015.

Doughty, C. E., Malhi, Y., Araujo-Murakami, A., Metcalfe, D. B., Silva-Espejo, J. E., Arroyo, L., Heredia, J. P., Pardo-Toledo, E., Mendizabal, L. M., and Rojas-Landivar, V. D.: Allocation tradeoffs dominate the response of tropical forest growth to seasonal and interannual drought, Ecology, 95, 2192-2201, 2014.

Dowling, A. J., Webb, A. A., and Scanlan, J. C.: Surface soil chemical and physical patterns in a Brigalow-Dawson gum forest, Central Queensland, Aust. J. Ecol., 11, 155-162, doi:10.1111/j.14429993.1986.tb01386.x, 1986.

Dunin, F. and Aston, A.: The development and proving of models of large scale evapotranspiration: an Australian study, Agr. Water Manage., 8, 305-323, 1984. 
Durigan, G. and Ratter, J. A.: Successional changes in cerrado and cerrado/forest ecotonal vegetation in Western São Paulo State, Brazil, 1962-2000, Edin. J. Bot., 63, 119-130, doi:10.1017/S0960428606000357, 2006.

Dye, P. and Walker, B.: Vegetation-environment relations on sodic soils of Zimbabwe Rhodesia, J. Ecol., 68, 589-606, 1980.

Egilla, J. N., Davies, F. T. J., and Drew, M. C.: Effect of potassium on drought resistance of Hibiscus rosa-sinensis cv. Leprechaun: plant growth, leaf macro- and micronutrient content and root longevity, Plant Soil, 229, 213-224, doi:10.1023/A:1004883032383, 2001.

Egilla, J. N., Davies, F. T. J., and Boutton, T. W.: Drought stress influences leaf water content, photosynthesis, and water-use efficiency of Hibiscus rosa-sinensis at three potassium concentrations, Photosynthetica, 43, 135-140, doi:10.1007/s11099-0055140-2, 2005.

Eiten, G.: Delimitation of the cerrado concept, Plant Ecol., 36, 169178, doi:10.1007/bf02342599, 1978.

El-Mesbahi, M. N., Azcon, R., Ruiz-Lozano, J. M., and Aroca, R.: Plant potassium content modifies the effects of arbuscular mycorrhizal symbiosis on root hydraulic properties in maize plants, Mycorrhiza, 22, 555-564, doi:10.1007/s00572012-0433-3, 2012.

Farquhar, G. D., Ehleringer, J. R., and Hubick, K. T.: Carbon isotope discrimination and photosynthesis, Annu. Rev. Plant Phys., 40, 503-537, 1989.

Farquhar, G. D., Buckley, T. N., and Miller, J. M.: Optimal stomatal control in relation to leaf area and nitrogen content, Silva Fenn., 36, 625-637, 2002.

Favier, C., Aleman, J., Bremond, L., Dubois, M. A., Freycon, V., and Yangakola, J.-M.: Abrupt shifts in African savanna tree cover along a climatic gradient, Global Ecol. Biogeogr., 21, 787-797, doi:10.1111/j.1466-8238.2011.00725.x, 2012.

Feldpausch, T. R., Banin, L., Phillips, O. L., Baker, T. R., Lewis, S. L., Quesada, C. A., Affum-Baffoe, K., Arets, E. J. M. M., Berry, N. J., Bird, M., Brondizio, E. S., de Camargo, P., Chave, J., Djagbletey, G., Domingues, T. F., Drescher, M., Fearnside, P. M., França, M. B., Fyllas, N. M., Lopez-Gonzalez, G., Hladik, A., Higuchi, N., Hunter, M. O., Iida, Y., Salim, K. A., Kassim, A. R., Keller, M., Kemp, J., King, D. A., Lovett, J. C., Marimon, B. S., Marimon-Junior, B. H., Lenza, E., Marshall, A. R., Metcalfe, D. J., Mitchard, E. T. A., Moran, E. F., Nelson, B. W., Nilus, R., Nogueira, E. M., Palace, M., Patiño, S., Peh, K. S.H., Raventos, M. T., Reitsma, J. M., Saiz, G., Schrodt, F., Sonké, B., Taedoumg, H. E., Tan, S., White, L., Wöll, H., and Lloyd, J.: Height-diameter allometry of tropical forest trees, Biogeosciences, 8, 1081-1106, doi:10.5194/bg-8-1081-2011, 2011.

Feng, X., Vico, G., and Porporato, A.: On the effects of seasonality on soil water balance and plant growth, Water Resour. Res., 48, W05543, doi:10.1029/2011WR011263, 2012.

Fraser, S., Van Rooyen, T., and Verster, E.: Soil-plant relationships in the central Kruger National Park, Koedoe, 30, 19-34, 1987.

Fromm, J.: Wood formation of trees in relation to potassium and calcium nutrition, Tree Physiol., 30, 1140-1147, doi:10.1093/treephys/tpq024, 2010.

Funk, J. L., Glenwinkel, L. A., and Sack, L.: Differential allocation to photosynthetic and non-photosynthetic nitrogen fractions among native and invasive species, PloS one, 8, e64502, doi:10.1371/journal.pone.0064502, 2013
Furley, P. A. and Ratter, J. A.: Soil resources and plant communities of the central Brazilian cerrado and their development, J. Biogeogr., 15, 97-108, 1988.

Fyllas, N. M., Patiño, S., Baker, T. R., Bielefeld Nardoto, G., Martinelli, L. A., Quesada, C. A., Paiva, R., Schwarz, M., Horna, V., Mercado, L. M., Santos, A., Arroyo, L., Jiménez, E. M., Luizão, F. J., Neill, D. A., Silva, N., Prieto, A., Rudas, A., Silviera, M., Vieira, I. C. G., Lopez-Gonzalez, G., Malhi, Y., Phillips, O. L., and Lloyd, J.: Basin-wide variations in foliar properties of Amazonian forest: phylogeny, soils and climate, Biogeosciences, 6 , 2677-2708, doi:10.5194/bg-6-2677-2009, 2009.

Fyllas, N. M., Quesada, C. A., and Lloyd, J.: Deriving plant functional types for Amazonian forests for use in vegetation dynamics models, Perspect. Plant Ecol., 14, 97-110, doi:10.1016/j.ppees.2011.11.001, 2012.

Fyllas, N. M., Gloor, E., Mercado, L. M., Sitch, S., Quesada, C. A., Domingues, T. F., Galbraith, D. R., Torre-Lezama, A., Vilanova, E., Ramírez-Angulo, H., Higuchi, N., Neill, D. A., Silveira, M., Ferreira, L., Aymard C., G. A., Malhi, Y., Phillips, O. L., and Lloyd, J.: Analysing Amazonian forest productivity using a new individual and trait-based model (TFS v.1), Geosci. Model Dev., 7, 1251-1269, doi:10.5194/gmd-7-1251-2014, 2014.

Gandiwa, E., Zisadza-Gandiwa, P., Goza, D., Mashapa, C., and Muboko, N.: Diversity and structure of woody vegetation across areas with different soils in Gonarezhou National Park, Zimbabwe, South. Forests, 76, 111-116, doi:10.2989/20702620.2014.921007, 2014.

Gee, G. W. and Bauder, J. W.: Particle-size analysis, in: Methods in Soil Analysis, Part 1, Physical and Mineralogical Methods, edited by: Klute, A., American Society of Agronomy and Soil Science Society of America, Madison, Wisconsin, USA, 383409, 1986.

Givan, C. V.: Metabolic detoxification of ammonia in tissues of higher plants, Phytochemistry, 18, 375-382, 1979.

Good, S. P. and Caylor, K. K.: Climatological determinants of woody cover in Africa, P. Natl. Acad. Sci. USA, 108, 4902-4907, doi:10.1073/pnas.1013100108, 2011.

Goodland, R. and Pollard, R.: The Brazilian cerrado vegetation: a fertility gradient, J. Ecol., 61, 219-224, 1973.

Grace, J., Lloyd, J., Miranda, A. C., Miranda, H., and Gash, J. H. C.: Fluxes of carbon dioxide and water vapour over a $\mathrm{C} 4$ pasture in southwestern Amazonia (Brazil), Aust. J. Plant Physiol., 25, 519-530, 1998.

Grace, J. B. and Bollen, K. A.: Interpreting the results from multiple regression and structural equation models, Bull. Ecol. Soc. Am., 86, 283-295, 2005.

Grigal, D. F.: A soil-based aspen productivity index for Minnesota, Forest Ecol. Manag., 257, 1465-1473, doi:10.1016/j.foreco.2008.12.022, 2009.

Guswa, A. J.: The influence of climate on root depth: a carbon cost-benefit analysis, Water Resour. Res., 44, W02427, doi:10.1029/2007WR006384, 2008.

Guswa, A. J.: Effect of plant uptake strategy on the water - optimal root depth, Water Resour. Res., 46, 1-5, 2010.

Guy, P. R.: Notes on the vegetation types of the Zambezi Valley, Rhodesia, between the Kariba and Mpata gorges, Kirkia, 10, 543-557, 1977. 
Guy, P. R.: Changes in the biomass and productivity of woodlands in the Sengwa Wildlife Research Area, Zimbabwe, J. Appl. Ecol., 18, 507-519, doi:10.2307/2402412, 1981.

Haase, R. and Beck, G.: Structure and composition of savanna vegetation in northern Bolivia: a preliminary report, Brittonia, 41, 80-100, doi:10.2307/2807594, 1989.

Hafsi, C., Debez, A., and Abdelly, C.: Potassium deficiency in plants: effects and signaling cascades, Acta Physiol. Plant, 36, 1055-1070, doi:10.1007/s11738-014-1491-2, 2014.

Halliwell, B.: Chloroplast Metabolism, The Structure and Function of Chloroplasts in Green Leaf Cells, Clarendon Press, Oxford,257 pp., 1981.

Hanan, N. P., Tredennick, A. T., Prihodko, L., Bucini, G., and Dohn, J.: Analysis of stable states in global savannas: is the CART pulling the horse?, Global Ecol. Biogeogr., 23, 259-263, 2013.

Hänsch, R. and Mendel, R. R.: Physiological functions of mineral micronutrients $(\mathrm{Cu}, \mathrm{Zn}, \mathrm{Mn}, \mathrm{Fe}, \mathrm{Ni}, \mathrm{Mo}, \mathrm{B}, \mathrm{Cl})$, Curr. Opin. Plant Biol., 12, 259-266, 2009.

Hart, C.: Relative humidity, EMC, and collapse shrinkage in wood, Forest Prod. J., 32, 45-54, 1984.

Hedley, M. J., Stewart, J. W. B., and Chauhan, B. S.: Changes in inorganic and organic soil phosphorus fractions induced by cultivation practices and by laboratory incubations, Soil Sci. Soc. Am. J., 46, 970-976, 1982.

Hietz, P., Horsky, M., Prohaska, T., Lang, I., and Grabner, M.: Highresolution densitometry and elemental analysis of tropical wood, Trees, 1-11, 2014.

Hijmans, R. J., Cameron, S. E., Parra, J. L., Jones, P. G., and Jarvis, A.: Very high resolution interpolated climate surfaces for global land areas, Int. J. Climatol., 25, 1965-1978, doi:10.1002/joc.1276, 2005.

Hirota, M., Holmgren, M., Van Nes, E. H., and Scheffer, M.: Global resilience of tropical forest and savanna to critical transitions, Science, 334, 232-235, doi:10.1126/science.1210657, 2011.

Hodnett, M. G. and Tomasella, J.: Marked differences between van Genuchten soil water-retention parameters for temperate and tropical soils a new water-retention pedo-transfer functions developed for tropical soils, Geoderma, 108, 155-180, doi:10.1016/S0016-7061(02)00105-2, 2002.

Hoffmann, W. A., Franco, A. C., Moreira, M. Z., and Haridasan, M.: Specific leaf area explains differences in leaf traits between congeneric savanna and forest trees, Funct. Ecol., 19, 932-940, 2005.

Hoffmann, W. A., Geiger, E. L., Gotsch, S. G., Rossatto, D. R., Silva, L. C., Lau, O. L., Haridasan, M., and Franco, A. C.: Ecological thresholds at the savanna-forest boundary: how plant traits, resources and fire govern the distribution of tropical biomes, Ecol. Lett., 15, 759-768, 2012.

Hollander, M. and Wolfe, D. A.: Nonparametric Statistical Methods, J. Wiley \& Sons, New York, 816 pp., 1999.

Kenzo, T., Ichie, T., Watanabe, Y., Yoneda, R., Nonomiya, I., and Koike, T.: Changes in photosynthesis and leaf characteristics with tree height in five diperocarp species in a tropical rain forest, Tree Physiol., 26, 865-873, doi:10.1093/treephys/26.7.865, 2006.

Killeen, T. J., Jardim, A., Mamani, F., and Rojas, N.: Diversity, composition and structure of a tropical semideciduous forest in the Chiquitania region of Santa Cruz, Bolivia, J. Trop. Ecol., 14 803-827, 1998.

Killeen, T. J., Chavez, E., Peña-Claros, M., Toledo, M., Arroyo, L., Caballero, J., Correa, L., Guillén, R., Quevedo, R., and Saldias, M.: The Chiquitano dry forest, the transition between humid and dry forest in eastern lowland Bolivia, in: Neotropical Savannas and Seasonally Dry Forests: Plant Diversity, Biogeography, and Conservation, edited by: Pennington, R. T., Lewis, G. P., and Ratter, J. A., CRC Press, Boca Rato, 213-233, 2006.

Kim, Y., Knox, R. G., Longo, M., Medvigy, D., Hutyra, L. R., Pyle, E. H., Wofsy, S. C., Bras, R. L., and Moorcroft, P. R.: Seasonal carbon dynamics and water fluxes in an Amazon rainforest, Glob. Change Biol., 18, 1322-1334, doi:10.1111/j.13652486.2011.02629.x, 2012.

Kloke, J.D., and Mckean, J.W.: Rfit: Rank-based estimation for linear models, The R Journal, 4, 57-64, 2012.

Kronzucker, H., Coskun, D., Schulze, L., Wong, J., and Britto, D.: Sodium as nutrient and toxicant, Plant Soil, 369, 1-23, doi:10.1007/s11104-013-1801-2, 2013.

Kugbe, J., Fosu, M., and Vlek, P. G.: Impact of season, fuel load and vegetation cover on fire mediated nutrient losses across savanna agro-ecosystems: the case of northern Ghana, Nutr. Cycl. Agroecosys., doi:10.1007/s10705-014-9635-8, 2014.

Le Roux, C., Grunow, J., Morris, J., Bredenkamp, G., and Scheepers, J.: Classification of the vegetation of the Etosha National Park, S. Afr. J. Bot., 54, 1-10, 1988.

Lebaudy, A., Vavasseur, A., Hosy, E., Dreyer, D., Leonhardt, N., Thibaud, J. B., Véry, A.-A., Simonneau, T., and Hervé, S.: Plant adaptation to fluctuating environment and biomass production are strongly dependent on guard cell potassium channels, P. Natl. Acad. Sci. USA, 105, 5271-5276, doi:10.1073/pnas.0709732105, 2008.

Lehmann, C. E. R., Archibald, S. A., Hoffmann, W. A., and Bond, W. J.: Deciphering the distribution of the savanna biome, New Phytol., 191, 197-209, doi:10.1111/j.14698137.2011.03689.x, 2011.

Lehmann, C. E. R., Anderson, T. M., Sankaran, M., Higgins, S. I., Archibald, S., Hoffmann, W. A., Hanan, N. P., Williams, R. J., Fensham, R. J., Felfili, J.,Hutley, L. B., Ratnam, J., San Jose, J., Montes, R., Franklin, D., Russell-Smith, J., Ryan, C. M., Durigan, G., Hiernaux, P., Haidar, R., Bowman, D. M. J. S., and Bond, W. J.: Savanna vegetation-fire-climate relationships differ among continents, Science, 343, 548-552, 2014.

Leigh, R. A. and Wyn Jones, R. G.: A hypothesis relating critical potassium concentrations for growth to the distribution and function of this ion in the plant cell, New Phytol., 97, 1-13, doi:10.1111/j.1469-8137.1984.tb04103.x, 1984.

Lloyd, J. and Farquhar, G. D.: ${ }^{13} \mathrm{C}$ discrimination during $\mathrm{CO}_{2}$ assimilation by the terrestrial biosphere, Oecologia, 99, 201-215, doi:10.1007/bf00627732, 1994.

Lloyd, J., Bird, M. I., Vellen, L., Miranda, A. C., Veenendaal, E. M., Djagbletey, G., Miranda, H. S., Cook, G., and Farquhar, G. D.: Contributions of woody and herbaceous vegetation to tropical savanna ecosystem productivity: a quasi-global estimate, Tree Physiol., 28, 451-468, doi:10.1093/treephys/28.3.451, 2008.

Lloyd, J., Goulden, M., Ometto, J. P., Fyllas, N. M., Quesada, C. A., and Patino, S.: Ecophysiology of forest and savanna vegetation, in: Amazonia and Climate Change, edited by: Keller, M., 
Gash, J. and Silva Dias, P., American Geophysical Union, Washington D.C., 463-484, 2009.

Lloyd, J., Patiño, S., Paiva, R. Q., Nardoto, G. B., Quesada, C. A., Santos, A. J. B., Baker, T. R., Brand, W. A., Hilke, I., Gielmann, H., Raessler, M., Luizão, F. J., Martinelli, L. A., and Mercado, L. M.: Optimisation of photosynthetic carbon gain and within-canopy gradients of associated foliar traits for Amazon forest trees, Biogeosciences, 7, 1833-1859, doi:10.5194/bg-71833-2010, 2010.

Lopes, A. and Cox, F.: Cerrado vegetation in Brazil: an edaphic gradient, Agron. J., 69, 828-831, 1977.

Lopez-Gonzalez, G., Lewis, S. L., Burkitt, M., and Phillips, O. L.: ForestPlots net: a web application and research tool to manage and analyse tropical forest plot data, J. Veg. Sci., 22, 610-613, 2011.

Maathuis, F. J. M.: Physiological functions of mineral macronutrients, Curr. Opin. Plant Biol., 12, 250-258, doi:10.1016/j.pbi.2009.04.003, 2009.

Male, P. S.: Site index studies of established exotic species for the Granite Belt, Research Paper no. 11., Department of Forestry, Queensland, Australia, 36 pp., 1981.

Mantlana, K. B., Arneth, A., Veenendaal, E. M., Wohland, P., Wolski, P., Kolle, O., Wagner, M., and Lloyd, J.: Photosynthetic properties of $\mathrm{C}_{4}$ plants growing in an African savanna/wetland mosaic, J. Exp. Bot., 59, 3941-3952, doi:10.1093/jxb/ern237, 2008.

Mapaure, I.: The distribution of Colophospermum mopane (Leguminosae: Caesalpinioideae) in Africa, Kirkia, 15, 1-5, 1994.

Marimon, B. S., Lima, E. de S. , Duarte, T., Chieregatto, L., and Ratter, J. A.: Observations on the vegetation of northeastern Mato Grosso, Brazil. IV. An analysis of the Cerrado-Amazonian Forest ecotone, Edin. J. Bot., 63, 323-341, 2006.

Marques, J. J., Schulze, D. G., Curi, N., and Mertzman, S. A.: Trace element geochemistry in Brazilian Cerrado soils, Geoderma, 121, 31-43, 2004.

McKean, J. W., Terpstra, J. T., and Kloke, J. D.: Computational rank-based statistics, Wiley Interdisciplinary Reviews: Computational Statistics, 1, 132-140, doi:10.1002/wics.29, 2009.

Milewski, A. V. and Mills, A. J.: Does life consistently maximise energy intensity?, Biol. Rev., 85, 859-879, 2010.

Mengel, K. and Arneke, W.-W.: Effect of potassium on the water potential, the pressure potential, the osmotic potential and cell elongation in leaves of Phaseolus vulgaris, Physiol. Plantarum, 54, 402-408, 1982.

Mengel, K., Viro, M., and Hehl, G.: Effect of potassium on uptake and incorporation of ammonium-nitrogen of rice plants, Plant Soil, 44, 547-558, 1976.

Mercado, L. M., Patiño, S., Domingues, T. F., Fyllas, N. M., Weedon, G. P., Sitch, S., Quesada, C. A., Phillips, O. L., Aragão, L. E. O. C., Malhi, Y., Dolman, A. J., RestrepoCoupe, N., Saleska, S. R., Baker, T. R., Almeida, S., Higuchi, N., and Lloyd, J.: Variations in Amazon forest productivity correlated with foliar nutrients and modelled rates of photosynthetic carbon supply, Philos. T. R. Soc. B, 366, 3316-3329, doi:10.1098/rstb.2011.0045, 2011.

Mews, H., Marimon, B. S., and Ratter, J. A.: Observations on the vegetation of Mato Grosso, Brazil. V. Changes in the woody species diversity of a forest in the Cerrado-Amazonian forest transition zone and notes on the forests of the region, Edin. J. Bot., 69, 239-253, 2012.
Miller, J. M., Williams, R. J., and Farquhar, G. D.: Carbon isotope discrimination by a sequence of Eucalyptus species along a subcontinental rainfall gradient in Australia, Funct. Ecol., 15, 222 232, doi:10.1046/j.1365-2435.2001.00508.x, 2001.

Mills, A. J. , and Fey, M.: Frequent fires intensify soil crusting: physicochemical feedback in the pedoderm of long-term burn experiments in South Africa, Geoderma, 121, 45-64, 2004.

Mills, A. J., Rogers, K. H., Stalmans, M., and Witkowski, E. T. F.: A framework for exploring the determinants of savanna and grassland distribution, Bioscience, 56, 579-589, 2006.

Mills, A. J., Milewski, A. V., Fey, M. V., Gröngröft, A., Petersen, A., and Sirami, C.: Constraint on woody cover in relation to nutrient content of soils in western southern Africa, Oikos, 122, 136-148, doi:10.1111/j.1600-0706.2012.20417.x, 2013.

Miranda, A. C., Miranda, H. S., Lloyd, J., Grace, J., Francey, R. J., McIntyre, J. A., Meir, P., Riggan, P., Lockwood, R., and Brass, J.: Fluxes of carbon, water and energy over Brazilian cerrado: an analysis using eddy covariance and stable isotopes, Plant Cell Environ., 20, 315-328, doi:10.1046/j.1365-3040.1997.d01-80.x, 1997.

Mlambo, D.: Influence of soil fertility on the physiognomy of the African savanna tree Colophospermum mopane, Afr. J. Ecol., 45, 109-111, doi:10.1111/j.1365-2028.2006.00676.x, 2007.

Moene, A. F. and van Dam, J. C.: Transport in the AtmosphereVegetation-Soil Continuum, Cambridge University Press, New York, 436 pp., 2014.

Mokany, K., Raison, R. J., and Prokushkin, A. S.: Critical analysis of root: shoot ratios in terrestrial biomes, Glob. Change Biol., 12, 84-96, doi:10.1111/j.1365-2486.2005.001043.x, 2006.

Morel-Seytoux, H. J., Meyer, P. D., Nachabe, M., Tourna, J., van Genuchten, M. T., and Lenhard, R. J.: Parameter equivalence for the Brooks-Corey and Van Genuchten soil characteristics: preserving the effective capillary drive, Water Resour. Res., 32, 1251-1258, doi:10.1029/96WR00069, 1996.

Mualem, Y.: A new model for predicting the hydraulic conductivity of unsaturated porous media, Water Resour. Res., 12, 513-522, 1976.

Murdoch, G., Ojo Atere, J., Colborne, G., Olomu, E., and Odugbesan, E.: Soils of the Western State savanna in Nigeria, Vol. 1, The Environment, Land Resource Study (UK), no. 23., 1976.

Murphy, B. P. and Bowman, D. M.: What controls the distribution of tropical forest and savanna?, Ecol. Lett., 15, 748-758, 2012.

Nardoto, G. B., Quesada, C. A., Patiño, S., Saiz, G., Baker, T. R., Schwarz, M., Schrodt, F., Feldpausch, T. R., Domingues, T. F., Marimon, B. S., Marimon Junior, B.-H., Vieira, I. C. G., Silveira, M., Bird, M. I., Phillips, O. L., Lloyd, J., and Martinelli, L. A.: Basin-wide variations in Amazon forest nitrogen-cycling characteristics as inferred from Plant Soil ${ }^{15} \mathrm{~N}:{ }^{14} \mathrm{~N}$ measurements, Plant Ecol. Divers., 7, 173-187, doi:10.1080/17550874.2013.807524, 2013.

Nelson, D. W. and Sommers, L. E.: Total carbon and total nitrogen, in: Methods of Soil Analysis: Part 3 - Chemical Methods, edited by: Sparks, D. L., SSSA Book Series No 5, American Society of Agronomy/Soil Science Society of America, Madison, WI, 9611010, 1996.

Norman, J. S. and Barrett, J. E.: Substrate and nutrient limitation of ammonia-oxidizing bacteria and archaea in temperate forest soil, Soil Biol. Biochem., 69, 141-146, doi:10.1016/j.soilbio.2013.11.003, 2014. 
Nyamapfene, K.: A note on some Zimbabwean soil-vegetation relationships of important indicator value in soil survey, Kirkia, 13, 239-242, 1988.

O'Connor, T.: Woody vegetation-environment relations in a semiarid savanna in the northern Transvaal, S. Afr. J. Bot., 58, 268274, 1992

Oliveira-Filho, A. T. and Ratter, J. A.: Vegetation physiognomies and woody flora of the cerrado biome, in: The Cerrados of Brazil. Ecology and Natural History of a Neotropical Savanna, Columbia University Press, 91-120, 2002.

Oliveras, I., Meirelles, S. T., Hirakuri, V. L., Freitas, C. R., Miranda, H. S., and Pivello, V. R.: Effects of fire regimes on herbaceous biomass and nutrient dynamics in the Brazilian savanna, Int. J. Wildland Fire, 22, 368-380, doi:10.1071/WF10136, 2013.

Olsen, S. R. and Sommers, E. L.: Phosphorus soluble in sodium bicarbonate, in: Methods of Soil Analysis, Part 2, Chemical and Microbiological Properties, edited by: Page, A. L., Miller, RH. H., and Keeney, D. R., American Society of Agronomy, Soil Science Society of America, Madison, WIS, 404-430, 1982.

Osakabe, Y., Arinaga, N., Umezawa, T., Katsura, S., Nagamachi, K., Tanaka, H., Ohiraki, H., Yamada, K., Seo, S.U., Abo, M., Yoshimura, E., Shinozaki, K., and YamaguchiShinozaki, K.: Osmotic stress responses and plant growth controlled by potassium transporters in arabidopsis, Plant Cell Online, 25, 609-624, doi:10.1105/tpc.112.105700, 2013.

Ostle, N. J., Smith, P., Fisher, R., Ian Woodward, F., Fisher, J. B., Smith, J. U., Galbraith, D., Levy, P., Meir, P., McNamara, N. P., and Bardgett, R. D.: Integrating plant-soil interactions into global carbon cycle models, J. Ecol., 97, 851-863, doi:10.1111/j.1365-2745.2009.01547.x, 2009.

Pavlick, R., Drewry, D. T., Bohn, K., Reu, B., and Kleidon, A.: The Jena Diversity-Dynamic Global Vegetation Model (JeDiDGVM): a diverse approach to representing terrestrial biogeography and biogeochemistry based on plant functional trade-offs, Biogeosciences, 10, 4137-4177, doi:10.5194/bg-10-4137-2013, 2013

Pella, E.: Elemental organic analysis, Part 2, State of the art, Am. Lab., 22, 28-32, 1990.

Pennington, R. T., Lewis, G. P., and Ratter, J. A.: An overview of the plant diversity, biogeography and conservation of neotropical savannas and seasonally dry forests, in: Neotropical Savannas and Seasonally Dry Forests: Plant Biodiversity, Biogeography and Conservation, 1-29, 2006.

Pineda-Garcia, F., Paz, H., and Meinzer, F. C.: Drought resistance in early and late secondary successional species from a tropical dry forest: the interplay between xylem resistance to embolism, sapwood water storage and leaf shedding, Plant Cell Environ., 36, 405-418, 2013.

Pleysier, J. L. and Juo, A. S. R.: A single-extraction method using silver-thiourea for measuring exchangeable cations and effective CEC in soils with variable charges, Soil Sci., 129, 205-211, 1980.

Poorter, H. and de Jong, R.: A comparison of specific leaf area, chemical composition and leaf construction costs of field plants from 15 habitats differing in productivity, New Phytol., 143, 163-176, doi:10.1046/j.1469-8137.1999.00428.x, 1999.

Poorter, H., Niinemets, U., Poorter, L., Wright, I. J., and Villar, R.: Causes and consequences of variation in leaf mass per area (LMA): a meta-analysis, New Phytol., 182, 565-588, doi:10.1111/j.1469-8137.2009.02830.x, 2009.

Prado, D. E. and Gibbs, P. E.: Patterns of species distributions in the dry seasonal forests of South America, Ann. Mo. Bot. Gard., 80, 902-927, 1993.

Priess, J., Then, C., and Fölster, H.: Litter and fine-root production in three types of tropical premontane rain forest in SE Venezuela, Plant Ecol., 143, 171-187, 1999.

Quesada, C. A. and Lloyd, J.: Soil-vegetation interactions in Amazonia, in: The Large-scale Biosphere-Atmosphere Programme in Amazonia, edited by: Nagy, L., Forsberg, B., and Artaxo, P., Ecological Studies, Springer-Verlag, in press, 2015.

Quesada, C. A., Hodnett, M. G., Breyer, L. M., Santos, A. J. B., Andrade, S., Miranda, H. S., Miranda, A. C., and Lloyd, J.: Seasonal variations in soil water in two woodland savannas of central Brazil with different fire histories, Tree Physiol., 28, 405-415, doi:10.1093/treephys/28.3.405, 2008.

Quesada, C. A., Lloyd, J., Schwarz, M., Patiño, S., Baker, T. R., Czimczik, C., Fyllas, N. M., Martinelli, L., Nardoto, G. B., Schmerler, J., Santos, A. J. B., Hodnett, M. G., Herrera, R., Luizão, F. J., Arneth, A., Lloyd, G., Dezzeo, N., Hilke, I., Kuhlmann, I., Raessler, M., Brand, W. A., Geilmann, H., Moraes Filho, J. O., Carvalho, F. P., Araujo Filho, R. N., Chaves, J. E., Cruz Junior, O. F., Pimentel, T. P., and Paiva, R.: Variations in chemical and physical properties of Amazon forest soils in relation to their genesis, Biogeosciences, 7, 1515-1541, doi:10.5194/bg-7-15152010, 2010.

Quesada, C. A., Lloyd, J., Anderson, L. O., Fyllas, N. M., Schwarz, M., and Czimczik, C. I.: Soils of Amazonia with particular reference to the RAINFOR sites, Biogeosciences, 8, 1415-1440, doi:10.5194/bg-8-1415-2011, 2011.

Quesada, C. A., Phillips, O. L., Schwarz, M., Czimczik, C. I., Baker, T. R., Patiño, S., Fyllas, N. M., Hodnett, M. G., Herrera, R., Almeida, S., Alvarez Dávila, E., Arneth, A., Arroyo, L., Chao, K. J., Dezzeo, N., Erwin, T., di Fiore, A., Higuchi, N., Honorio Coronado, E., Jimenez, E. M., Killeen, T., Lezama, A. T., Lloyd, G., López-González, G., Luizão, F. J., Malhi, Y., Monteagudo, A., Neill, D. A., Núñez Vargas, P., Paiva, R., Peacock, J., Peñuela, M. C., Peña Cruz, A., Pitman, N., Priante Filho, N., Prieto, A., Ramírez, H., Rudas, A., Salomão, R., Santos, A. J. B., Schmerler, J., Silva, N., Silveira, M., Vásquez, R., Vieira, I., Terborgh, J., and Lloyd, J.: Basin-wide variations in Amazon forest structure and function are mediated by both soils and climate, Biogeosciences, 9, 2203-2246, doi:10.5194/bg-9-2203-2012, 2012.

$\mathrm{R}$ Core Team: A language and environment for statistical computing, R Foundation for Statistical Computing, Vienna, Austria, 2013.

Ratter, J. A.: Transition between cerrado and forest vegetation in Brazil, in: Nature and Dynamics of Forest-Savanna Boundaries, edited by: Furley, P. A., Proctor, J., and Ratter, J. A., Chapman and Hall, London, 417-430, 1992.

Rawls, W. J., Pachepsky, Y. A., Ritchie, J. C., Sobecki, T. M., and Bloodworth, H.: Effect of soil organic carbon on soil water retention, Geoderma, 116, 61-76, doi:10.1016/S00167061(03)00094-6, 2003.

Rieuwerts, J. S.: The mobility and bioavailability of trace metals in tropical soils: a review, Chem. Spec. Bioavailab., 19, 75-85, 2007. 
Ringrose, S., Matheson, W., Wolski, P., and Huntsman-Mapila, P.: Vegetation cover trends along the Botswana Kalahari transect, J. Arid Environ., 54, 297-317, doi:10.1006/jare.2002.1092, 2003.

Ritchie, M. W. and Hamann, J. D.: Individual-tree height, diameter-and crown-width increment equations for young Douglas-fir plantations, New Forest., 35, 173-186, 2008.

Robertson, G.: Nitrification and denitrification in humid tropical ecosystems: potential controls on nitrogen retention, in: Mineral nutrients in tropical forest and savanna ecosystems, edited by: Proctor, J. British Ecological Society Special Publication, Blackwell, 9, 55-69, 1989.

Römheld, V. and Kirkby, E. A.: Research on potassium in agriculture: needs and prospects, Plant Soil, 335, 155-180, 2010.

Rossatto, D.: Spatial patterns of species richness and phylogenetic diversity of woody plants in the neotropical savannas of Brazil, Braz. J. Bot, 37, 1-10, doi:10.1007/s40415-014-0070-5, 2014.

Rossatto, D., Hoffmann, W., de Carvalho Ramos Silva, L., Haridasan, M., Sternberg, L. L., and Franco, A.: Seasonal variation in leaf traits between congeneric savanna and forest trees in Central Brazil: implications for forest expansion into savanna, Trees, 27, 1139-1150, doi:10.1007/s00468-013-0864-2, 2013.

Russell, J., Moore, A., and Coaldrake, J.: Relationships between subtropical, semiarid forest of Acacia harpophylla (Brigalow), microrelief, and chemical properties of associated gilgai soil, Aust. J. Bot., 15, 481-498, doi:10.1071/BT9670481, 1967.

Saiz, G., Bird, M. I., Domingues, T., Schrodt, F., Schwarz, M., Feldpausch, T. R., Veenendaal, E., Djagbletey, G., Hien, F., Compaore, H., Diallo, A., and Lloyd, J.: Variation in soil carbon stocks and their determinants across a precipitation gradient in West Africa, Glob. Change Biol., 18, 1670-1683, doi:10.1111/j.1365-2486.2012.02657.x, 2012.

Sanchez, P. A.: Properties and Management of Soils in the Tropics, Wiley, New York,618 pp., 1976.

Sankaran, M., Hanan, N. P., Scholes, R. J., Ratnam, J., Augine, D. J., Cade, B. S., Gignoux, J., Higgins, S. I., Le Roux, X., Ludwig, F., Ardo, J., Banyikwa, F., Bronn, A., Bucini, G., Caylor, K. K., Coughenour, M. B., Diouf, A., Ekaya, W., Feral, C. J., Feb, E. C., Frost, P. G. H., Hiernaux, P., Hrabar, H., Metzger, K. L., Prins, H. H. T., Ringrose, S., Sea, W., Tews, J., Worden, J., and Zambatis, N.: Determinants of woody cover in African savannas, Nature, 438, 846-849, 2005.

Sankaran, M., Ratnam, J., and Hanan, N.: Woody cover in African savannas: the role of resources, fire and herbivory, Global Ecol. Biogeogr., 17, 236-245, 2008.

Santiago, L. S., Wright, S. J., Harms, K. E., Yavitt, J. B., Korine, C., Garcia, M. N., and Turner, B. L.: Tropical tree seedling growth responses to nitrogen, phosphorus and potassium addition, $\mathrm{J}$. Ecol., 100, 309-316, doi:10.1111/j.1365-2745.2011.01904.x, 2012.

Sayer, E. J., Wright, S. J., Tanner, E. V., Yavitt, J. B., Harms, K. E., Powers, J. S., Kaspari, M., Garcia, M. N., and Turner, B. L.: Variable responses of lowland tropical forest nutrient status to fertilization and litter manipulation, Ecosystems, 15, 387-400, 2012.

Scheiter, S. and Higgins, S. I.: Impacts of climate change on the vegetation of Africa: an adaptive dynamic vegetation modelling approach, Glob. Change Biol., 15, 2224-2246, doi:10.1111/j.13652486.2008.01838.x, 2009.
Schenk, H. J.: The shallowest possible water extraction profile: a null model for global root distributions, Vadose Zone J., 7, 1119-1124, doi:10.2136/vzj2007.0119, 2008.

Schenk, H. J. and Jackson, R. B.: Rooting depths, lateral root spreads and below-ground/above-ground allometries of plants in water-limited ecosystems, J. Ecol., 90, 480-494, 2002.

Schmidt, S. and Stewart, G. R.: Transport, storage and mobilization of nitrogen by trees and shrubs in the wet/dry tropics of northern Australia, Tree Physiol., 18, 403-410, doi:10.1093/treephys/18.6.403, 1998.

Schmimper, A. F. W.: Plant-geography upon a Physiological Basis, Clarendon Press, Oxford, 839 pp., 1903.

Scholtz, R., Kiker, G. A., Smit, I. P. J., and Venter, F. J.: Identifying drivers that influence the spatial distribution of woody vegetation in Kruger National Park, South Africa, Ecosphere, 5, art71, doi:10.1890/ES14-00034.1, 2014.

Schrodt, F., Domingues, T. F., Feldpausch, T., Saiz, G., Quesada, C. A., Schwarz, M., Ishida, F. Y., Compaore, H., Diallo, A., Djagbletey, G., Hien, F., Hiernaux, P., Mougin, E., Sonké, B., Zapfack, L., Bird, M. I., Lewis, S. L., Meir, P., Phillips, O. L., Grace, J., Veenendaal, E., and Lloyd, J.: Foliar trait contrasts between African forest and savanna trees: genetic versus environmental effects, Funct. Plant Biol., 42, 63-83, doi:10.1071/FP14040, 2014.

Schulze, E.-D., Williams, R. J., Farquhar, G. D., Schulze, W., Langridge, J., Miller, J. M., and Walker, B. H.: Carbon and nitrogen isotope discrimination and nitrogen nutrition of trees along a rainfall gradient in northern Australia, Funct. Plant Biol., 25, 413-425, doi:10.1071/PP97113, 1998.

Shabala, S. and Pottosin, I.: Regulation of potassium transport in plants under hostile conditions: implications for abiotic and biotic stress tolerance, Physiol. Plantarum, 151, 257-279, doi:10.1111/ppl.12165, 2014.

Shukla, M. K.: Soil Physics: an Introduction, 458 pp., CRC Press, 2013.

Silva, J., Fariñas, M., Felfili, J., and Klink, C.: Spatial heterogeneity, land use and conservation in the cerrado region of Brazil, J. Biogeogr., 33, 536-548, 2006.

Silva, L. C., Hoffmann, W. A., Rossatto, D. R., Haridasan, M., Franco, A. C., and Horwath, W. R.: Can savannas become forests? A coupled analysis of nutrient stocks and fire thresholds in central Brazil, Plant Soil, 373, 1-14, 2013.

Skarpe, C.: Plant community structure in relation to grazing and environmental changes along a north-south transect in the western Kalahari, Vegetatio, 68, 3-18, 1986.

Smith, J.: Distribution of tree species in the Sudan in relation to rainfall and soil texture, Suan. Min. Agr. Bull. 4, Agricultural Publications Committee, Khartoum, 1951.

Spicer, R.: Symplasmic networks in secondary vascular tissues: parenchyma distribution and activity supporting long-distance transport, J. Exp. Bot., 65, 1829-1848, doi:10.1093/jxb/ert459, 2014.

Stamp, N.: Out of the quagmire of plant defense hypotheses, Q. Rev. Biol., 78, 23-55, 2003.

Staver, A. C., Archibald, S., and Levin, S. A.: The global extent and determinants of savanna and forest as alternative biome states, Science, 334, 230-232, doi:10.1126/science.1210465, 2011. 
Steininger, M. K., Tabor, K., Small, J., Pinto, C., Soliz, J., and Chavez, E.: A satellite model of forest flammability, Environ. Manage., 52, 136-150, 2013.

Stewart, G. R., Hegarty, E. E., and Specht, R. L.: Inorganic nitrogen assimilation in plants of Austrlian rainforest communities, Physiol. Plantarum, 74, 26-33, doi:10.1111/j.13993054.1988.tb04936.x, 1988.

Thomas, M. F.: Tropical Geomorphology: a Study of Weathering and Landform Development in Warm Climates, Focal Problems in Geography Series, The McMillan Press, London, 331 pp., 1974.

Thompson, J., Viana, J., Proctor, J., and Ratter, J. A.: Contrasting forest-savanna boundaries on Maraca Island, Roraima, Brazil, in: Nature and Dynamics of Forest-Savanna Boundaries, edited by: Furley, P., Proctor, J., and Ratter, J. A., Chapman and Hall, London, 367-391, 1992.

Tomasella, J. and Hodnett, M. G.: Estimating unsaturated hydraulic conductivity of Brazilian soils using soil-water retention data, Soil Sci., 162, 703-712, 1997.

Torello-Raventos, M., Feldpausch, T. R., Veenendaal, E., Schrodt, F., Saiz, G., Domingues, T. F., Djagbletey, G., Ford, A., Kemp, J., Marimon, B. S., Marimon, B. H., Lenza, E., Ratter, J. A., Maracahipes, L., Sasaki, D., Sonke, B., Zapfack, L., Taedoumg, H., Villarroel, D., Schwarz, M., Quesada, C. A., Ishida, F. Y., Nardoto, G. B., Affum-Baffoe, K., Arroyo, L., Bowman, D. M. J. S., Compaore, H., Davies, K., Diallo, A., Fyllas, N. M., Gilpin, M., Hien, F., Johnson, M., Killeen, T. J., Metcalfe, D., Miranda, H. S., Steininger, M., Thomson, J., Sykora, K., Mougin, E., Hiernaux, P., Bird, M. I., Grace, J., Lewis, S. L., Phillips, O. L., and Lloyd, J.: On the delineation of tropical vegetation types with an emphasis on forest/savanna transitions, Plant Ecol. Divers., 6, 101-137, doi:10.1080/17550874.2012.762812, 2013.

Trapnell, C. G., Martin, J. D., and Allan, W.: Vegetation-soil map of Northern Rhodesia, 2nd ed., Ministry of Agriculture Lusaka, 1950.

Tripler, C. E., Kaushal, S. S., Likens, G. E., and Todd Walter, M.: Patterns in potassium dynamics in forest ecosystems, Ecol. Lett., 9, 451-466, 2006.

Tsay, Y.-F., Ho, C.-H., Chen, H.-Y., and Lin, S.-H.: Integration of nitrogen and potassium signaling, Annu. Rev. Plant Biol., 62, 207226, 2011

Turner, J., Thompson, C., Turvey, N., Hopmans, P., and Ryan, P.: A soil technical classification system for Pinus radiata (D. Don) plantations. I. Development, Aust. J. Soil Res., 28, 797-811, doi:10.1071/SR9900797, 1990.

Umar, S.: Alleviating adverse effects of water stress on yield of sorghum, mustard and groundnut by potassium application, Pak. J. Bot., 38, 1373-1380, 2006.

VanDerWal, J., Falconi, L., Januchowski, S., Shoo, L., Storlie, C.:SDMTools: Species Distribution Modelling Tools: Tools for processing data associated with species distribution modelling exercises, R package version 1.1-20, 2015.

Van Reeuwijk, L. P.: Procedures for Soil Analysis, 6th edn., International Soil Reference Information Centre, ISRIC, Wageningen, the Netherlands, 120 pp., 2002.

Veenendaal, E. M., Torello-Raventos, M., Feldpausch, T. R., Domingues, T. F., Gerard, F., Schrodt, F., Saiz, G., Quesada, C. A., Djagbletey, G., Ford, A., Kemp, J., Marimon, B. S.,
Marimon-Junior, B. H., Lenza, E., Ratter, J. A., Maracahipes, L., Sasaki, D., Sonké, B., Zapfack, L., Villarroel, D., Schwarz, M., Yoko Ishida, F., Gilpin, M., Nardoto, G. B., Affum-Baffoe, K., Arroyo, L., Bloomfield, K., Ceca, G., Compaore, H., Davies, K., Diallo, A., Fyllas, N. M., Gignoux, J., Hien, F., Johnson, M., Mougin, E., Hiernaux, P., Killeen, T., Metcalfe, D., Miranda, H. S., Steininger, M., Sykora, K., Bird, M. I., Grace, J., Lewis, S., Phillips, O. L., and Lloyd, J.: Structural, physiognomic and above-ground biomass variation in savanna-forest transition zones on three continents - how different are co-occurring savanna and forest formations?, Biogeosciences, 12, 2927-2951, doi:10.5194/bg-12-2927-2015, 2015.

Viani, R. A. G., Rodrigues, R. R., Dawson, T. E., and Oliveira, R. S.: Savanna soil fertility limits growth but not survival of tropical forest tree seedlings, Plant Soil, 349, 341-353, doi:10.1007/s11104-011-0879-7, 2011.

Viani, R. A. G., Rodrigues, R. R., Dawson, T. E., Lambers, H., and Oliveira, R. S.: Soil pH accounts for differences in species distribution and leaf nutrient concentrations of Brazilian woodland savannah and seasonally dry forest species, Perspect. Plant Ecol., 16, 64-74, doi:10.1016/j.ppees.2014.02.001, 2014.

Villarroel, D., Catari, J. C., Calderon, D., Mendez, R., and Feldpausch, T.: Estructura, composición y diversidad arbórea de dos áreas de Cerrado sensu stricto de la Chiquitanía (Santa Cruz, Bolivia), Ecología en Bolivia, 45, 116-130, 2010.

Vitousek, P. M. and Sanford, R. L.: Nutrient cycling in moist tropical forest, Annu. Rev. Ecol. Syst., 17, 137-167, doi:10.1146/annurev.es.17.110186.001033, 1986.

Wakeel, A., Farooq, M., Qadir, M., and Schubert, S.: Potassium substitution by sodium in plants, Crit. Rev. Plant Sci., 30, 401-413, doi:10.1080/07352689.2011.587728, 2011.

Wang, M., Zheng, Q., Shen, Q., and Guo, S.: The critical role of potassium in plant stress response, Int. J. Mol. Sci., 14, 7370 7390, 2013.

Ward, D., Wiegand, K., and Getzin, S.: Walter's two-layer hypothesis revisited: back to the roots!, Oecologia, 172, 617-630, 2013.

Warman, L. and Moles, A. T.: Alternative stable states in Australia's Wet Tropics: a theoretical framework for the field data and a field-case for the theory, Landscape Ecol., 24, 1-13, 2009.

Weiskittel, A. R., Hann, D. W., Kershaw Jr, J. A., and Vanclay, J. K.: Forest Growth and Yield Modeling, John Wiley \& Sons,413 pp., 2011.

Werger, M. J. A.: Vegetation Structure in the Southern Kalahari, J. Ecol., 66, 933-941, doi:10.2307/2259305, 1978.

Wesseling, J., van Wijk, W. R., Fireman, M., van't Woudt, B. D., and Hagan, R. M.: Land drainage in relation to soils and crops, in: Drainage of Agricultural Lands, edited by: Luthin, J. N., Agronomy Monograph, Am. Soc. Agr., 461-578, 1957.

White, D. A. and Hood, C. S.: Vegetation patterns and environmental gradients in tropical dry forests of the northern Yucatan Peninsula, J. Veg. Sci., 15, 151-160, doi:10.1111/j.16541103.2004.tb02250.x, 2004.

Williams, R., Duff, G., Bowman, D., and Cook, G.: Variation in the composition and structure of tropical savannas as a function of rainfall and soil texture along a large-scale climatic gradient in the Northern Territory, Australia, J. Biogeogr., 23, 747-756, 1996.

Witkowski, E. T. F. and O'Connor, T. G.: Topo-edaphic, floristic and physiognomic gradients of woody plants in 
a semi-arid African savanna woodland, Vegetatio, 124, 9-23, doi:10.1007/BF00045140, 1996.

Wood, S. N.: Generalized Additive Models: an Introduction with R, Chapman \& Hall/CRC, Bota Racon, 392 pp., 2006.

Wood, S. N.: Fast stable restricted maximum likelihood and marginal likelihood estimation of semiparametric generalized linear models, J. Roy. Stat. Soc. B, 73, 3-36, 2011.

Wright, S. J., Yavitt, J. B., Wurzburger, N., Turner, B. L., Tanner, E. V. J., Sayer, E. J., Santiago, L. S., Kaspari, M., Hedin, L. O., Harms, K. E., Garcia, M. N., and Corre, M. D.: Potassium, phosphorus, or nitrogen limit root allocation, tree growth, or litter production in a lowland tropical forest, Ecology, 92, 1616-1625, doi:10.1890/10-1558.1, 2011.

Xu, G., Fan, X., and Miller, A. J.: Plant nitrogen assimilation and use efficiency, Annu. Rev. Plant Biol., 63, 153-182, 2012.

Yao, H., Gao, Y., Nicol, G. W., Campbell, C. D., Prosser, J. I., Zhang, L., Han, W., and Singh, B. K.: Links between ammonia oxidizer community structure, abundance, and nitrification potential in acidic soils, Appl. Environ. Microb., 77, 4618-4625, 2011.
Young, A.: Tropical Soils and Soil Survey, CUP Archive,468 pp., 1980.

Zerihun, A., Montagu, K., Hoffmann, M., and Bray, S.: Patterns of below- and aboveground biomass in Eucalyptus populnea woodland communities of Northeast Australia along a rainfall gradient, Ecosystems, 9, 501-515, doi:10.1007/s10021-005-0155-x, 2006.

Zörb, C., Senbayram, M., and Peiter, E.: Potassium in agriculture status and perspectives, J. Plant Physiol., 171, 656-669, 2014.

Zuur, A., Ieno, E. N., Walker, N., Saveliev, A. A., and Smith, G. M.: Mixed Effects Models and Extensions in Ecology with R, Springer,574 pp., 2009. 